INSTITUTO DE ASTRONOMIA, GEOFÍSICA E CIÊNCIAS ATMOSFÉRICAS DEPARTAMENTO DE CIÊNCIAS ATMOSFÉRICAS

Dissertação de Mestrado

\title{
Estudo da Transferência de Radiação em Dossel de Floresta com o Uso de Modelo de Transferência Radiativa Tridimensional
}

\author{
Aluno: Jeová Ramos da Silva Junior
}

$\mathrm{N}^{\mathrm{o}}$ USP: 10365517

Orientadora: Dra. Marcia Akemi Yamasoe 

Jeová Ramos da Silva Junior

\section{Estudo da Transferência de Radiação em Dossel de Floresta com o Uso de Modelo de Transferência Radiativa Tridimensional}

Dissertação apresentada ao Departamento de Ciências Atmosféricas do Instituto de Astronomia, Geofísica e Ciências Atmosféricas da Universidade de São Paulo para a obtenção do título de Mestre em Ciências

Orientadora: Profa Dra Marcia Akemi Yamasoe

Versão corrigida. 0 original encontra-se disponível na Unidade.

São Paulo 

Dedico este trabalho à minha amada avó Ester Zacarias (in memoriam). 



\section{Agradecimentos}

Agradeço, em primeiro lugar, à professora doutora Marcia Akemi Yamasoe pelo inestimável suporte ao desenvolvimento deste trabalho. Agradeço também pela paciência, ética e pronta disponibilidade. Por ser um exemplo de luta pelo crescimento dos alunos e para tornar o IAG um lugar melhor. À senhora, meu eterno agradecimento.

À minha mãe Maria José e minha tia Vera Lúcia pelo imenso amor, incessável incentivo à minha educação e por todo fundamental suporte durante todos os momentos da minha vida.

À Carina Mendes por todo o amor e companheirismo. Pelas conversas sem fim, pelas incontáveis horas cozinhando, sorrindo e por tornar minha vida mais viva. E, claro, pelas garrafas de café para aguentar as noites em claro.

Ao grande amigo professor doutor Marcos Antonio Lima Moura, pelo suporte no início, meio e final do caminho. Por suas sugestões e por me manter firme na árdua jornada de me tornar um cientista.

Aos meus amigos que o IAG me proporcionou: Igor, Enzo, Decker, Verônika, Marie, Victória, Franco, Camila, Laís, Isabela, Alan, Raianny, Leonardo, Thomas, Noélia, Jorge, Lucas, Luís, Lucão, Rebeca e Vivian.

Em especial a Natannael, Tailine e Guilherme, Carol, Bruno, Débora, Rubinei e Monique. Obrigado por todas as discussões, caminhadas pré e pós bandejão, infindáveis risadas e todos os momentos de alegria e amizade que compartilhamos nesses anos.

Ao amigo Tiago Bodê pelos milhares de litros de café, por zoar o Ozório e o Montañez, e pelas pizzas de fim de semana com a Nira. Obrigado por me receber no $503 \mathrm{G}$, esse templo sagrado.

Aos meus colegas de apartamento, Iago Dias e Humberto Martins. Muito obrigado por todas as conversas, todas as gargalhadas e todos os momentos de amizade. Obrigado pelas reflexões sobre a vida e rangos improvisados, mas deliciosos. 
Aos amigos que o CRUSP me deu: Iara, Gabi, Clelton, Yasmin, Gustavo, Paul, Léo, Flaubert, Juan, Tatiana, Adriana, Oziane, Yanina e todos que, por infelicidade, não consegui por aqui. Em especial à Kizzy, Josi, Fernanda e Adriane pelo acolhimento como hóspede.

Agradeço aos Demônios de Maxwell Rugby, meu eterno time. Serei sempre grato pelo ambiente seguro e construtivo. Em especial ao Roger, Achilles, Snap (Gabriel), Fada (Bruno) e Renato pelo incomparável acolhimento e incentivo. Vocês são exemplos dos pilares do rugby: paixão, disciplina, respeito, integridade e solidariedade.

Aos meus amigos e irmãos de Alagoas que, mesmo distantes, estavam sempre presentes: Luan Ricardo, Jonathas Veríssimo, Ismael Guidson, Samara Santos, Thays Paes, David Moraes, Nicolas Amad, Andreza Rêgo, Victor Bastos, Allysson Melo e Samuel Santos.

A SAS pelo auxílio moradia no CRUSP, ponto chave para minha permanência em São Paulo. Sem esse auxílio este trabalho não seria possível. Muito obrigado.

Aos professores do IAG Humberto Rocha, Fátima Andrade, Adalgiza Fornaro, Ricardo Hallak, Ricardo de Camargo e Edmilson Freitas. Obrigado por aproximarem o conhecimento científico do meu repertório e por tornarem o instituto um lugar mais fascinante.

Aos professores doutores Glauber Cirino e Demerval Moreira pelas considerações feitas na arguição de defesa deste trabalho. Certamente foram de grande valia para a finalização do mesmo. Muito obrigado.

Agradeço ao Dr. Gastellu pela licença de uso do DART e a Nicolas Lauret por produzir a maquete $3 \mathrm{D}$ da torre meteorológica que foi usada neste trabalho, ambos do CESBIO.

Por fim, obrigado ao CNPq pelo auxílio financeiro. 
"Le sage est celui qui parvient à regretter un peu moins, à espérer un peu moins et à aimer un peu plus"

(André Comte-Sponville) 



\section{Resumo}

SILVA JUNIOR, J. R. Estudo da Transferência de Radiação em Dossel de Floresta com o Uso de Modelo de Transferência Radiativa Tridimensional. 2020, 119 p. Dissertação (Mestrado). Instituto de Astronomia, Geofísica e Ciências Atmosféricas, Universidade de São Paulo, São Paulo, 2020.

A radiação solar ocupa papel central nos processos de trocas gasosas em todos os ecossistemas do mundo, tal como a fotossíntese. Em regiões florestais, a complexidade da arquitetura foliar exige um maior número de detalhes para avaliar os processos de propagação da radiação. A Amazônia é destaque mundial em biodiversidade, desmatamento e queimadas. Esta última lança grandes quantidades de aerossóis na atmosfera que interagem com a radiação solar e produzem luz difusa, propiciando um fenômeno conhecido como efeito fertilizante da luz difusa. Este trabalho avalia a transferência da radiação fotossinteticamente ativa (PAR) dentro do dossel em três sítios localizados no meio da floresta amazônica: ATTO, Reserva Biológica do Jaru e Humaitá. Como auxílio para a análise, fez-se uso do código de transferência radiativa tridimensional DART. Foi observado que os sensores em alturas intermediárias do dossel registraram aumento da transmitância (tmt) de até $\sim 100 \%$ com o aumento da profundidade óptica do aerossol (AOD em $415 \mathrm{~nm}$ ) de 1 a 2 unidades. Essas camadas estão entre 10 e $30 \mathrm{~m}$ de altura, e recebem cerca de $25 \%$ da radiação incidente em condições de céu claro. As regiões beneficiadas com a luz difusa são às que se encontram sombreadas. Por esse motivo, a resposta da transmitância também apresentou dependência com a geometria solar. Quanto maior a massa óptica, maior foi a resposta positiva da reta entre a transmitância e a profundidade óptica do aerossol. O modelo conseguiu replicar uma floresta genérica capaz de chegar na escala da folha e reproduzir os efeitos da transmitância observados bem como a fração difusa incidente no topo da copa das árvores (3\% abaixo do observado, em média). Através do DART também foi possível verificar que a área ocupada pela torre meteorológica pode reduzir até $40 \%$ da PAR incidente em superfície e de 50 a $90 \%$ em diferentes alturas. O que implica que sua presença é um fator que pode afetar fortemente a amostragem experimental. Todavia a atenuação da torre torna-se irrisória $(<0,25 \%)$ a partir de massa óptica maior que 1,7.

Palavras-chave: Efeito fertilizante da luz difusa, Aerossóis, Radiação fotossinteticamente ativa, Floresta Amazônica. 



\section{Abstract}

SILVA JUNIOR, J. R. Estudo da Transferência de Radiação em Dossel de Floresta com o Uso de Modelo de Transferência Radiativa Tridimensional. 2020, 119 p. Dissertação (Mestrado). Instituto de Astronomia, Geofísica e Ciências Atmosféricas, Universidade de São Paulo, São Paulo, 2020.

Solar radiation plays a central role in gas exchange processes in all the world's ecosystems, through photosynthesis for example. In forested regions, the complexity of leaf architecture requires more detail to evaluate the radiation propagation processes from treetops to the innermost layers. The Amazon is one of the largest forests in the world and suffers from problems such as deforestation and biomass burning. The last emits large amount of aerosols into the atmosphere, which interact with solar radiation and generate diffuse light, propitiating a phenomenon known as the fertilizing effect of diffuse light. This work evaluates the transfer of Photosynthetically Active Radiation (PAR) within the canopy at three Amazonian sites: ATTO, Jaru Biological Reserve and Humaitá. As a helpful tool to the analysis, the three-dimensional radiative transfer code DART was used. Sensors at intermediate canopy heights reported increase in transmittance (tmt) up to 100\% with increasing Aerosol Optical Depth (AOD at $415 \mathrm{~nm}$ ) of 1 to 2 units. These layers are between 10 and $30 \mathrm{~m}$ high, and receive about $25 \%$ of the incident radiation under clear sky conditions. The regions that benefit from diffuse light are those that are shaded. Transmittance response also depends on the solar geometry. For this reason, the transmittance response was also dependent on solar geometry. The higher the optical airmass, the higher the slope of the transmittance versus AOD line. The model was able to replicate a generic forest, capable of reaching the leaf scale, and similarly reproducing the observed transmittance effects as well as the incident radiation on the treetops ( $3 \%$ below that observed). It was verified that the area occupied by the meteorological tower could reduce up to $40 \%$ of the PAR incident on the surface and from 50 to $90 \%$ at different heights. Which implies that its presence is a factor that can strongly affect the experimental sampling. However, the tower's attenuation becomes negligible $(<0.25 \%)$ from an optical mass greater than 1.7.

Keywords: Fertilizing effect of diffuse light, Aerosols, Photosynthetically active radiation, Amazon forest. 



\section{Lista de Figuras}

Figura 1 - Média anual no topo da atmosfera da forçante radiativa devido às interações do aerossol (de origem antrópica) com a radiação (RFari) no período de 1750 a 2010. Siglas: $F F=$ combustível fóssil e biocombustível; $B C=$ carbono negro; $P O A$ = aerossol orgânico primário; $S O A$ = aerossol orgânico secundário e $B B=$ aerossol de queimada. Fonte: Boucher et al., (2013).

Figura 2 - Esquematização da premissa fundamental do Efeito Fertilizante da luz difusa. As linhas contínuas representam os feixes de radiação solar que não interagiram com a atmosfera (fração direta) e as linhas tracejadas representam a radiação espalhada pelos constituintes da mesma (aerossóis, nuvens e moléculas de ar). $O$ incremento na fotossíntese foliar está representado no canto inferior direito em função da resposta das folhas sombreadas com a alteração da PAR, sendo diminuição da fração direta (b) e aumento da difusa (a). Fonte: Adaptado de Kaniah et al. (2012). 36

Figura 3-Resultados simulados para o efeito fertilizante da luz difusa (tendência da Produção Primária Bruta normalizada versus fração difusa) em função do a) índice de área foliar, b) índice de aglomeração foliar (clumping), ângulo de inclinação e d) propriedades ópticas das folhas. Fonte: Adaptado de Knohl e Baldocchi, (2008).

Figura 4 - Exemplo da variabilidade da transmitância dentro de floresta amazônica em um dia totalmente nublado em dois pontos distintos. As variabilidades estão associadas apenas ao arranjo espacial das árvores e suas componentes (i.e. galhos, folhas, troncos etc.). Fonte: adaptado de Anhuf \& Rollenbeck (2001).

Figura 5 - Irradiância solar espectral incidente no topo da atmosfera (amarelo) e ao nível médio do mar (vermelho) e função de Planck à temperatura de $5778 \mathrm{~K}$ (preto) em função do comprimento de onda. Fonte: disponível em https://commons.wikimedia.org/wiki/File:Solar_spectrum_en.svg (adaptado). Acesso em 23/10/2019. 
Figura 6 - Variação horária da irradiância solar incidente no topo da atmosfera, em diferentes dias do ano, para dois sítios de diferentes latitudes. Fonte: Adaptado de lqbal. 2012.

Figura 7 - Comparação entre espalhamento Rayleigh (simétrico) e Mie (assimétrico, anisotrópico) para radiação incidente com mesmo comprimento de onda, variando o tamanho da partícula espalhadora. Fonte: Adaptado de http://hyperphysics.phy-astr.gsu.edu/hbase/atmos/blusky.html. Acesso em: novembro 2019. 48

Figura 8 - Esquema de atenuação de um feixe monocromático após atravessar um meio atenuador homogêneo. 50

Figura 9 - Tipos de reflexão superficiais em gráficos polares. A intensidade relativa da radiação refletida para cada ângulo de espalhamento é indicada pela distância entre a curva e o ponto central. A seta indica a direção de incidência da radiação e em a) direção da reflexão Fonte: Adaptado de Petty, 2006....... 53

Figura 10 - Localização dos sítios experimentais. Fonte: Costa, T. S. (2013). 55

Figura 11 - Exemplo do arranjo experimental dos radiômetros PAR (SKE 510 $P A R$ Energy Sensor) em perfil vertical durante a campanha intensiva realizada no ATTO, durante a estação de queimadas de 2015. Fonte: acervo pessoal de Márcia Akemi Yamasoe. 57

Figura 12 - Ilustração da montagem do MFRSR na Reserva Biológica do Jaru em 2007. Fonte: acervo pessoal de Márcia Akemi Yamasoe. 58

Figura 13 - Frequência de dados por hora e por dia em cada sítio amostral. . 60

Figura 14 - Esquematização da matriz de representação do sistema Terra/atmosfera pelo modelo DART. Níveis verticais da atmosfera: superior (camadas), média (células/voxels de qualquer tamanho), inferior (células do mesmo tamanho que os da superfície). Na figura é possível ver alguns produtos do modelo e representações dos elementos da cena terrestre. Estes últimos são fixos e podem ser representados por facetas ou um meio túrbido. Fonte: Adaptado de Gastellu-Etchegorry et al., (2015). 
Figura 15 - Ilustração 3D da cena simulada. A torre está representada em branco nas figuras em escala de cinza $(B$ a $D)$.

Figura 16- Representação 3D de um bloco da torre usado na construção da cena simulada.

Figura 17 - Propriedades ópticas das folhas das árvores que compõem a cena simulada. T.reflectance $=$ Reflectância da parte superior das folhas, B.reflectance = reflectância da parte inferior das folhas, Transmittance $=$ transmitância das folhas. 64

Figura 18 - Reflectância espectral dos componentes da cena: tronco, liteira e torre. 65

Figura 19 - Perfil vertical de concentração normalizada de aerossol referente ao modelo DESERV76. 66

Figura 20 - Aproximação de Henyey-Greenstein uniparamétrica para a função de fase do aerossol de queimadas na Amazônia para cada comprimento de onda em função do ângulo de espalhamento.

Figura 21 - Perfil vertical de temperatura e pressão da atmosfera do modelo TROPICAL da biblioteca do DART. 68

Figura 22 - Perfil vertical da concentração de alguns componentes gasosos da atmosfera do modelo TROPICAL da biblioteca do DART. 68

Figura 23 - Linhas de transmitância dos principais componentes gasosos da atmosfera para a região espectral da PAR, respectivos ao modelo TROPICAL da biblioteca do DART.

Figura 24 - Distribuição da profundidade óptica do aerossol (AOD) em 415 nm por intervalo de massa óptica na torre ATTO, no período matutino. 72

Figura 25 - Distribuição da profundidade óptica do aerossol (AOD) em $415 \mathrm{~nm}$ por intervalo de massa óptica no sítio experimental de Humaitá, no período matutino. 73 
Figura 26 - Distribuição da profundidade óptica do aerossol (AOD) em $415 \mathrm{~nm}$ por intervalo de massa óptica, no sítio experimental da REBIO Jaru, no período matutino.

Figura 27 - Razão entre a irradiância espectral difusa e a global para os três sítios experimentais em função da AOD em $415 \mathrm{~nm}$ para as seguintes massas ópticas: 1,0 (topo à esquerda); 1,5 (topo à direita); 2,5 (embaixo à esquerda); e 3,0 (embaixo à direita). ATTO = att, Humaitá $=$ hmt e REBIO = rbo. 76

Figura 28 - Irradiância PAR incidente por intervalo de massa óptica para cada nível de altura dentro do dossel da torre ATTO. Os números acima dos quadros indicam a altura do sensor acima da superfície $(m)$, o eixo vertical é a irradiância PAR incidente $\left(\mathrm{W} / \mathrm{m}^{2}\right)$ e o eixo horizontal é o intervalo de massa óptica. Os sensores totalmente sombreados não foram exibidos. 77

Figura 29 - Irradiância PAR incidente por intervalo de massa óptica para cada nível de altura dentro do dossel em Humaitá. Os números ao lado indicam a altura acima da superfície $(m)$, o eixo vertical é a irradiância PAR e o eixo horizontal é o intervalo de massa óptica. Cada coluna representa uma das faces $(\mathrm{L}$ - leste, $\mathrm{N}$ - norte, $\mathrm{O}$ - oeste) nas quais os sensores foram instalados. Os sensores totalmente sombreados não foram exibidos. 78

Figura 30 - Irradiância PAR incidente por intervalo de massa óptica para cada nível de altura dentro do dossel na Reserva Biológica do Jaru (REBIO). Os números ao lado indicam a altura acima da superfície $(\mathrm{m})$, o eixo vertical é a irradiância PAR e o eixo horizontal é o intervalo de massa óptica. Cada coluna representa uma das faces ( $\mathrm{L}$ - leste, $\mathrm{N}$ - norte, $\mathrm{O}$ - oeste) nas quais os sensores foram instalados. Os sensores totalmente sombreados não foram exibidos. .. 80

Figura 31 - Transmitância PAR por intervalo de massa óptica para cada nível de altura dentro do dossel da torre ATTO. Os números acima das caixas indicam a altura acima da superfície $(m)$, o eixo vertical é a transmitância PAR incidente e o eixo horizontal é o intervalo de massa óptica

Figura 32 - Transmitância PAR por intervalo de massa óptica para cada nível de altura dentro do dossel no sítio de Humaitá. Os números na lateral indicam a 
altura acima da superfície $(m)$, o eixo vertical é a transmitância PAR incidente e o eixo horizontal é o intervalo de massa óptica. As colunas indicam em qual lado da torre está o sensor, norte $(N)$, leste $(L)$ e oeste $(O)$ 83

Figura 33 - Transmitância PAR por intervalo de massa óptica para cada nível de altura dentro do dossel da Reserva Biológica do Jaru (REBIO). Os números na lateral indicam a altura acima da superfície $(\mathrm{m})$, o eixo vertical é a transmitância PAR incidente e o eixo horizontal é o intervalo de massa óptica. As colunas indicam em qual lado da torre está o sensor, norte $(N)$, leste $(L)$ e oeste $(O)$. . 84

Figura 34 - Relação entre a transmitância e a profundidade óptica do aerossol (415 nm) nos três níveis mais altos, excetuando-se o nível do topo (39 m) em casos com massa óptica $=1$. Sítio experimental: ATTO. As linhas representam o ajuste linear aos dados (pontos) e a área ao redor da reta representa o intervalo com $95 \%$ de confiança.

Figura 35 - Relação entre a transmitância e a profundidade óptica do aerossol (415 nm) nos três níveis mais altos excetuando-se o nível do topo (39 m) em casos com massa óptica $=1,3$. Sítio experimental: ATTO. 86

Figura 36 - Relação entre a transmitância PAR e a profundidade óptica do aerossol (415 nm) nos três níveis mais altos excetuando-se o nível do topo (39 m) em casos com massa óptica = 1,8. Sítio experimental: ATTO. 87

Figura 37 - Relação entre a transmitância e a profundidade óptica do aerossol (415 nm) em casos com massa óptica = 1,1 para cada nível de sensor separando os pontos pelos lados nos quais os sensores estão voltados em relação à torre. Verde: lado norte, azul: lado oeste e rosa: lado leste. Sítio experimental: Humaitá.

Figura 38 - Relação entre a transmitância e a profundidade óptica do aerossol (415 nm) em casos com massa óptica = 1,5 para cada nível de sensor separando os pontos pelos lados nos quais os sensores estão voltados em relação à torre. Verde) lado norte, azul) lado oeste e rosa), lado leste. Sítio experimental: Humaitá. 89 
Figura 39 - Relação entre a transmitância e a profundidade óptica do aerossol (415 $\mathrm{nm}$ ) em casos com massa óptica $=2,7$ para cada nível de altura de instalação do sensor, separando os pontos pelos lados nos quais os sensores estão voltados em relação à torre. Verde) lado norte, azul) lado oeste e rosa), lado leste. Sítio experimental: Humaitá. 90

Figura 40 - Relação entre a transmitância e a profundidade óptica do aerossol $(415 \mathrm{~nm})$ em casos com massa óptica = 1,0 para cada nível de sensor separando os pontos pelos lados nos quais os sensores estão voltados em relação à torre. Verde) lado norte, azul) lado oeste e rosa), lado leste. Sítio experimental: REBIO.

Figura 41 - Relação entre a transmitância e a profundidade óptica do aerossol ( $415 \mathrm{~nm}$ ) em casos com massa óptica = 1,2 para cada nível de sensor separando os pontos pelos lados nos quais os sensores estão voltados em relação à torre. Verde) lado norte, azul) lado oeste e rosa), lado leste. Sítio experimental: REBIO.

Figura 42 - Efeito de borda: contaminação da cena pela radiação que incide pela região lateral da cena simulada considerando o método "cena isolada". O efeito de borda é destacado pela região em amarelo e indica a direção predominante de incidência solar. O número acima de cada quadro indica a respectiva massa óptica. Neste caso, o observador está olhando para o nadir, e o sol está a leste (manhã), isto é, à direita do observador.

Figura 43 - Razão entre a irradiância espectral difusa e a global em $415 \mathrm{~nm}$ para os três sítios experimentais em função da AOD (415 nm). A massa óptica para cada rodada está indicada acima de dos quadros. ATTO = att (vermelho), Humaitá = hmt (verde), REBIO = rbo (azul) e DART (preto). 95

Figura 44 - Diferença relativa entre a irradiância espectral em $415 \mathrm{~nm}$ simulada pelo DART e as respectivas observações no ATTO (att), em Humaitá (hmt) e na REBIO (rbo). As diferenças foram normalizadas pelas irradiâncias observadas referentes a cada sítio. Os números acima de cada quadro indicam a massa óptica correspondente. 
Figura 45 - Perfil vertical da irradiância PAR simulada dentro do dossel para cada condição de massa óptica. Os números acima das caixas indicam a massa óptica, o eixo vertical é a irradiância PAR descendente $\left(\mathrm{W} / \mathrm{m}^{2}\right)$ e o eixo horizontal é a altura $(\mathrm{m})$.

Figura 46 - Perfil vertical de transmitância PAR simulada dentro do dossel para cada condição de massa óptica. Os números acima das caixas indicam a massa óptica, o eixo vertical é a transmitância PAR descendente normalizada pela PAR incidente no topo do dossel para cada coordenada e o eixo horizontal é a altura $(\mathrm{m})$. 98

Figura 47 - Corte horizontal da cena simulada a $30 \mathrm{~m}$ de altura sob diversas condições de AOD (415 nm) (indicada pelos números acima dos quadros) e diferentes geometrias solares (indicada na legenda ao lado). As cores representam a transmitância (tmt) para cada pixel na altura mencionada. .... 100

Figura 48 - Corte horizontal da cena simulada a $30 \mathrm{~m}$ de altura sob diversas condições de AOD (415 nm) (indicada pelos números acima dos quadros) e diferentes geometrias solares (indicada na legenda ao lado). As cores representam a transmitância para cada pixel na altura mencionada. Continuação da figura anterior 101

Figura 49 - Corte vertical da cena simulada na região central sob diversas condições de AOD (415 nm) (indicada pelos números acima dos quadros) e diferentes geometrias solares (indicada pelos números à direita dos quadros). As cores representam a transmitância para cada pixel. $O$ eixo vertical é a altura e o horizontal representa a distância entre a borda oeste e a leste, ambas em metro. 103

Figura 50 - Corte vertical da cena simulada na região central sob diversas condições de $m_{\circ}$ (indicada pelos números acima dos quadros) e diversas comparações de AOD (indicada pelos números à direita dos quadros). As cores representam a diferença absoluta da transmitância de AOD > 0,3 menos a transmitância para $A O D=0,3$. O eixo vertical representa a altura e a horizontal a distância entre a borda oeste e a leste, ambas em metro. 104 
Figura 51 - Perfil vertical da transmitância PAR em quatro pontos distintos da cena simulada em diferentes condições de AOD em $415 \mathrm{~nm}$ (cores), sendo que o valor de $A O D=0,3$ é representado pela cor azul mais escura (limite inferior da escala de cores) e mo (indicada pelo número acima de cada quadro). O eixo vertical indica a altura $(\mathrm{m})$ e o eixo horizontal a transmitância. 106

Figura 52 - Imagens de nadir da cena simulada A) com torre e B) sem torre. 107

Figura 53 - Transmitância PAR média do perfil vertical da área central simulada em diferentes ângulos para distintas condições de AOD (415 nm). Cena com torre. 108

Figura 54 - Diferença entre a transmitância da área central $(10 \times 10 \mathrm{~m})$ da cena com torre e sem torre. 109

Figura 55 - Corte vertical no centro da cena $(30 \mathrm{~m})$ da variabilidade espacial da diferença entre a transmitância da cena com torre e sem torre em diferentes condições de AOD (415 nm) e massa óptica. Os números acima dos quadros indicam a massa óptica e os números nas laterais indicam a AOD. 110

Figura 56 - Irradiância PAR que atingiu a superfície do solo e troncos em cena A) com torre e B) sem torre para $m_{0}=1$.

Figura 57 - Diferença absoluta entre a transmitância da cena com o albedo da torre reduzido por um fator multiplicativo de 0,7 e albedo da torre reduzido por um fator multiplicativo de 0,2 em diversas condições de AOD em $415 \mathrm{~nm}$ (indicadas no topo dos quadros) e $m_{\circ}$ (indicada pela legenda à direita dos quadros). 


\section{Lista de tabelas}

Tabela 1 - Sumário do período de coleta de dados utilizado no trabalho para cada localização.

Tabela 2 - Disposição dos radiômetros SKE 510 PAR Energy Sensor no perfil vertical do dossel de cada sítio experimental. 56

Tabela 3 - Relações alométricas para a caracterização das árvores da cena. Fonte: Poorter et al. (2006). 63

Tabela 4 - Recorte espectral das propriedades ópticas do aerossol de queimada do sul da Amazônia. 

Lista de siglas e abreviaturas

att

ATTO

ATTO

Amazon Tall Tower Observatory

DART Discrete Anisotropic Radiative Transfer

hmt Humaitá

PAR Photosynthetically Active Radiation / Radiação Fotossinteticamente Ativa

rbo

REBIO

REBIO Reserva Biológica

tmt Transmitância

AOD Aerosol Optical Depth

MFRSR Multi-Filter Rotating Shadowband Radiometer

N, S, L, O Norte, Sul, Leste, Oeste

TOA Top of Atmosphere - Topo da Atmosfera

BOA Bottom of Atmosphere - Base da atmosfera

DBH Diameter at breast height - Diâmetro à altura do peito

UV Ultravioleta

TL Tempo solar médio local

TVL Tempo solar verdadeiro

SSA Single scattering albedo - Albedo simples 



\begin{tabular}{|c|c|}
\hline \multicolumn{2}{|c|}{ Lista de símbolos } \\
\hline $\mathrm{m}_{\mathrm{o}}$ & Massa óptica \\
\hline$r$ & Tamanho de grade \\
\hline I & Raio para presença de árvore \\
\hline d & Diâmetro da copa \\
\hline A & Área da copa \\
\hline $\mathrm{H}$ & Altura total \\
\hline $\mathrm{h}_{\mathrm{c}}$ & Altura da copa \\
\hline$h_{t}$ & Altura do tronco abaixo da copa \\
\hline $\mathrm{P}(\cos \Theta)$ & Função de fase \\
\hline$g_{1}, g_{2}$ & Fator de assimetria \\
\hline $\mathrm{HNO}_{3}$ & Ácido nítrico \\
\hline $\mathrm{SO}_{2}$ & Dióxido de enxofre \\
\hline $\mathrm{NO}_{2}$ & Dióxido de nitrogênio \\
\hline NO & Óxido de nitrogênio \\
\hline $\mathrm{NH}_{3}$ & Amônia \\
\hline $\mathrm{H}_{2} \mathrm{O}$ & Molécula de água \\
\hline $\mathrm{O}_{2}$ & Molécula de oxigênio \\
\hline $\mathrm{O}_{3}$ & Ozônio \\
\hline$\varphi$ & Latitude \\
\hline$\lambda_{0}$ & Longitude \\
\hline$\lambda$ & Comprimento de onda \\
\hline $\mathrm{H}_{0}$ & Ângulo horário \\
\hline
\end{tabular}




\begin{tabular}{|c|c|}
\hline$\varphi \mathrm{a}$ & Azimute \\
\hline$\xi$ & Ângulo zenital \\
\hline$\xi_{0}$ & Ângulo zenital solar \\
\hline$\delta$ & Declinação \\
\hline$\epsilon_{t}$ & Equação do tempo \\
\hline$d_{n}$ & Dia juliano \\
\hline$\omega_{0}$ & Albedo simples \\
\hline$\Theta$ & Ângulo de espalhamento \\
\hline$\Omega$ & Coordenadas de orientação do espalhamento \\
\hline$\tau_{a}, \tau_{r}, \tau_{g}$ & profundidade óptica do aerossol, de Rayleigh e gasosa \\
\hline$L_{\lambda}$ & Radiância espectral \\
\hline z & Altura \\
\hline$\mu, \mu_{0}$ & Cosseno do ângulo zenital, Cosseno do ângulo zenital solar \\
\hline$J_{\lambda}$ & Função fonte de espalhamento \\
\hline$\alpha$ & Coeficiente de Ångström \\
\hline
\end{tabular}




\section{Sumário}

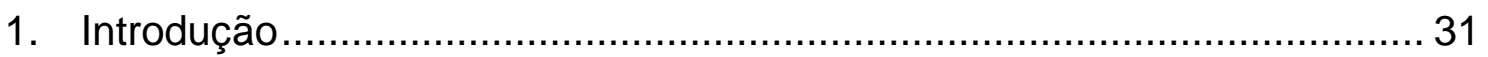

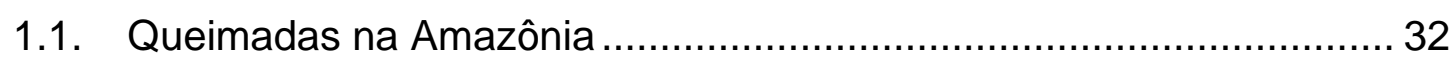

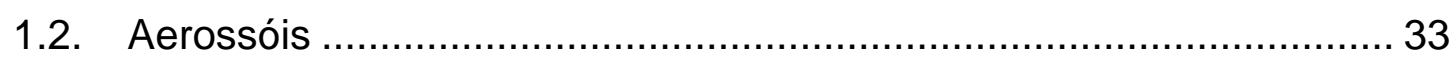

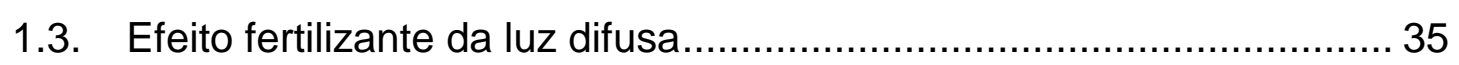

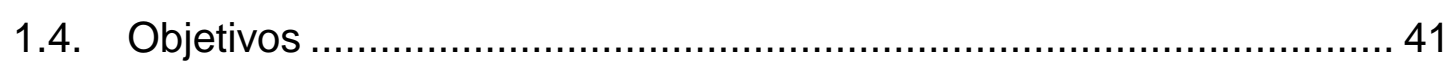

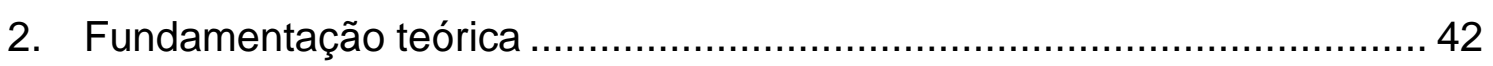

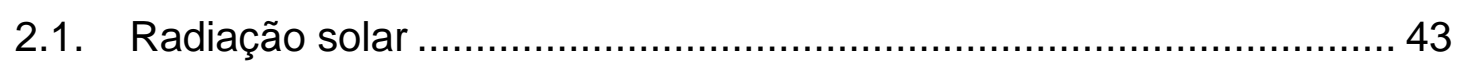

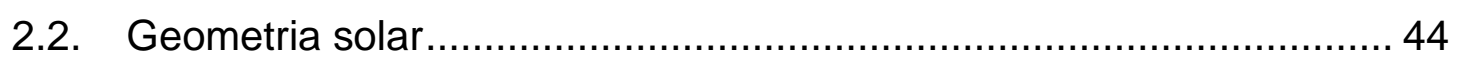

2.3. Processos de atenuação da radiação na atmosfera ........................... 47

2.4. Reflexão especular e lambertiana ................................................ 52

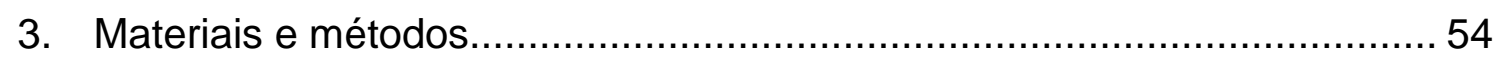

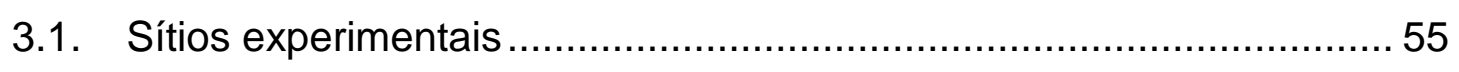

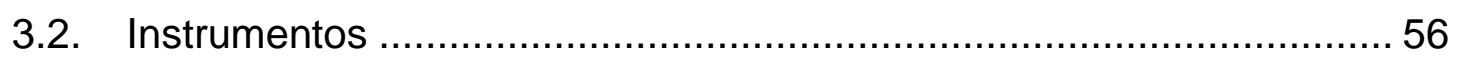

3.2.1. Processamento de dados ..................................................... 58

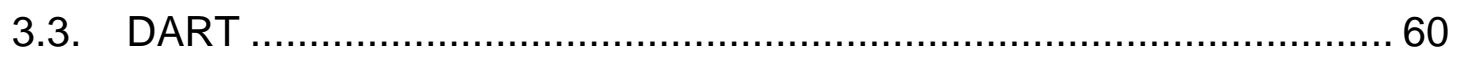

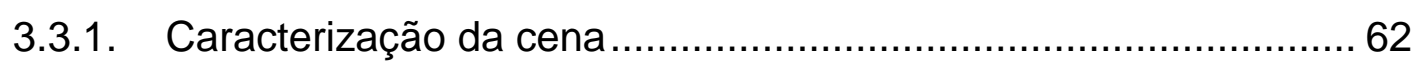

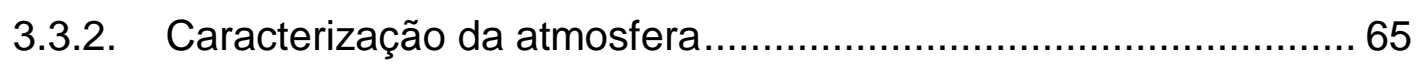

3.3.3. Simulações e processamento dos dados simulados ..................... 69

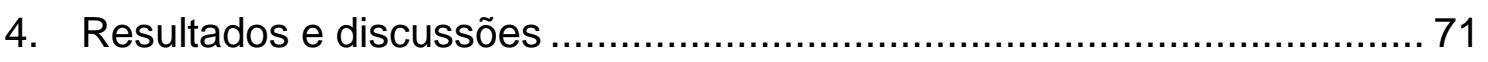

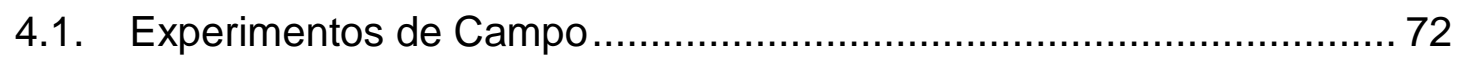


4.1.1. Distribuição temporal da AOD ............................................... 72

4.1.2. O efeito do aerossol sobre a radiação solar incidente .................. 75

4.1.3. Variação geral da PAR dentro do dossel................................... 76

4.1.4. Variação geral da transmitância dentro do dossel ....................... 80

4.1.5. Relações entre transmitância PAR dentro do dossel e AOD ........ 84

4.2. Resultados simulados numericamente com o DART .......................... 92

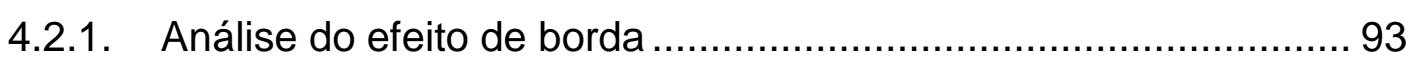

4.2.2. Radiação solar incidente simulada no topo do dossel .................. 94

4.2.3. Variação geral da PAR dentro do dossel .................................... 96

4.2.4. Variação geral da transmitância dentro do dossel ........................ 98

4.2.5. Heterogeneidade horizontal da transmitância ............................. 99

4.2.6. Análise da transmitância PAR simulada no perfil vertical da floresta 102

4.2.7. Transmitância pontual .......................................................... 105

4.2.8. Impacto da torre na transmitância ......................................... 107

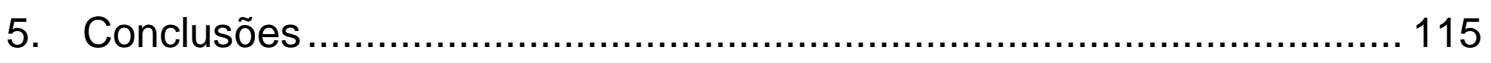

5.1 Considerações finais .............................................................. 116

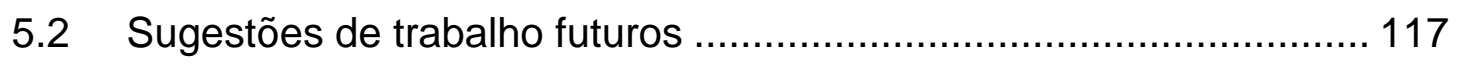

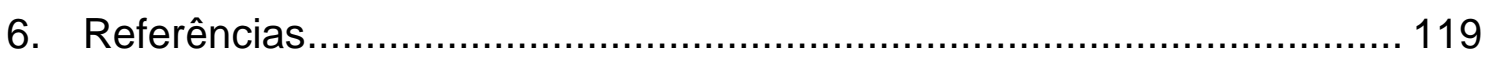




\section{Introdução}




\subsection{Queimadas na Amazônia}

De todos os domínios climáticos, as florestas tropicais apresentam significativa tendência de perda florestal (aumento estimado no desmatamento de $2101 \mathrm{~km}^{2} \mathrm{ano}^{-1}$ ) ao mesmo tempo em que experimentaram a maior relação de não reflorestamento (Hansen et al., 2013). Esses são alguns fatores que indicam o porquê das florestas tropicais da América do Sul totalizarem 32\% da perda total de cobertura florestal mundial (Hansen et al., 2013).

A Amazônia é a maior floresta da América do Sul. O desmatamento que acontece nela é preocupante. Esse tipo de intervenção humana visando substituir o ambiente nativo florestal por pastagem, por exemplo, pode estender a estação seca (temperaturas mais altas e menos precipitação) (Malhi et al., 2008). Isso acaba fragilizando ainda mais a floresta tanto em sua manutenção como em outros processos intrínsecos característicos (Shukla et al., 1990; Bonan, 2008; Fraga et al., 2012; Lima et al., 2014).

A forma como se é feito o desmatamento e a queimada depende do tipo de floresta (Homma et al., 1993). Em florestas densas, torna-se necessário o uso de motosserras e até mesmo tratores adaptados. Em florestas secundárias pode ser utilizado o "correntão". Este consiste numa forte corrente que é fixada em dois tratores.

Quanto às queimadas, elas têm diferentes utilidades (Homma et al., 1993). Uma das principais vantagens é a limpeza de vegetais não plantáveis. Ela está presente tanto na queima de floresta densa quanto secundária e até mesmo em pastos. Sobretudo, a queimada é utilizada, principalmente, porque é o meio menos oneroso de limpeza de vegetação indesejada.

A Bacia Amazônica, particularmente no chamado Arco do Desmatamento, é uma das grandes fontes de emissão de gases de efeito estufa e de partículas de aerossol no cenário mundial (Yamasoe et al., 2000; Eck et al., 2003; da Rocha et al., 2012, Bond et al., 2013).

As queimadas apresentam seu ápice melhor observado no fim da estação seca e perduram por aproximadamente 75 dias até o início da estação chuvosa, 
que é o período com os maiores valores de profundidade óptica de aerossol (da Rocha et al., 2012). Como será discutido no próximo capítulo, a profundidade óptica do aerossol é uma grandeza que indica a quantidade de partículas de aerossol em suspensão na atmosfera.

\subsection{Aerossóis}

Descrever a influência dos aerossóis antrópicos e naturais é uma grande lacuna nos estudos climáticos atuais (Figura 1), tais como sua atuação como núcleos de condensação, modificador das características das nuvens e precipitação (Dusek et al., 2006; Bond et al., 2013) e no balanço radiativo do planeta (Hansen et al., 2011).

A influência do aerossol é complexa, uma vez que, dependendo de sua origem, tamanho, composição, forma e quantidade, pode ter diferentes papeis no tempo e clima, tanto podendo aquecer (forçante positiva) como resfriar (forçante negativa) a atmosfera (Hansen et al., 2011), facilitar ou dificultar a ocorrência de chuva, por exemplo.

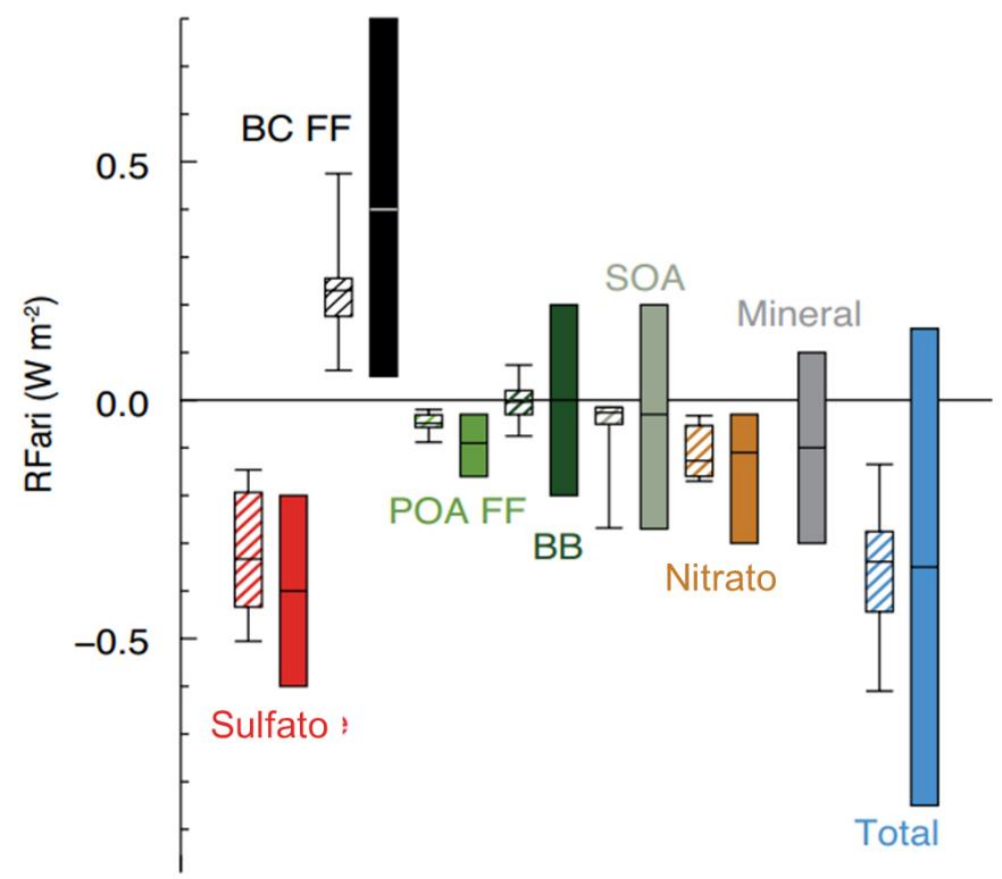

Figura 1 - Média anual no topo da atmosfera da forçante radiativa devido às interações do aerossol de origem antrópica com a radiação (RFari) no período de 1750 a 2010. Siglas: $F F=$ combustível fóssil e biocombustível; $B C=$ carbono negro; $P O A=$ aerossol orgânico primário; $S O A=$ aerossol orgânico secundário e $B B=$ aerossol de queimada. Fonte: Boucher et al., (2013). 
O efeito direto que os aerossóis causam no clima terrestre é devido ao seu potencial para absorver e/ou refletir radiação solar de volta para o espaço (Hansen et al., 2011), diminuindo, através desses processos, de absorção ou de espalhamento, a quantidade de radiação solar incidente em superfície. Tais processos dependem tanto da quantidade de aerossol presente na atmosfera como também das suas propriedades físico-químicas intrínsecas. Todas essas apresentam grande variabilidade, e estão muito ligadas às suas fontes de emissão.

Indiretamente, o aerossol pode causar três efeitos e todos envolvem nuvens (Hansen et al., 2011). O aerossol pode funcionar como um facilitador para a condensação de vapor d'água presente na atmosfera e formação de gotículas que, por sua vez, formam as nuvens. Isto é, ele atua como um núcleo de condensação ( $\mathrm{CCN}$ - do inglês Cloud Condensation Nuclei). As nuvens, por sua vez, têm um albedo (refletância) muito alto e, por isso, refletem uma grande parte da radiação solar de volta para o espaço, principalmente na região espectral do visível. Com isso, temos, novamente, menos radiação incidindo sobre a superfície.

Os outros efeitos indiretos estão relacionados a alterações que o aerossol pode provocar nas nuvens (Hansen et al., 2011). O primeiro é um aumento no albedo das nuvens. Esse aumento se dá em função do número de gotículas, pois quanto maior o número de partículas de aerossóis, maior o número de gotículas, para uma mesma quantidade de vapor d'água disponível.

Esse aumento do número de gotículas pode fazer com que as mesmas não se desenvolvam para estágios com maiores diâmetros e, portanto, maior massa, inibindo a precipitação. Isso faz com que o tempo de vida da nuvem aumente.

Novamente, os dois efeitos (aumento do albedo e do tempo de vida da nuvem) reduzem a quantidade de radiação solar que chega até a superfície. São por esses motivos que a forçante radiativa do aerossol sobre o clima é negativa.

Ainda de acordo com Hansen et al. (2011), há também um outro efeito do aerossol sobre as nuvens. Alguns tipos de aerossol apresentam maior eficiência 
em absorver radiação solar, como o carbono negro por exemplo, consequentemente, aquecem a camada de ar na qual se encontram. $O$ ar aquecido consegue reter mais umidade e, com isso, a temperatura necessária para a condensação (temperatura de ponto de orvalho) também será maior.

Esse efeito, portanto, gera uma supressão na formação de nuvens. Com menos nuvens na atmosfera, a radiação solar sofre menos. E, ao contrário dos demais, é o único que pode ser considerado como uma forçante positiva dos aerossóis sobre o clima terrestre.

Portanto, a presença de aerossóis na atmosfera pode afetar significativamente a quantidade de radiação solar que incide sobre a superfície terrestre e a forma como ela vai incidir, isto é, direta ou difusa. A partir deste ponto, outros desdobramentos podem ser observados, tal como o efeito sobre 0 funcionamento de ecossistemas florestais, através da fertilização de luz difusa sobre a copa das árvores

\subsection{Efeito fertilizante da luz difusa}

As taxas de fotossíntese aumentam com a disponibilidade da radiação fotossinteticamente ativa (PAR, do inglês, photosynthetically active radiation, que compreende a região espectral entre 400 a $700 \mathrm{~nm}$ ). Contudo, novos estudos apontam (Oliveira et al., 2007; Mercado et al., 2009, Cirino et al., 2014; Rap et al., 2015, Moreira et al., 2017, Rap et al., 2018) que a fotossíntese pode ser estimulada não somente com a irradiância incidente, como também com o aumento da sua fração na forma difusa.

Assim, mesmo com uma diminuição da PAR promovida por nuvens e aerossóis, o efeito causado pelo processo de espalhamento de radiação aumenta a fração difusa que, por sua vez, está associada à promoção de aumento nas taxas de fotossíntese para espécies de plantas adaptadas às condições de pouca luz (radiação solar direta).

Geralmente esse efeito é observado através do aumento no fluxo negativo de $\mathrm{CO}_{2}$, da atmosfera para a vegetação (Yamasoe et al., 2006; Mercado et al., 2009). Mas também pode ser associado a outros índices (e. g., Light Use Efficiency, Gross Primary Productivity e Net Primary Productivity, Vapour 
Pressure Deficit) que não serão abordados neste trabalho, mas podem ser facilmente encontrados em Kanniah et al., (2012).

Esse efeito é conhecido como efeito fertilizante da luz difusa. Ele acontece quando folhas de dentro do dossel, sombreadas (shaded leaves) para luz solar direta, são iluminadas. Essa iluminação advém do aumento da fração difusa, uma vez que esta não tem ângulo de incidência único. A Figura 2 esquematiza o processo de espalhamento da radiação solar que leva à iluminação de folhas do interior do dossel.

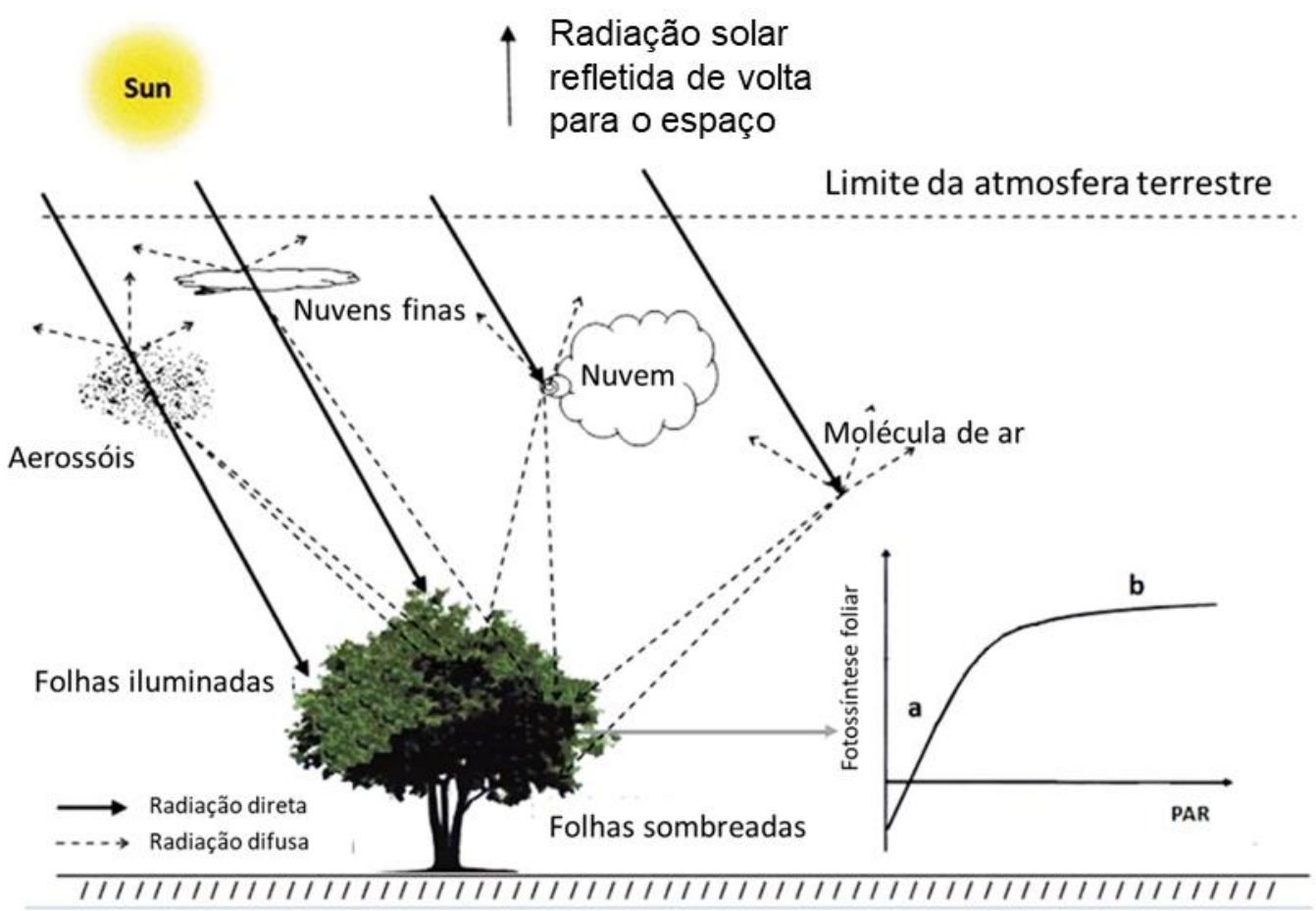

Figura 2 - Esquematização da premissa fundamental do Efeito Fertilizante da luz difusa. As linhas contínuas representam os feixes de radiação solar que não interagiram com a atmosfera (fração direta) e as linhas tracejadas representam a radiação espalhada pelos constituintes da mesma (aerossóis, nuvens e moléculas de ar). O incremento na fotossíntese foliar está representado no canto inferior direito em função da resposta das folhas sombreadas com a alteração da PAR, sendo diminuição da fração direta (b) $e$ aumento da difusa (a). Fonte: Adaptado de Kaniah et al. (2012).

O efeito fertilizante da luz difusa também varia de acordo com as características intrínsecas da vegetação. Um estudo realizado por Knohl e Baldocchi (2008) simulou, em um modelo biofísico multicamada unidimensional (CANVEG), a tendência que esse efeito tem em função de quatro variáveis morfológicas das folhas de uma floresta localizada na Alemanha. 
Dos resultados por eles (Knohl e Baldocchi, 2008) obtidos (Figura 3), os que têm impacto positivo (aumento na fotossíntese) são o índice de área foliar (IAF) e o ângulo de inclinação da folha. Quanto maior a área foliar significa que maior é a densidade de folhas na copa das árvores e, portanto, mais luz elas conseguem interceptar. Quanto maior o ângulo de inclinação em relação à superfície, menos sombra é projetada para as camadas inferiores.
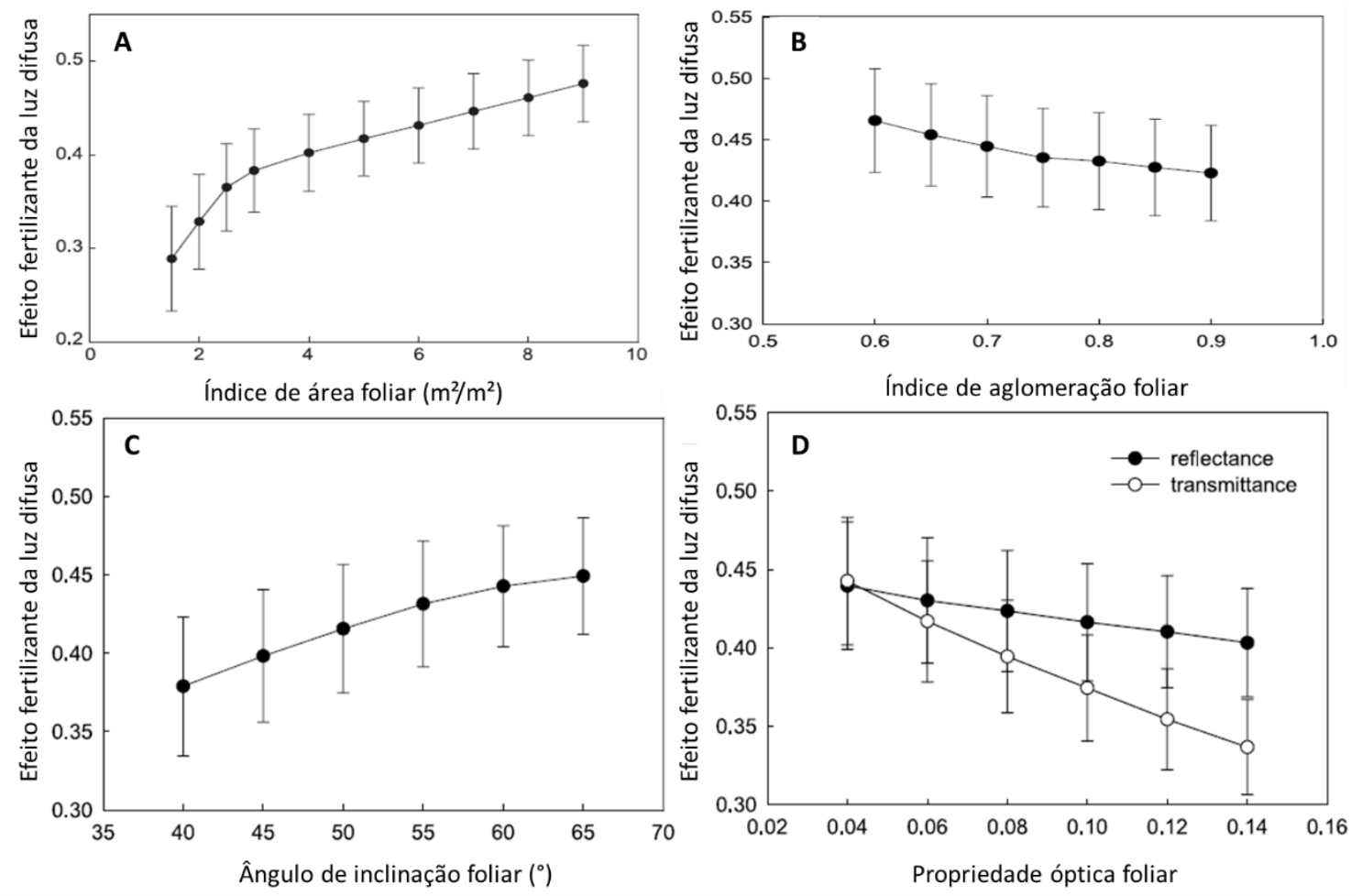

Figura 3 - Resultados simulados para o efeito fertilizante da luz difusa (tendência da Produção Primária Bruta normalizada versus fração difusa) em função do a) índice de área foliar, b) índice de aglomeração foliar (clumping), ângulo de inclinação e d) propriedades ópticas das folhas. Fonte: Adaptado de Knohl e Baldocchi, (2008).

Os fatores que contribuem negativamente são a aglomeração foliar $\mathrm{e}$ baixa absortância (i. e. alta refletância e transmitância). O impacto da transmitância é maior que o da refletância pois a refletância pode aumentar 0 espalhamento múltiplo e comprometer menos a absorção da PAR.

Em resumo, pode-se entender que a eficiência do efeito fertilizante da luz difusa sofre incremento com maior interceptação da PAR e propagação da mesma para camadas mais internas do dossel. 
O efeito fertilizante da luz difusa tem sido observado em diversos sistemas vegetais do mundo, como florestas e pastos, em diversos trabalhos, como relataram Kanniah et al., (2012). Porém, de 33 estudos relatados pelos autores, apenas 3 tiveram como sítios experimentais as florestas tropicais (Oliveira et al., 2007; Doughty et al., 2010 e Yamasoe et al., 2006), todos na floresta amazônica.

Em Santarém (Pará), na Floresta Nacional do Tapajós (Doughty et al., 2010), foi possível separar o efeito da atenuação da temperatura do dossel foliar e do aumento proporcional de PAR difusa devido às condições esfumaçadas (overcast) e de céu claro. A diminuição de temperatura do dossel contribuiu para um aumento de quase $20 \%$ no fluxo de $\mathrm{CO}_{2}$ atmosférico (NEE) e o aumento no $A O D$, para um incremento de quase $40 \%$ nas taxas fotossintéticas daquela floresta.

Oliveira et al. (2007) observaram um aumento de 18\% (11\%) no total de carbono assimilado pela floresta da Reserva Biológica do Jaru/RO (Floresta Nacional de Tapajós/PA) quando nuvens e aerossóis atenuavam 70\% (65\%) da radiação incidente quando comparada com a radiação de um céu limpo.

Cirino et al. (2014) mostraram um aumento de $40 \%$ na fração difusa da radiação PAR e um consequente aumento de até 20-30\% no NEE em áreas de floresta tropical da Amazônia Central (Manaus-AM) e do arco do desmatamento. Rap et al. (2015; 2018), por meio de simulações numéricas, mostraram resultados espacializados semelhantes, em praticamente toda a Amazônia Legal

Os mesmos autores também reportaram resultados semelhantes, porém isolando o efeito do aerossol. Foi observado aumento relativo na captura de carbono de 16\% (8,4\%) na Reserva Biológica do Jaru (Floresta Nacional de Tapajós) quando sob condições de poluição por aerossol de queimada.

Desses trabalhos, apenas Yamasoe et al. (2006) analisaram a transmitância PAR em diferentes níveis de altura da floresta sob diferentes condições de AOD. Com isso foi possível observar em quais camadas da floresta ocorre maior interação com a luz assim como a resposta da transmitância com o aumento da AOD. 
Yamasoe et al. (2006) observaram que com o aumento da AOD o perfil vertical da transmitância sob o dossel tende a se tornar mais constante. Isto é, uma iluminação mais homogênea. Também foi possível observar uma relação exponencial da transmitância com o perfil acumulado do índice de área foliar.

Um estudo mais antigo de Anhuf \& Rollenbeck (2001) mostrou uma grande variabilidade no perfil vertical da transmitância sob o dossel florestal (Figura 4). Todas as medidas desse estudo foram realizadas sob circunstâncias de céu predominantemente nublado e no período das 10 às $12 \mathrm{~h}$ (horário local).

Ou seja, situações de céu encoberto "overcast", ou de alta cobertura de nuvens, garantem condições semelhantes de iluminação (fração de radiação difusa) e o horário garante um caminho óptico constante entre as observações. Desta forma, pode-se entender que a variabilidade apontada no estudo está relacionada com a heterogeneidade das características estruturais das árvores, tais como posição de galhos, folhas, troncos e altura do dossel.

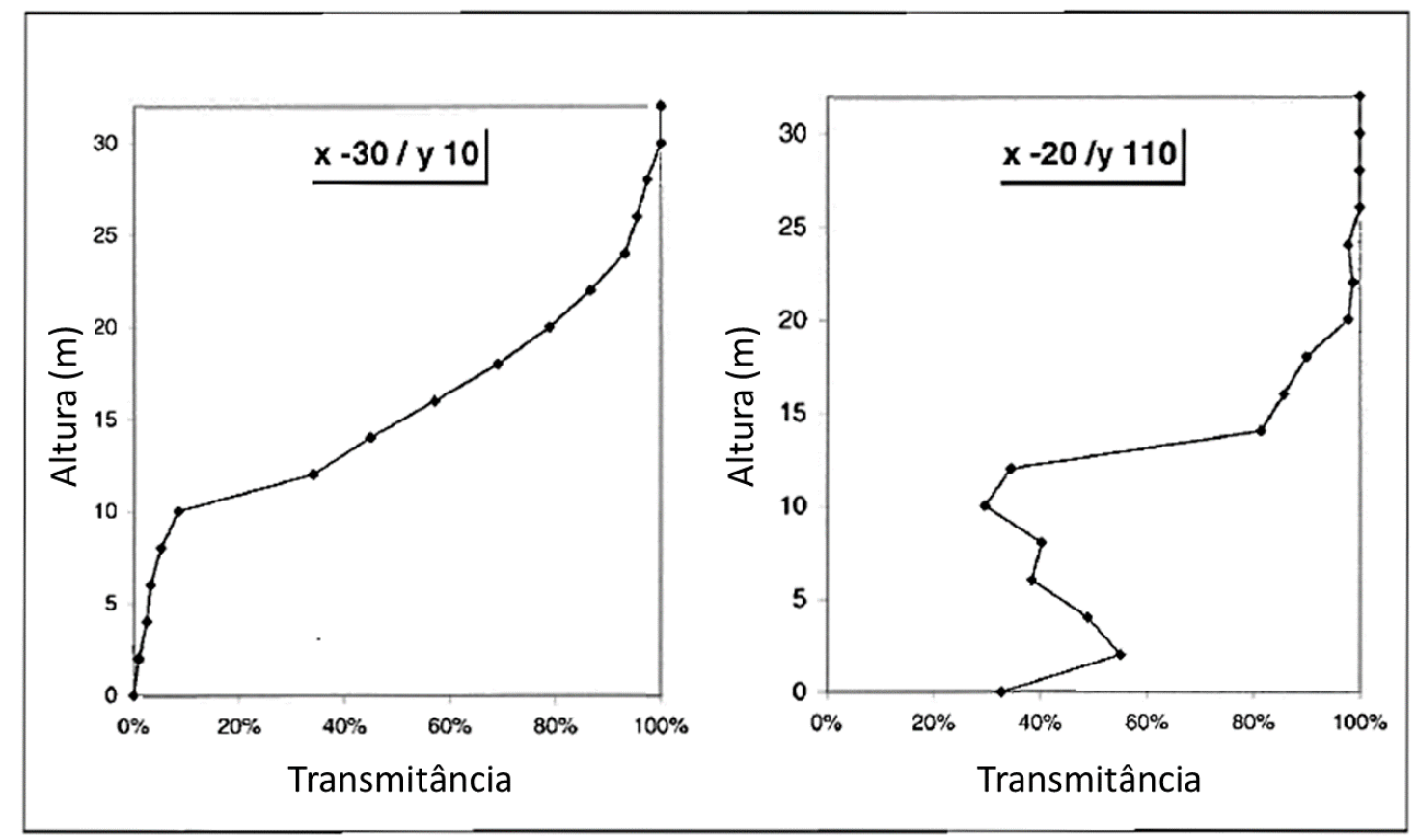

Figura 4 - Exemplo da variabilidade da transmitância dentro de floresta amazônica em um dia totalmente nublado em dois pontos distintos. As variabilidades estão associadas apenas ao arranjo espacial das árvores e suas componentes (i.e. galhos, folhas, troncos etc.). Fonte: adaptado de Anhuf \& Rollenbeck (2001). 
Uma floresta tropical é imensamente heterogênea em quantidade de espécies. Uma grande quantidade de espécies implica em grande variedade de formatos de folhas (diferentes áreas), diferentes propriedades ópticas de folhas, galhos e troncos, diferentes alturas. Essa variedade faz com que surjam clareiras, frestas (sunflecks) e aglomerados de galhos e folhas.

Além disso, árvores de mesma espécie também podem possuir diferentes idades e, com isso, alturas diferentes. As folhas também podem sofrer mudanças nas suas características ópticas conforme a idade. Em um estudo recente, Wu et al. (2018) observaram que a reflectância espectral das folhas diminui com 0 tempo.

Existem inúmeros fatores que podem influenciar a propagação da radiação solar dentro do dossel. Por exemplo, queda de árvores e galhos, fungos etc. Toomey et al. (2009) reportaram implicações no sensoriamento remoto associadas à doença fúngica típica de florestas úmidas. Os autores observaram que conforme o grau de infestação de Epiphylls (fungos colonizadores de superfícies foliares) aumenta, há implicações na reflectância e transmitância em diferentes espécies de folhas, de maneira que a reflectância e transmitância caem significativamente em todos os comprimentos de onda.

Souza e Válio (2003) observaram que as folhas das árvores podem sofrer alteração das suas características ópticas e morfológicas (e.g. espessura da folha) com variações na escala dimensional da folha. Espécies que são tolerantes a sombreamento, quando induzidas a tais condições apresentaram maior capacidade de absorver PAR e aumento na quantidade de clorofila. Outras espécies apresentaram comportamento oposto.

Modelos chamados "big leaf", são base para estudos ao nível de folha (Kanniah et al., 2012). Estudos baseados nessa metodologia consideram atenuação exponencial da luz sob o dossel e não consideram variabilidade horizontal. Esses modelos podem ser considerados limitados pois não conseguem representar mecanismos de feedback na interação superfícieatmosfera entre luz difusa, espalhamento e temperatura do dossel (Knohl e Baldocchi, 2008). 
Em contrapartida há os modelos sunflecks que conseguem reproduzir a presença de frestas por onde passam feixes de luz sem nenhuma ou pouca interação com a vegetação. Modelos que não consideram sunflecks são insensíveis aos efeitos da radiação difusa e direta (Alton et al., 2007).

O papel dos sunflecks ainda não é bem compreendido quanto ao tempo de duração e distribuição espacial (Kanniah et al., 2012). Outros fatores potencialmente significativos são o tamanho da folha, formato da copa e adaptação das folhas às diferentes condições de iluminação (Knohl e Baldocchi, 2008; Kanniah et al., 2012).

Dessa maneira, a literatura tem se preocupado em averiguar a consequência direta do efeito da luz difusa, NEE. Por outro lado as diferenças de iluminação que o movimento aparente do Sol proporciona juntamente com o efeito dos aerossóis de queimada, ainda não são bem relatados no ambiente de floresta Amazônica.

\subsection{Objetivos}

Dado o exposto, o principal objetivo deste trabalho é avaliar a propagação da radiação fotossinteticamente ativa (PAR) em dossel de florestas na região amazônica, durante a estação de queimadas, na presença de distintas quantidades de aerossol na atmosfera, utilizando um código de transferência radiativa tridimensional, o DART (Discrete Anisotropic Radiative Transfer).

Uma vez que o modelo de transferência radiativa tridimensional dá a possibilidade de incorporar qualquer figura na cena analisada, propõe-se como objetivo específico, analisar o efeito que a torre meteorológica causa na PAR transmitida. 
1. Fundamentação teórica 


\subsection{Radiação solar}

O sol tem uma temperatura superficial de aproximadamente $5780 \mathrm{~K}$. Isso faz com que sua região espectral de emissão majoritária seja entre 400 e 760 nm (Figura 5). Esse intervalo é denominado como região do visível (Liou, 2002), pois é a parte do espectro de emissão solar que nós, seres humanos, conseguimos enxergar. Radiação com comprimento de onda menor que $400 \mathrm{~nm}$ é denominada ultravioleta (UV) e maior que $700 \mathrm{~nm}$ é classificada como infravermelho.

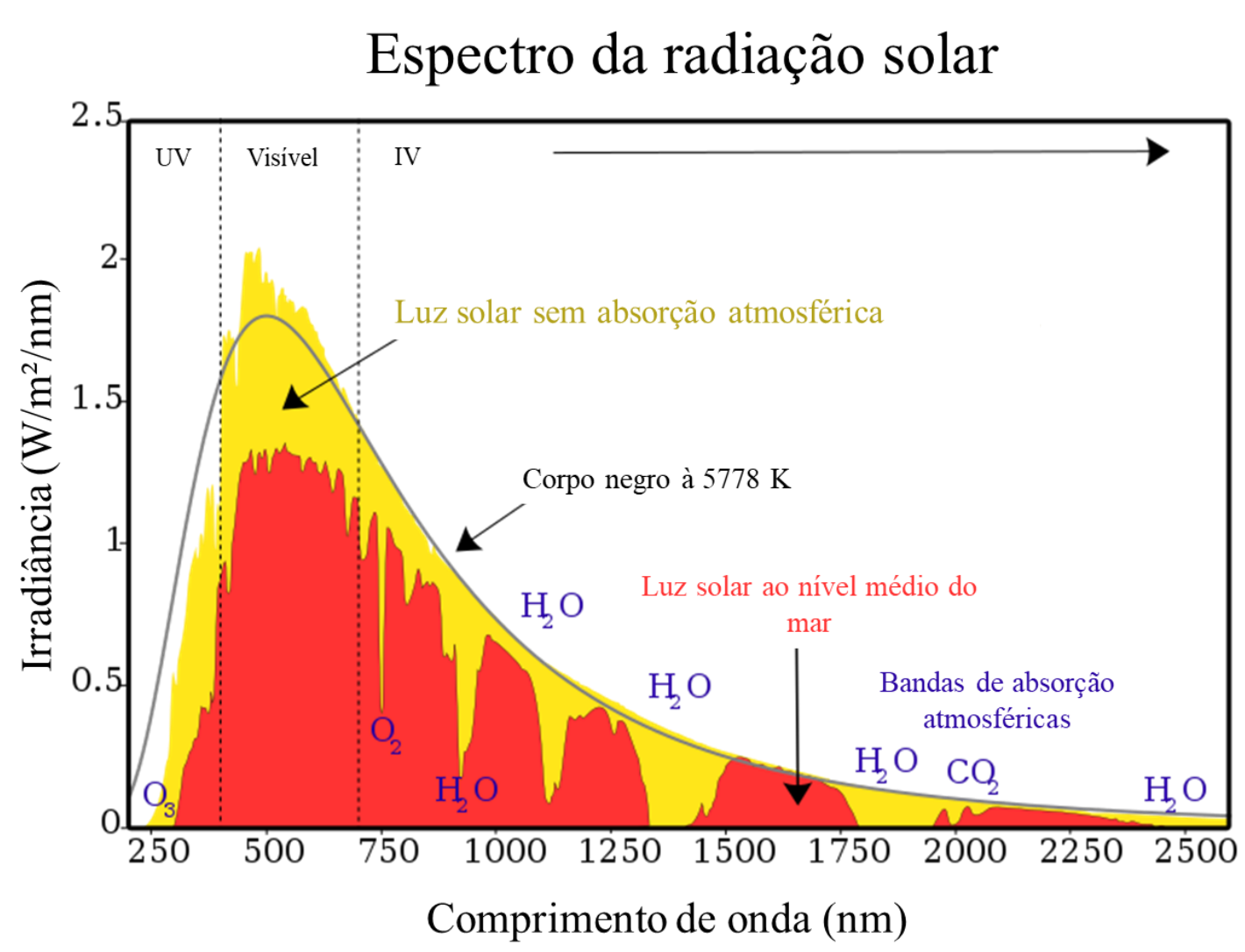

Figura 5 - Irradiância solar espectral incidente no topo da atmosfera (amarelo) e ao nível médio do mar (vermelho) e função de Planck à temperatura de $5778 \mathrm{~K}$ (preto) em função do comprimento de onda. Fonte: disponível em https://commons.wikimedia.org/wiki/File:Solar_spectrum_en.svg (adaptado). Acesso em 23/10/2019.

Conforme mencionado no capítulo introdutório, a fração do espectro da radiação luminosa emitida pelo Sol entre 400 a $700 \mathrm{~nm}$ é denominada como radiação fotossinteticamente ativa (Finch et al., 2004). A mesma é utilizada pelos indivíduos autotróficos na produção de substâncias orgânicas que lhes sirvam de nutrientes. 
O principal processo utilizado por esses indivíduos (e. g. plantas, algas e algumas bactérias) é a fotossíntese. O que torna esse processo possível é a clorofila. A clorofila é um pigmento fotossensível presente nas plantas, que, de maneira simplificada, absorve a luz solar (PAR) e a utiliza para transformar gás carbônico em energia química (carboidrato e oxigênio) no processo de fotossíntese.

A cor verde característica das folhas das plantas é devida à baixa capacidade de absorção de radiação no comprimento de onda referente à cor (aproximadamente $500 \mathrm{~nm}$ ) pela clorofila. Acima de $700 \mathrm{~nm}$, a reflectância (absortância), isto é, fração da irradiância solar refletida (absorvida) em relação à incidente pela clorofila contida nas folhas aumenta (diminui) significativamente. Como consequência, nessa região espectral, tem-se um baixo aproveitamento da radiação solar nos processos fotossintéticos.

\subsection{Geometria solar}

A quantidade de radiação solar incidente sobre a terra está diretamente relacionada com a posição do disco solar aparente no céu. Quanto mais perpendicular à superfície terrestre (meio-dia solar), maior é a quantidade de radiação incidente. Essa posição varia de acordo com a localidade, época do ano e hora do dia.

Fatores meteorológicos também influenciam na radiação incidente em superfície, tais como nebulosidade, partículas de aerossol ou a composição gasosa da atmosfera. Porém, se tomarmos como exemplo um dia limpo, sem nuvens e sem nenhuma variação na composição da atmosfera local, temos que a radiação solar incidente no período matutino será idêntica ao vespertino (IQBAL, 2012).

A Figura 6 apresenta as possíveis variações da radiação solar incidente sobre uma superfície plana e horizontal em duas cidades com coordenadas geográficas distintas em três dias especiais do ano. As variações são vistas na intensidade da radiação incidente e o tempo de duração de brilho solar, sendo elas menores no inverno (do hemisfério sul, local das cidades apresentadas). 
Os dias especiais indicam a passagem aparente do Sol sobre pontos de latitudes chaves no estudo da radiação solar: o equador (equinócio) e nos trópicos (solstício). O solstício de dezembro indica a passagem aparente do Sol sobre o Trópico de Capricórnio (máximo afastamento angular ao sul do equador $\sim-23,5^{\circ}$ ) e o solstício de junho, sobre o Trópico de Câncer (máximo afastamento angular ao norte do equador $\sim 23,5^{\circ}$ ).

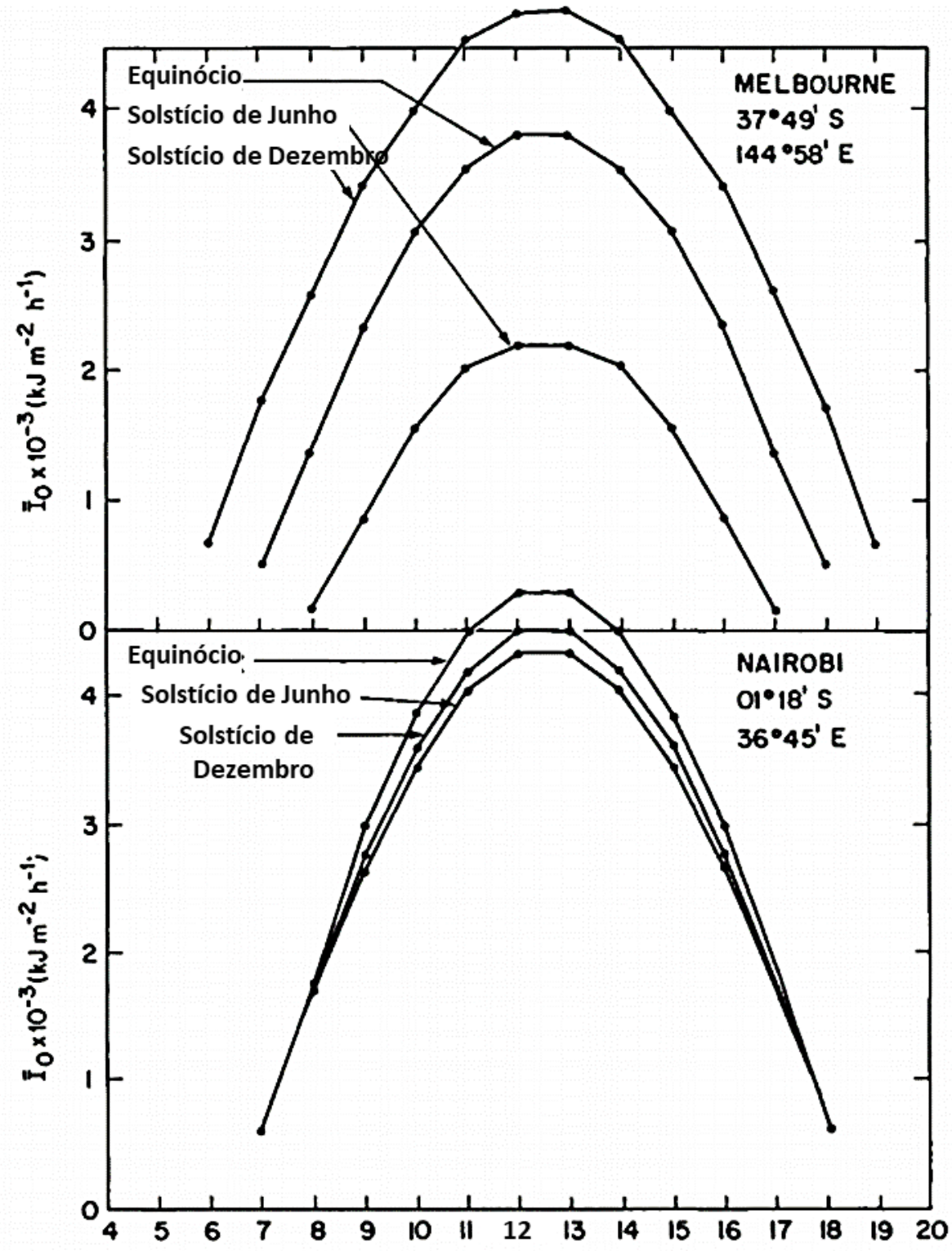

Figura 6 - Variação horária da irradiância solar incidente no topo da atmosfera, em diferentes dias do ano, para dois sítios de diferentes latitudes. Fonte: Adaptado de lqbal. 2012. 
Para a determinação da posição aparente do disco solar na abóbada celeste é preciso, primeiro, uma breve apresentação sobre os três sistemas de coordenadas necessários para tal. São eles, sistema geográfico, sistema equatorial horário e sistema horizontal local (Yamasoe e Corrêa, 2016).

O sistema geográfico é utilizado para localizar um ponto sobre a superfície terrestre através das conhecidas coordenadas, em graus, latitude $(\varphi)$ e longitude $\left(\lambda_{0}\right)$. A posição de astros no céu com o sistema equatorial é dada pelas coordenadas: ângulo horário $(\mathrm{H})$, onde $\mathrm{H}=0^{\circ}$ ao meio dia solar, $\mathrm{H}>0^{\circ}$ no período da tarde $\mathrm{e} H<0^{\circ}$ no período matutino; e declinação $(\delta)$ que é semelhante à latitude, mas com relação ao equador celeste.

A introdução do observador é dada pelo sistema horizontal local, no qual o mesmo está sobre uma superfície plana (plano horizontal local) que delimita o hemisfério celeste observado. Abaixo deste plano não é possível a observação de quaisquer astros.

As coordenadas são azimute $(\varphi \mathrm{a})$ - que é o ângulo entre o ponto cardeal norte e a projeção do astro observado no plano horizontal local -, e ângulo zenital (६). Este último é um ângulo complementar ao ângulo de elevação que é aquele entre o objeto observado e o plano horizontal local.

Relacionando esses três sistemas de coordenadas, tem-se a equação do ângulo zenital solar $\xi_{0}$ em função da latitude $(\varphi)$, declinação $(\delta)$ e ângulo horário $\left(\mathrm{H}_{0}\right)$.

$$
\xi_{0}=\operatorname{acos}\left(\operatorname{sen} \varphi \cdot \operatorname{sen} \delta_{0}+\cos \varphi \cdot \cos \delta_{0} \cdot \cos H_{0}\right)
$$

O ângulo horário é definido, em graus, como:

$$
H_{0}=\left[U T C+\frac{\lambda}{15^{\circ}}-\left(12-\epsilon_{t}\right)\right] \times 15^{\circ} / 1 h
$$

Onde a correção entre o tempo solar verdadeiro (TVL) e o tempo solar médio local (TL) é dada pela equação do tempo $\epsilon_{t}$.

$$
\epsilon_{t}=T V L-T L
$$

A declinação por sua vez é uma variável que pode ser estimada empiricamente em relação ao dia do ano conforme a equação: 


$$
\begin{gathered}
\delta_{0}=[0,006918-0,399912 \cos \Gamma+0,070257 \operatorname{sen} \Gamma-0,006758 \cos (2 \Gamma) \\
+0,000907 \operatorname{sen}(2 \Gamma)-0,002697 \cos (3 \Gamma) \\
+0,00148 \operatorname{sen}(3 \Gamma)]\left(180^{\circ} / \pi\right)
\end{gathered}
$$

Sendo $\Gamma$ definido como:

$$
\Gamma=2 \pi\left(d_{n}-1\right) / 365
$$

Onde $d_{n}$ é o dia juliano, ou o dia do ano a partir de uma contagem de dias consecutivos a partir de primeiro de janeiro, em que não se considera anos bissextos.

\subsection{Processos de atenuação da radiação na atmosfera}

A radiação, ao incidir sobre uma partícula, pode ser atenuada por dois principais processos: absorção, que ocorre quando a energia luminosa incidente é transformada em outro tipo de energia (e. g., energia interna), e espalhamento, que é um desvio angular da propagação do feixe incidente sem alterações no seu comprimento de onda (Yamasoe e Corrêa, 2016).

A irradiância que sofre processos de espalhamento é denominada difusa. Uma de suas características é não projetar sombra, ao contrário da radiação direta (fração da irradiância incidente que não sofreu processos de atenuação). A radiação difusa é, portanto, a radiação que incide sobre uma superfície sem ângulo preferencial, ou seja, incide de diferentes direções.

Dois principais modelos matemáticos são utilizados para descrever 0 espalhamento da radiação: Rayleigh e Mie. A principal característica que define qual dos modelos utilizar é a razão entre o tamanho da partícula espalhadora (de raio $r$, no caso de partículas esféricas) e o comprimento de onda da radiação incidente $(\lambda)$.

O modelo de Rayleigh pode ser considerado uma situação limite da teoria Mie, sendo usado para descrever o espalhamento por partículas muito menores que o comprimento de onda $\lambda$. O espalhamento Mie descreve o espalhamento em que o tamanho da partícula ( $r$ ) é da mesma ordem ou maior que $\lambda$. 
A principal diferença na distribuição angular de espalhamento (função de fase) dos modelos é a simetria. O espalhamento Rayleigh tem espalhamento simétrico, no qual a fração espalhada frontalmente é igual à que foi retro espalhada. Já o Mie apresenta predominância de espalhamento na região dianteira da partícula, na mesma direção e sentido da radiação incidente (Yamasoe e Corrêa, 2016). Essa predominância frontal aumenta com o tamanho da partícula assim como a complexidade da geometria do espalhamento (Figura 7).

Há também diferenças em relação à dependência espectral entre os dois tipos de espalhamento. O espalhamento Rayleigh tem sua maior eficiência para radiação com comprimentos de onda muito pequenos, uma vez que varia com $\lambda^{-4}$ (Wallace \& Hobbs, 2006).

Por outro lado, o espalhamento descrito pela teoria Mie apresenta menor dependência espectral e, caso o tamanho da partícula seja muito maior que o comprimento de onda da radiação incidente, a dependência espectral é nula.

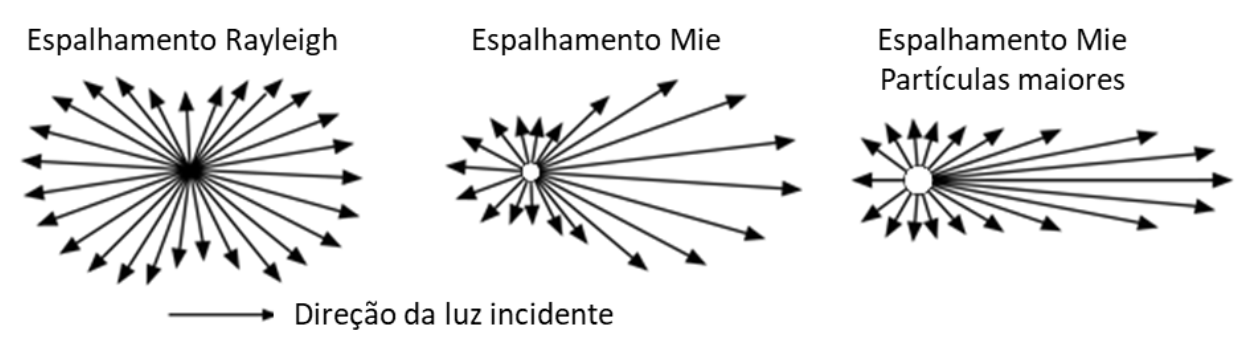

Figura 7 - Comparação entre espalhamento Rayleigh (simétrico) e Mie (assimétrico, anisotrópico) para radiação incidente com mesmo comprimento de onda, variando o tamanho da partícula espalhadora. Fonte: Adaptado de http://hyperphysics.phy-astr.gsu.edu/hbase/atmos/blusky.html. Acesso em: novembro 2019.

Um exemplo de espalhamento Mie pode ser visto nas gotículas de água que formam as nuvens. O exemplo clássico de espalhamento Rayleigh é o céu azul causado pelas moléculas que constituem nossa atmosfera.

A grandeza física que quantifica a fração da radiação que foi espalhada num processo de atenuação é denominada albedo simples ( $\omega_{0}$ ou SSA, do inglês Single Scattering Albedo). É a razão da contribuição da atenuação que foi causada por espalhamento pela atenuação total (absorção + espalhamento). 
A descrição matemática do espalhamento Mie, por ser anisotrópico e assimétrico, é complexa e de difícil representação. A função de fase é a função que descreve o padrão angular de espalhamento da radiação incidente sobre uma partícula espalhadora.

Abaixo segue a função de fase normalizada, onde $\Theta$ é o ângulo de espalhamento (ângulo entre a direção do feixe incidente e espalhado) e $\Omega$ representa as coordenadas de orientação do espalhamento.

$$
\frac{1}{4 \pi} \int_{4 \pi} P(\cos \Theta) d \Omega=1
$$

Em estudos específicos, que requerem uma precisão muito alta do espalhamento anisotrópico, a função de fase é decomposta em polinômios em função do ângulo de espalhamento (e. g. polinômios de Legendre). Todavia, para essa precisão, é necessário um grande custo computacional (Yamasoe e Corrêa, 2016).

Entretanto, dependendo da aplicação, pode-se simplificar a representação matemática da função de fase. O modelo de Henyey-Greenstein provê uma conveniente aproximação para a caracterização da distribuição angular da luz espalhada (função de fase) anisotropicamente. A função dupla de Henyey-Greenstein é dada pela equação (Zhang \& Li, 2016):

$$
\frac{P(\cos \Theta)}{4 \pi}=\frac{1}{4 \pi} \cdot\left[\frac{a \cdot\left(1-g_{1}^{2}\right)}{\left[1+g_{1}^{2}-2 g_{1} \cdot \cos (\Theta)\right]^{1.5}}+\frac{(1-a) \cdot\left(1-g_{2}^{2}\right)}{\left[1+g_{2}^{2}-2 g_{2} \cdot \cos (\Theta)\right]^{1.5}}\right]
$$

Onde $a$ é o peso para o primeiro termo da função de fase de HenyeyGreenstein, $g_{1}$ é o fator de assimetria para espalhamento frontal (adimensional), $\mathrm{g}_{2}$ é o fator de assimetria para espalhamento traseiro (adimensional).

Dado um feixe de luz monocromático que atravessa um meio material homogêneo e sofre atenuação, tal atenuação pode ser descrita pela lei de BeerBouguer-Lambert, ou somente Lei de Beer.

Essa lei descreve uma atenuação exponencial para a situação supracitada e tem diversas utilidades nas ciências atmosféricas, na química 
entre outras. No caso da radiação solar, essa lei descreve como o feixe direto é atenuado ao atravessar a atmosfera desde o topo até a superfície ou até a posição do observador.

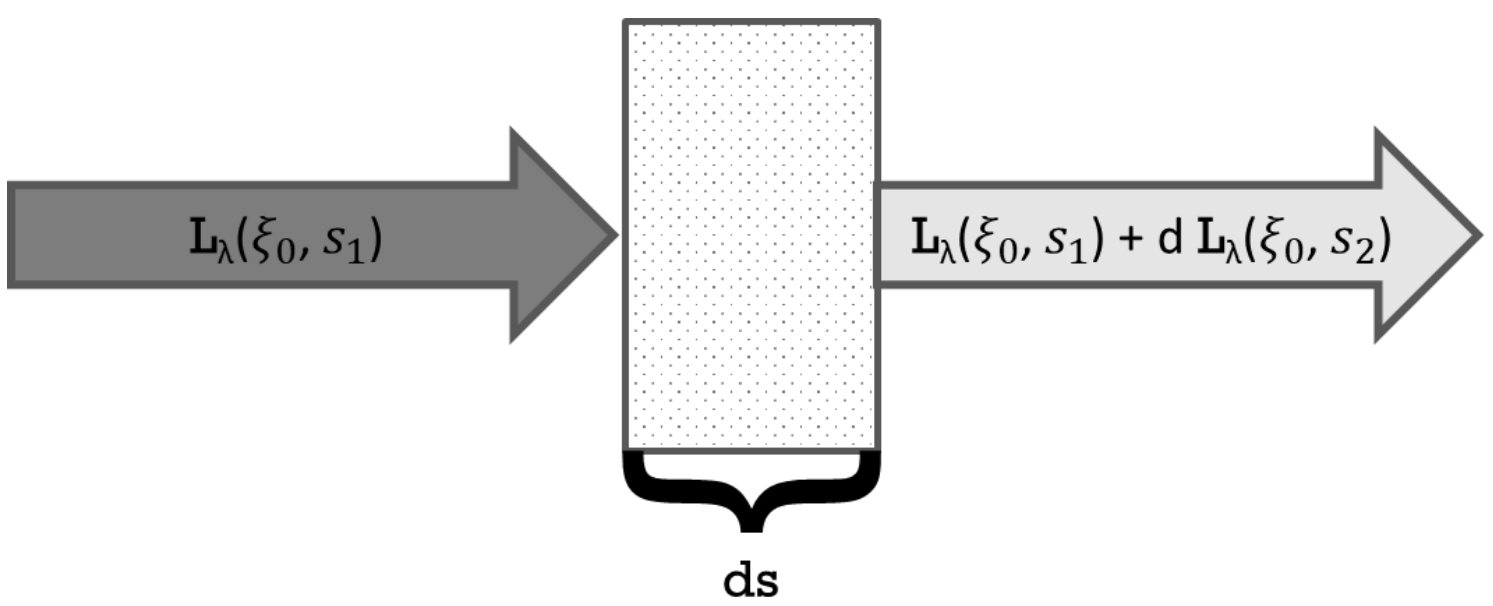

Figura 8 - Esquema de atenuação de um feixe monocromático após atravessar um meio atenuador homogêneo.

A Lei de Beer é expressa pela equação abaixo:

$$
L_{\lambda}\left(\xi_{0}, s_{2}\right)=L_{\lambda}\left(\xi_{0}, s_{1}\right) e^{-m(\theta) \tau_{\lambda}}
$$

Onde $L_{\lambda}\left(\xi_{0}, s_{1}\right)$ é o feixe de luz monocromático na posição (s) inicial $\left(s_{1}\right)$ de análise e $L_{\lambda}\left(\xi_{0}, s_{2}\right)$ é a radiação emergente após sofrer os processos de atenuação. $\tau_{\lambda}$ é a profundidade óptica total para o mesmo comprimento de onda da radiação incidente e é definida pela soma das profundidades ópticas de aerossol (AOD) $\left(\tau_{a}\right)$, Rayleigh $\left(\tau_{r}\right)$ e gasosa $\left(\tau_{g}\right)$. No caso de um mesmo tipo de aerossol, quanto maior a profundidade óptica do aerossol (AOD), maior é a concentração desse aerossol na atmosfera.

$$
\tau_{\lambda}=\tau_{a}+\tau_{r}+\tau_{g}
$$

Assim, define-se como a profundidade óptica, a capacidade de um determinado constituinte da atmosfera em atenuar a radiação num determinado comprimento de onda. Entretanto, a profundidade óptica é definida com relação à vertical, ou seja, na camada entre uma determinada altura e outra. Sendo a altura $z=s \cdot \cos \xi$, onde $\xi$ é o ângulo zenital da orientação de propagação do feixe de radiação incidente. 
Por fim, a massa óptica mo é o inverso do cosseno do ângulo solar zenital $\xi_{0}$ (na aproximação atmosfera plano-paralela) ou a secante de $\xi_{0}$.

$$
m\left(\xi_{0}\right)=\frac{1}{\cos \xi_{0}}=\sec \xi_{0}
$$

Já, para quantificar a irradiância espectral incidente na forma difusa em superfície, assim como a transferência de radiação dentro do dossel, se faz necessário resolver a equação de transferência radiativa.

$$
\mu \frac{d L_{\lambda}\left(\tau, \mu, \varphi_{0}\right)}{d \tau}=L_{\lambda}\left(\tau, \mu, \varphi_{0}\right)-\omega_{0_{\lambda}}(\tau, \lambda) J_{\lambda}\left(\tau, \mu, \varphi_{0}\right)
$$

Onde $\mu$ é o cosseno do ângulo zenital de observação, $\varphi_{0}$ é 0 ângulo azimutal também de observação, $L_{\lambda}$ é a radiância espectral, $\omega_{0_{\lambda}}$ albedo simples e $J_{\lambda}$ é a função fonte de espalhamento.

A radiação que foi espalhada pode sofrer, recursivamente, espalhamentos subsequentes antes de chegar até o observador. Esse espalhamento pode ser causado, por exemplo, por aerossóis, gotículas de nuvem ou até mesmo por folhas dentro do dossel. Por esse motivo, a função fonte de espalhamento surge para contabilizar a contribuição do espalhamento múltiplo de todas as outras direções.

Vale ressaltar que radiância é definida como a razão entre a intensidade de radiação de um corpo em uma determinada direção projetada perpendicularmente por unidade de área. Ao integrar a radiância para todo um hemisfério, obtém-se a irradiância.

Um importante parâmetro para o entendimento das flutuações da profundidade óptica de aerossol numa série temporal é o coeficiente de Ångström, $\alpha\left(\lambda_{1}, \lambda_{2}\right)$. Através desse parâmetro é possível identificar o tamanho predominante do aerossol e a possibilidade de um dado contaminado por nuvens, visto que as gotículas de nuvens apresentam tamanho muito maior que o aerossol de queimadas, por exemplo (Mcarthur et al., 2003; Sayão, 2008). 
O valor de $\alpha$ funciona como um indicador diretamente proporcional da dependência espectral. Com efeito, também é possível relacionar o tamanho das partículas de uma maneira geral, de forma que quanto maior for o valor de $\alpha$, menor será o tamanho das partículas em suspensão na atmosfera no instante da observação.

$$
\alpha\left(\lambda_{1}, \lambda_{2}\right)=\frac{-\ln \left({ }^{\tau_{a, \lambda_{1}}} / \tau_{a, \lambda_{2}}\right)}{\ln \left({ }^{\lambda_{1}} / \lambda_{2}\right)}
$$

De maneira resumida, $\alpha$ pequeno $(\sim 0)$ indica aerossóis da moda grossa, uma vez que a dependência espectral é baixa. Com $\alpha \sim 2$, tem-se aerossóis de moda fina, dada a maior dependência espectral (Mcarthur et al., 2003).

\subsection{Reflexão especular e lambertiana}

A fração de radiação refletida por uma superfície, isto é, espalhada de volta para o hemisfério de origem, em relação à orientação da radiação incidente é denominada albedo. Porém, o albedo não é uma propriedade que só depende da composição da superfície pois também depende da distribuição angular e espectral da luz sobre ela incidente (Coakley, 2003). A Figura 9 exemplifica alguns tipos de reflexão.

Se uma superfície espacialmente uniforme for suficientemente grande a ponto de que seus elementos individuais possam ser tratados como planos, a radiação refletida tem o mesmo ângulo que a incidente (lei de Fresnel) (Coakley, 2003; Petty, 2006). Neste caso em particular, a reflexão é denominada especular.

Por exemplo, a luz que incide sobre um espelho é refletida de volta com o mesmo ângulo. Uma superfície de água calma (lâmina d'água, poça ou lago), isto é, sem ondas, possui reflexão semelhante. Uma vez que surgem perturbações nesta superfície, o ângulo de reflexão difere do ângulo de incidência. 

a) Especular
b) Quasi-Especular
c) Lambertiano
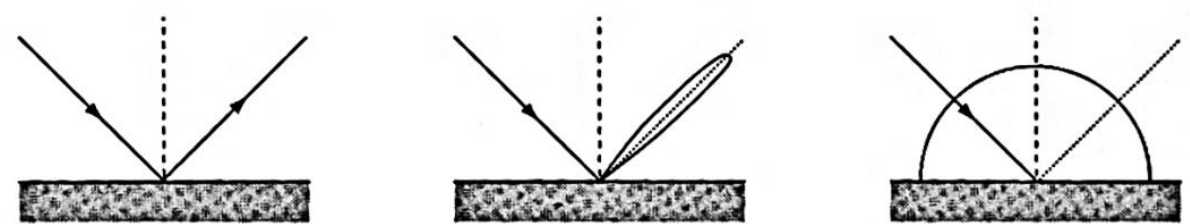

d) Quasi-Lambertiano

e) Complexo
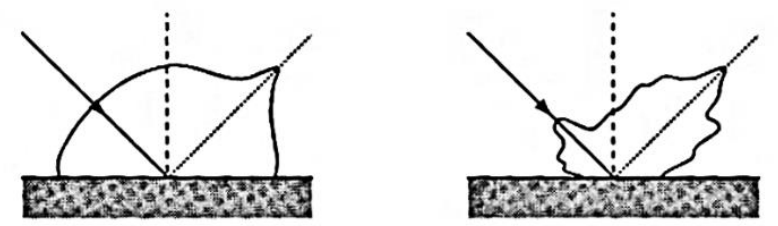

Figura 9 - Tipos de reflexão superficiais em gráficos polares. A intensidade relativa da radiação refletida para cada ângulo de espalhamento é indicada pela distância entre a curva e o ponto central. A seta indica a direção de incidência da radiação e em a) direção da reflexão Fonte: Adaptado de Petty, 2006.

Conforme aumenta a rugosidade do material, a reflexão observada tende a ser mais uniforme. Por exemplo, um passageiro a bordo de um avião ao sobrevoar um canavial, não vê grandes diferenças de iluminação, isto é, com poucas variações de brilho. Em outras palavras, o passageiro não verá uma região muito mais brilhante (ou um hotspot) do que a região ao lado, ao contrário do nascer da lua no mar onde é possível ver uma trilha luminosa da lua na água.

A primeira aproximação para reflexão superficial de corpos rugosos é a lambertiana, que descreve a reflexão como isotrópica, ou seja, independente da geometria de iluminação (Coakley, 2003). Esse é o tipo de reflexão observada pelo passageiro do avião.

$\mathrm{Na}$ natureza, os materiais não apresentam reflexão perfeitamente lambertiana ou especular, eles tendem a ter uma geometria de reflexão mais complexa (exemplificada na Figura 9). Contudo, a aproximação lambertiana é muito útil para a maioria dos estudos fora da microescala. 
3. Materiais e métodos 


\subsection{Sítios experimentais}

Neste trabalho são apresentadas e discutidas medições efetuadas em três sítios experimentais: Amazon Tall Tower Observatory (ATTO) $\left(-2,150^{\circ} ;-59,005^{\circ}\right)$, Reserva Biológica do Jaru (Rebio) $\left(-10,146^{\circ} ;-61,908^{\circ}\right)$ e Humaitá $\left(-7,456^{\circ}\right.$; $\left.-63,228^{\circ}\right)$, todos localizados na região Norte do Brasil, sendo dois no estado do Amazonas e um em Rondônia. As observações foram realizadas na estação de queimadas, final da estação seca. A localização destes está disposta na Figura 10.

Sintetizando, o período de coleta de dados em cada local está apresentado na Tabela 1 junto com a localização em coordenadas geográficas dos mesmos.

Tabela 1 - Sumário do período de coleta de dados utilizado no trabalho para cada localização.

\begin{tabular}{lccc}
\hline & ATTO & Rebio & Humaitá \\
\cline { 2 - 4 } Coordenadas & $-2,150^{\circ} ;-59,005^{\circ}$ & $-10,146^{\circ} ;-61,908^{\circ}$ & $-7,456^{\circ} ;-63,228^{\circ}$ \\
Início & $29 /$ set & $20 /$ ago & $23 /$ ago \\
Fim & $06 /$ nov & $01 /$ out & $25 /$ set \\
Ano & 2015 & 2007 & 2012 \\
\hline
\end{tabular}

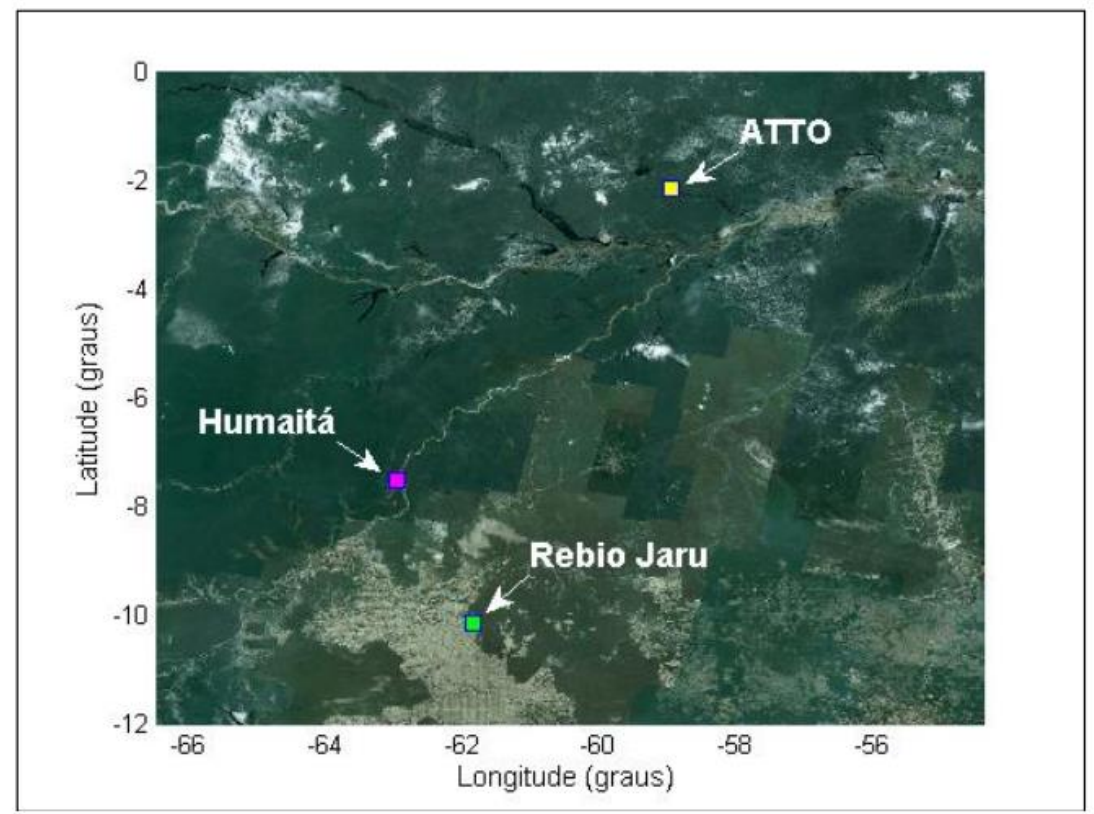

Figura 10 - Localização dos sítios experimentais. Fonte: Costa, T. S. (2013). 


\subsection{Instrumentos}

Neste subcapítulo são detalhados os arranjos experimentais, as variáveis medidas e os respectivos instrumentos utilizados.

A irradiância na região espectral fotossinteticamente ativa (PAR - de 400 $\mathrm{nm}$ a $700 \mathrm{~nm}$ ) foi medida com radiômetros SKE 510 PAR Energy Sensor manufaturados por Skye Instruments Ltd. em distintas alturas (Figura 11), voltados para diferentes faces, ao longo de uma torre meteorológica, a uma distância aproximada desta de 4 metros. A Tabela 2 esquematiza a disposição dos sensores nos diferentes sítios experimentais.

Tabela 2 - Arranjo dos radiômetros SKE 510 PAR Energy Sensor no perfil vertical do dossel de cada sítio experimental.

\begin{tabular}{|c|c|c|c|c|c|c|c|c|c|c|c|c|c|c|}
\hline \multicolumn{15}{|c|}{ Local } \\
\hline \multicolumn{5}{|c|}{ ATTO } & \multicolumn{5}{|c|}{ Rebio } & \multicolumn{5}{|c|}{ Humaitá } \\
\hline $\begin{array}{l}\widehat{\Xi} \\
\dot{\Sigma}\end{array}$ & $\begin{array}{l}\stackrel{0}{ \pm} \\
\text { 을 }\end{array}$ & $\underset{\Xi}{\Phi}$ & $\overline{\bar{D}}$ & 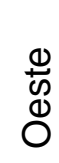 & $\begin{array}{l}\widehat{\xi} \\
\dot{E}\end{array}$ & $\begin{array}{l}\frac{0}{ \pm} \\
\frac{1}{2}\end{array}$ & 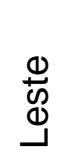 & $\overline{\bar{S}}$ & $\begin{array}{l}\frac{0}{00} \\
0 \\
0\end{array}$ & $\begin{array}{l}\widehat{\Xi} \\
\frac{\dot{E}}{ \pm}\end{array}$ & $\begin{array}{l}\stackrel{0}{ \pm} \\
\text { 을 }\end{array}$ & 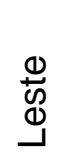 & $\overline{\bar{S}}$ & $\begin{array}{l}\frac{\Phi}{09} \\
\Phi \\
0\end{array}$ \\
\hline 39 & $x$ & $\checkmark$ & $\checkmark$ & $\checkmark$ & 47 & $\checkmark$ & $\checkmark$ & $x$ & $\checkmark$ & 33 & $\checkmark$ & $\checkmark$ & $x$ & $\checkmark$ \\
\hline 33 & $x$ & $x$ & $\checkmark$ & $x$ & 34 & $\checkmark$ & $\checkmark$ & $x$ & $\checkmark$ & 25 & $\checkmark$ & $\checkmark$ & $x$ & $\checkmark$ \\
\hline 28 & $x$ & $x$ & $x$ & $\checkmark$ & 25 & $\checkmark$ & $\checkmark$ & $x$ & $\checkmark$ & 17 & $\checkmark$ & $\checkmark$ & $x$ & $\checkmark$ \\
\hline 22 & $x$ & $\checkmark$ & $x$ & $x$ & 17 & $\checkmark$ & $\checkmark$ & $x$ & $\checkmark$ & 11 & $\checkmark$ & $\checkmark$ & $x$ & $x$ \\
\hline 16 & $x$ & $x$ & $\checkmark$ & $x$ & 10 & $\checkmark$ & $\checkmark$ & $x$ & $\checkmark$ & 5 & $\checkmark$ & $\checkmark$ & $x$ & $\checkmark$ \\
\hline 10 & $x$ & $x$ & $x$ & $\checkmark$ & 5 & $\checkmark$ & $\checkmark$ & $x$ & $\checkmark$ & & & & & \\
\hline 5 & $x$ & $\checkmark$ & $x$ & $x$ & & & & & & & & & & \\
\hline
\end{tabular}




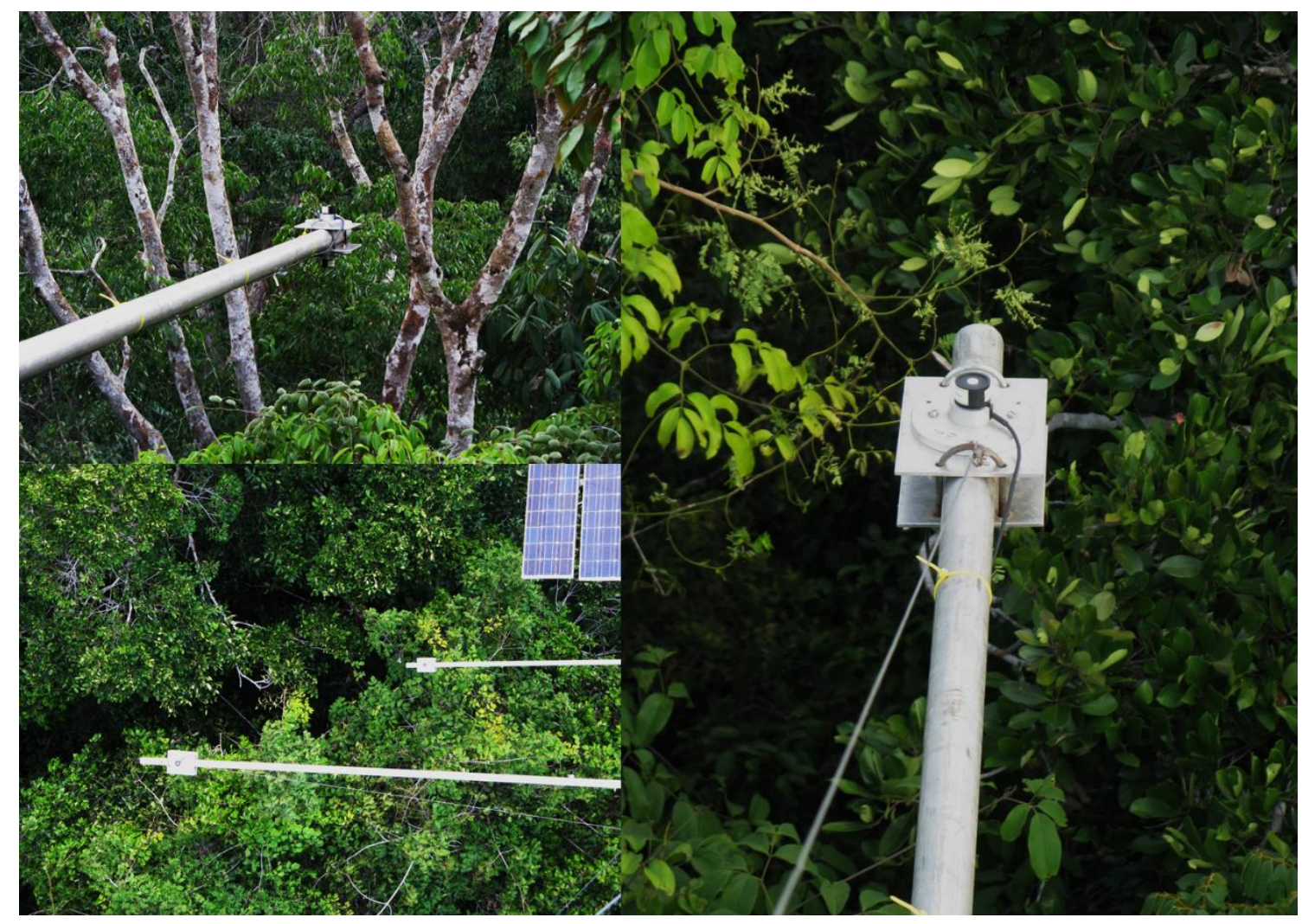

Figura 11 - Exemplo do arranjo experimental dos radiômetros PAR (SKE 510 PAR Energy Sensor) em perfil vertical durante a campanha intensiva realizada no ATTO, durante a estação de queimadas de 2015. Fonte: acervo pessoal de Márcia Akemi Yamasoe.

Para o cálculo da transmitância dentro do dossel, a irradiância medida em cada altura foi dividida pela irradiância PAR incidente no topo do dossel, entendido como o sensor mais alto (39 m, $47 \mathrm{~m}$ e $33 \mathrm{~m}$, respectivamente para o ATTO, Rebio Jaru e Humaitá). O mesmo vale para as transmitâncias determinadas numericamente, cujo código de transferência radiativa utilizado será detalhado mais adiante neste mesmo capítulo. Foram realizadas médias horárias para agrupamento em intervalo de ângulo zenital solar e, posteriormente, médias por intervalo de AOD para simplificação da apresentação dos dados.

As medições foram feitas no final da estação seca, conhecido como período da estação de queimadas (da Rocha \& Yamasoe, 2013). Os dados de irradiância espectral foram medidos com um Multi-Filter Rotating Shadowband Radiometer (MFRSR - Figura 12) manufaturado pela Yes Inc. em bandas estreitas centradas em $415 \mathrm{~nm}, 670 \mathrm{~nm}, 870 \mathrm{~nm}$ e $1036 \mathrm{~nm}$ e em banda larga de (300 a 2700nm), correspondente ao espectro solar. 


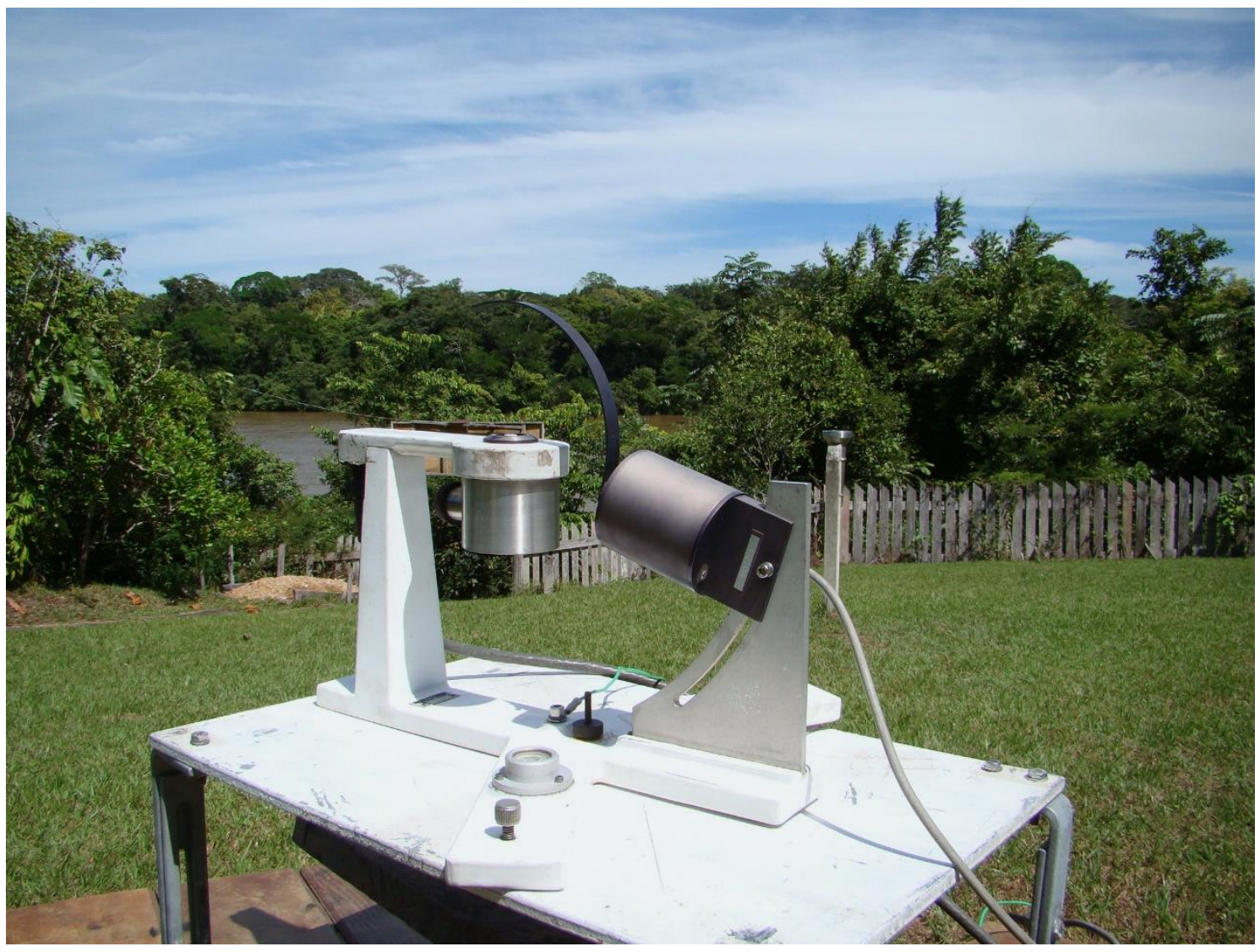

Figura 12 - Ilustração da montagem do MFRSR na Reserva Biológica do Jaru em 2007. Fonte: acervo pessoal de Márcia Akemi Yamasoe.

Com o MFRSR e utilizando a metodologia descrita em Sayão (2008), é possível a estimativa da profundidade óptica do aerossol (AOD) sem o risco de ter-se dados contaminados por nuvens. O motivo para isto é isolar o máximo possível o efeito da AOD na propagação de PAR dentro do dossel florestal.

\subsubsection{Processamento de dados}

Para analisarmos especificamente o efeito do aerossol na transmitância de radiação PAR através do dossel devemos garantir que não haja contaminação por nuvens. Desta forma, foram descartados dados que continham nuvem. Para tal, um algoritmo desenvolvido por Sayão (2008) foi utilizado neste trabalho.

O algoritmo para identificação de contaminação por nuvens nos dados de profundidade óptica de aerossol descrito por Sayão (2008) é baseado em três fatores e têm diferentes funções. Os critérios, os quais estão sumarizados 
abaixo, devem ser simultaneamente verificados para que o dado seja aceito e incorporado ao banco de dados.

- A razão entre irradiância direta normal e difusa em $870 \mathrm{~nm}>1,5$ é utilizada para:

a) Filtrar a presença de nuvens

b) Preservar casos muito poluídos (AOD > 1,5 em $415 \mathrm{~nm}$ )

- Coeficiente de Ångström nos canais $672 / 870 \mathrm{~nm}>0,5$

a) Filtrar nuvens

b) Preservar e detectar plumas com aerossol da moda grossa, isto é, com tamanho grande

- Desvio padrão da AOD em $870 \mathrm{~nm}<0,015$, estimado considerando um intervalo de 9 minutos

a) Filtrar contaminação de nuvens finas (tipo cirrus)

É necessária a ressalva que os dados referentes ao MFSR utilizados para caracterizar o sítio de Humaitá. O sensor não foi instalado no mesmo sítio onde está situada a torre meteorológica, mas sim na Universidade Federal do Amazonas (coordenadas geográficas: $-7,52^{\circ} ;-63,03^{\circ}$ ), no topo de um dos seus prédios, para evitar sombreamentos (Yamasoe et al., 2015).

A distribuição da frequência horária de observações para cada dia do ano em cada sítio experimental está disposta na Figura 13 abaixo. Nela é possível identificar os períodos com presença de nebulosidade, representados pelo branco. O ATTO é o sítio com maior contaminação por nuvens. Humaitá tem o banco de dados mais homogêneo e mais extenso.

De maneira geral, o banco de dados possui uma menor densidade de dados após às $12 \mathrm{~h}$ (horário local). Isso se dá devido à maior presença de nebulosidade a partir desse período. Sabendo que a radiação solar incidente na primeira metade do dia é, em condições ideais (sem nuvens), igual à segunda metade, optou-se por utilizar apenas dados referentes ao período matutino (7 - 12 h). 


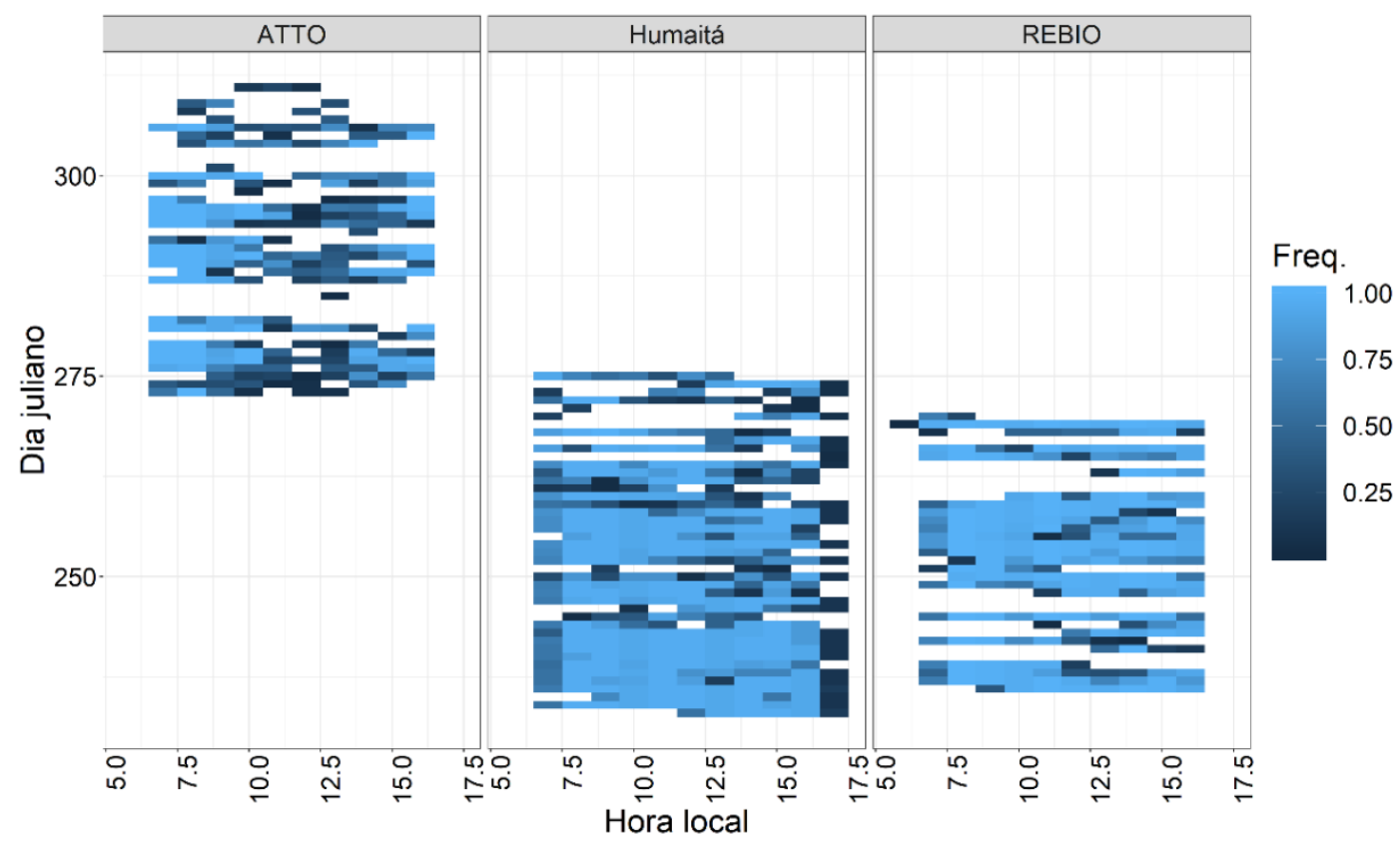

Figura 13 - Frequência de dados por hora e por dia em cada sítio amostral.

Para ter maior confiabilidade nos dados de transmitância, foram utilizados $50 \%$ dos dados de irradiância PAR que estavam dentro do espaço de variação interquartil, isto é, valores acima do percentil 0,25 e abaixo do percentil 0,75.

Este filtro foi aplicado para cada lado da torre (norte, leste etc.), em cada altura do sensor e para cada intervalo de massa óptica com margem de 0,1 . Isto é, o intervalo de massa óptica 1,1 abrange de 1,05 a 1,15. Desta forma, tornase possível a comparação de um caso que aconteceu no início do período de observação com um caso no último dia de observação.

As transmitâncias foram calculadas normalizando a irradiância PAR em uma dada altura pela incidente no topo do dossel (sensor mais alto), com exceção do ATTO, onde foi feita uma média dos três sensores do topo e considerado o perfil sem distinção por lado.

\subsection{DART}

O modelo DART (Discrete Anisotropic Radiative Transfer) simula a transferência radiativa em três dimensões de um meio heterogêneo em altíssima resolução (Gastellu-Etchegorry et al., 1996). Com ele é possível criar cenas (ou cenários) onde diferentes componentes da paisagem podem ser incluídos, tais como corpos d'água, relevo, folhas, grama, tronco, prédios, etc. (Figura 14). 


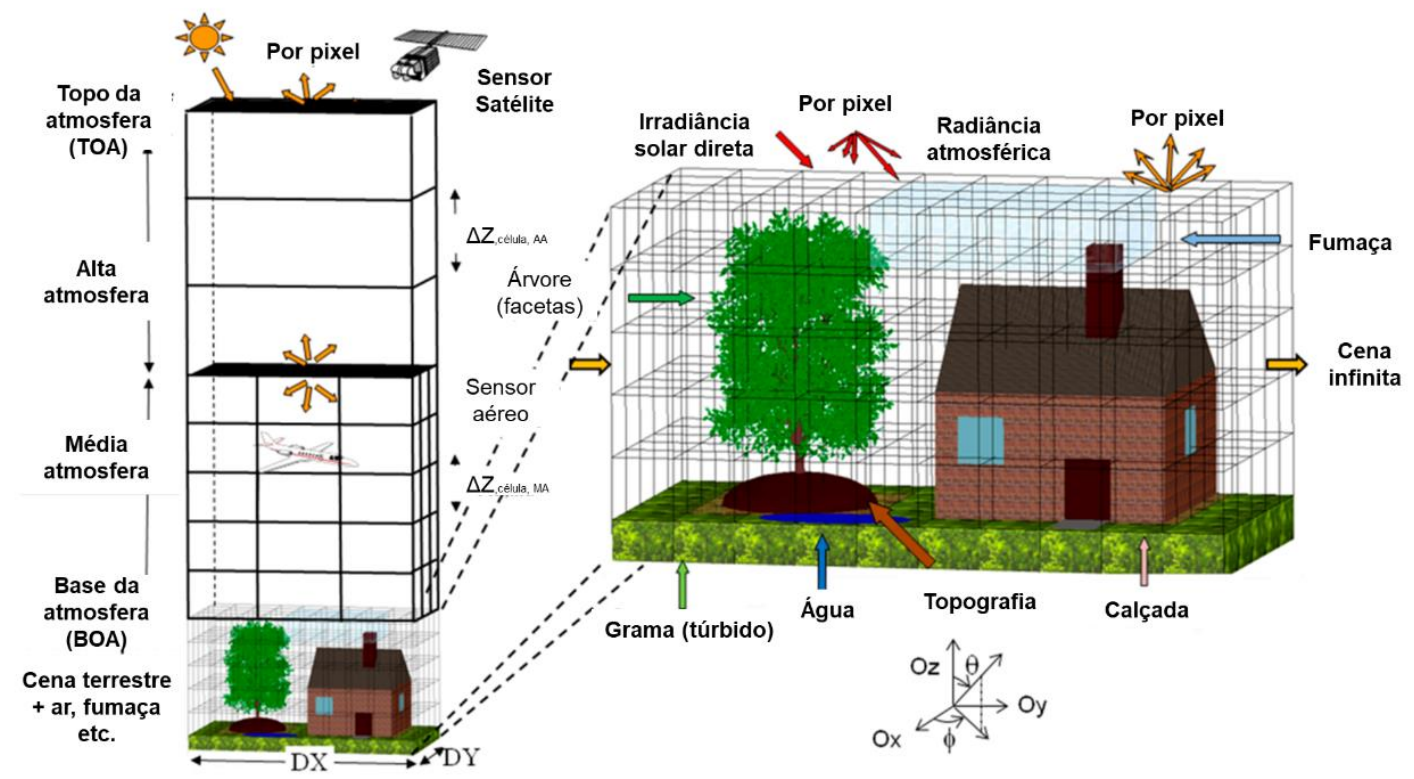

Figura 14 - Esquematização da matriz de representação do sistema Terra/atmosfera pelo modelo DART. Níveis verticais da atmosfera: superior (camadas), média (células/voxels de qualquer tamanho), inferior (células do mesmo tamanho que os da superfície). Na figura é possível ver alguns produtos do modelo e representações dos elementos da cena terrestre. Estes últimos são fixos e podem ser representados por facetas ou um meio túrbido. Fonte: Adaptado de Gastellu-Etchegorry et al., (2015).

A cena é construída a partir de células paralelepipédicas que atuam como blocos que formam uma matriz retangular. Cada célula tem suas características ópticas próprias (e. g. função de fase) que podem ser inseridas diretamente no modelo (Gastellu-Etchegorry et al., 1996).

A complexidade de um ambiente tridimensional heterogêneo (topografia, distribuição de folhas, construções) pode afetar fortemente as observações feitas in loco (Gastellu-Etchegorry et al., 2015). O espalhamento múltiplo e a conservação de energia são as maiores fontes de erros nos modelos, uma vez que não há uma forma analítica simples de descrever os consecutivos espalhamentos (ao contrário do espalhamento de primeira ordem) (GastelluEtchegorry et al., 2015).

Os modelos de transferência radiativa são uma alternativa de grande acurácia para esses tipos de estudo pois conseguem representar as paisagens terrestres de maneira realística. Além disso, esses modelos se baseiam na equação de transferência radiativa para descrever as variações da radiação ao longo de um caminho óptico devido ao espalhamento, absorção e emissão 
térmica (Gastellu-Etchegorry et al., 2015). Com isso, podem representar o espalhamento múltiplo em função da complexidade da cena.

\subsubsection{Caracterização da cena}

Neste trabalho, a cena foi representada como um volume de base quadrada com $60 \mathrm{~m}$ de lado por $49 \mathrm{~m}$ de altura. A resolução da cena, isto é, o tamanho de cada voxel (um pixel que contém volume) da cena é de $1 \mathrm{~m}^{3}$. Por se tratar de uma área relativamente pequena, a mesma pode ser representada com topografia simplificada, no caso, totalmente plana.

O tamanho da cena foi escolhido para que fosse possível evitar o efeito de borda (que será melhor discutido posteriormente nos resultados). A resolução da cena foi escolhida de forma que houvesse melhor otimização custo-benefício entre detalhes da cena e custo computacional.

Os parâmetros das árvores foram calculados a partir das equações alométricas conforme Poorter et al. (2006) (Tabela 3). A alometria é o estudo das relações de escala para características morfológicas e ecológicas. Essas relações foram feitas a partir de um conjunto de 54 espécies de árvores da floresta amazônica boliviana.

Posteriormente, Barbier et al. (2010) sumarizaram essas equações (Tabela 3) em estudo sobre distribuição do tamanho das copas de árvores amazônicas, cujo formato foi considerado como elíptico. A quantidade de tamanho de grade ( $r$ ) adotada, basicamente, indica a quantidade de camadas de copas de árvores que a cena tem. Neste trabalho foram utilizadas como tamanho de grade 2,5, 5, 10, 15 e $20 \mathrm{~m}$ e as relações de Poorter et al. (2006).

A partir disso, delimitou-se uma área central onde o modelo não poderia criar nenhuma árvore. Essa região foi reservada à torre meteorológica. Entretanto, a copa das árvores pode cruzar essa área delimitada e até tocar a torre, como pode ser observado na Figura 15. Assim, com exceção da área central, as árvores foram incluídas em posições aleatórias na cena. 
Tabela 3 - Relações alométricas para a caracterização das árvores da cena. Fonte: Poorter et al. (2006).

\begin{tabular}{|c|c|c|c|c|}
\hline \multirow[b]{2}{*}{ Parâmetro } & \multirow[b]{2}{*}{ Definição } & \multirow[b]{2}{*}{ Regra alométrica } & \multicolumn{2}{|l|}{ Desvio } \\
\hline & & & padrão & Unidade \\
\hline$r$ & Tamanho de grade & 2,5 - 20 (4 níveis) & $d / 4$ & $\mathrm{~m}$ \\
\hline & Raio para presença de & & & \\
\hline I & árvore & $r / 2$ & & $\mathrm{~m}$ \\
\hline$d$ & Diâmetro da copa & $r / 2$ & $d / 4$ & $\mathrm{~m}$ \\
\hline$A$ & Área da copa & $0,25 \pi d^{2}$ & & $\mathrm{~m}^{2}$ \\
\hline $\mathrm{H}$ & Altura total & $\exp [(\ln A+1,853) / 1,888]$ & & $\mathrm{m}$ \\
\hline$h_{c}$ & Altura da copa & $\exp (-1,169+1,098 \ln H)$ & $\mathrm{h}_{\mathrm{c}} / 4$ & $\mathrm{~m}$ \\
\hline & Altura do tronco abaixo & & & \\
\hline$h_{t}$ & da copa & $h-h_{c}$ & $h_{t} / 4$ & $\mathrm{~m}$ \\
\hline $\mathrm{DBH}$ & $\begin{array}{l}\text { Diâmetro à altura do } \\
\text { peito }\end{array}$ & $\mathrm{H} / 42$ & $\mathrm{DBH} / 4$ & $\mathrm{~m}$ \\
\hline
\end{tabular}

A torre simulada que abordaremos neste trabalho é uma representação simplificada de uma torre de observação meteorológica, tendo sido elaborada a partir de um único bloco (Figura 16) que foi empilhado e rotacionado diversas vezes. O intuito da rotação é que ficasse coerente o encaixe das escadas da torre de um nível com o seu conseguinte superior.

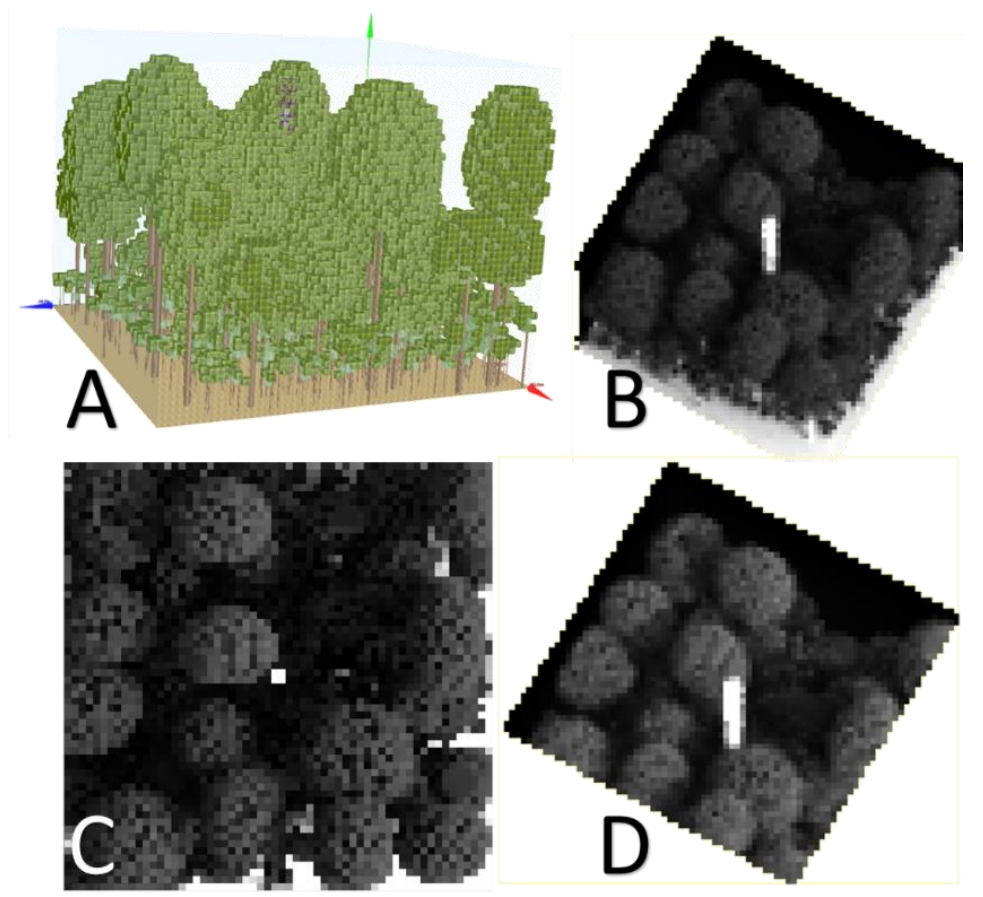

Figura 15 - llustração 3D da cena simulada. A torre está representada em branco nas figuras em escala de cinza ( $B$ a $D)$. 


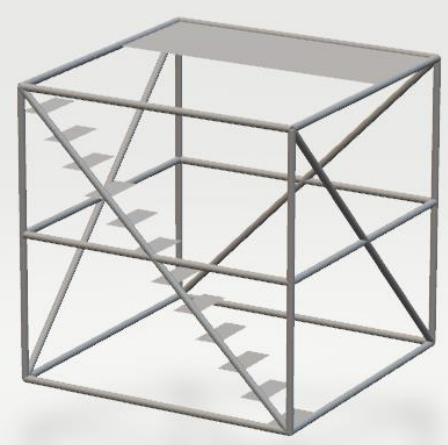

Figura 16- Representação 3D de um bloco da torre usado na construção da cena simulada.

Do banco de dados próprio do DART, foi escolhida a espécie Alnus glutinosa (Figura 17), espécie comum em Portugal e Chile, dentre as demais opções para representar todas as propriedades ópticas de árvores e liteira da cena por critério de aproximação visual com as árvores reais da Amazônia e pela maior semelhança também visual com o espectro de reflectância das folhas maduras apresentadas por Wu et al. (2018).

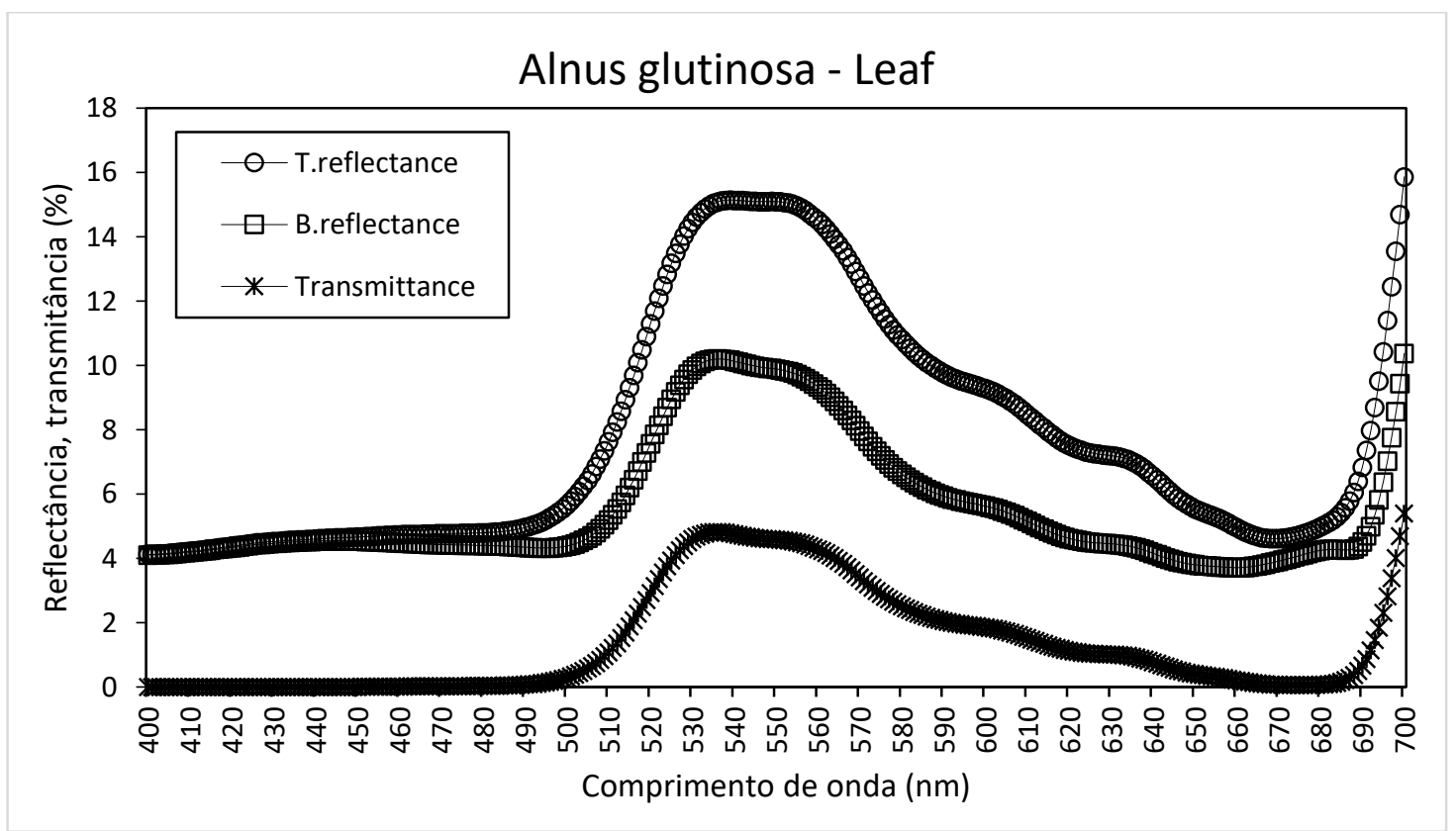

Figura 17 - Propriedades ópticas das folhas das árvores que compõem a cena simulada. T.reflectance $=$ Reflectância da parte superior das folhas, B.reflectance = reflectância da parte inferior das folhas, Transmittance $=$ transmitância das folhas . 
As demais propriedades ópticas dos componentes da cena, isto é, solo, tronco e torre estão representadas na Figura 18. A reflectância dos troncos das árvores recebe as características da mesma espécie (Alnus glutinosa), e tem transmitância $=0 \mathrm{em}$ todos os comprimentos de onda. $\mathrm{O}$ arquivo selecionado para representar os troncos é "Alnus_glutinosa_stem". A superfície é representada por liteira cujo arquivo que a representa no banco de dados do DART é "litter 3". Todos os parâmetros possuem 10\% de variabilidade espacial.

A reflectância da torre é referente ao arquivo do banco de dados Lambertian.db "aluminium_gray_dull_new" com variabilidade de $10 \%$, no qual foi usado um fator multiplicativo para todo o intervalo espectral de análise de 0,7. 0 motivo para essa correção é tentar simular a situação atual real da torre, uma vez que o tempo de uso contribui para o acúmulo de sujeira que acaba reduzindo a reflectância da mesma como um todo.

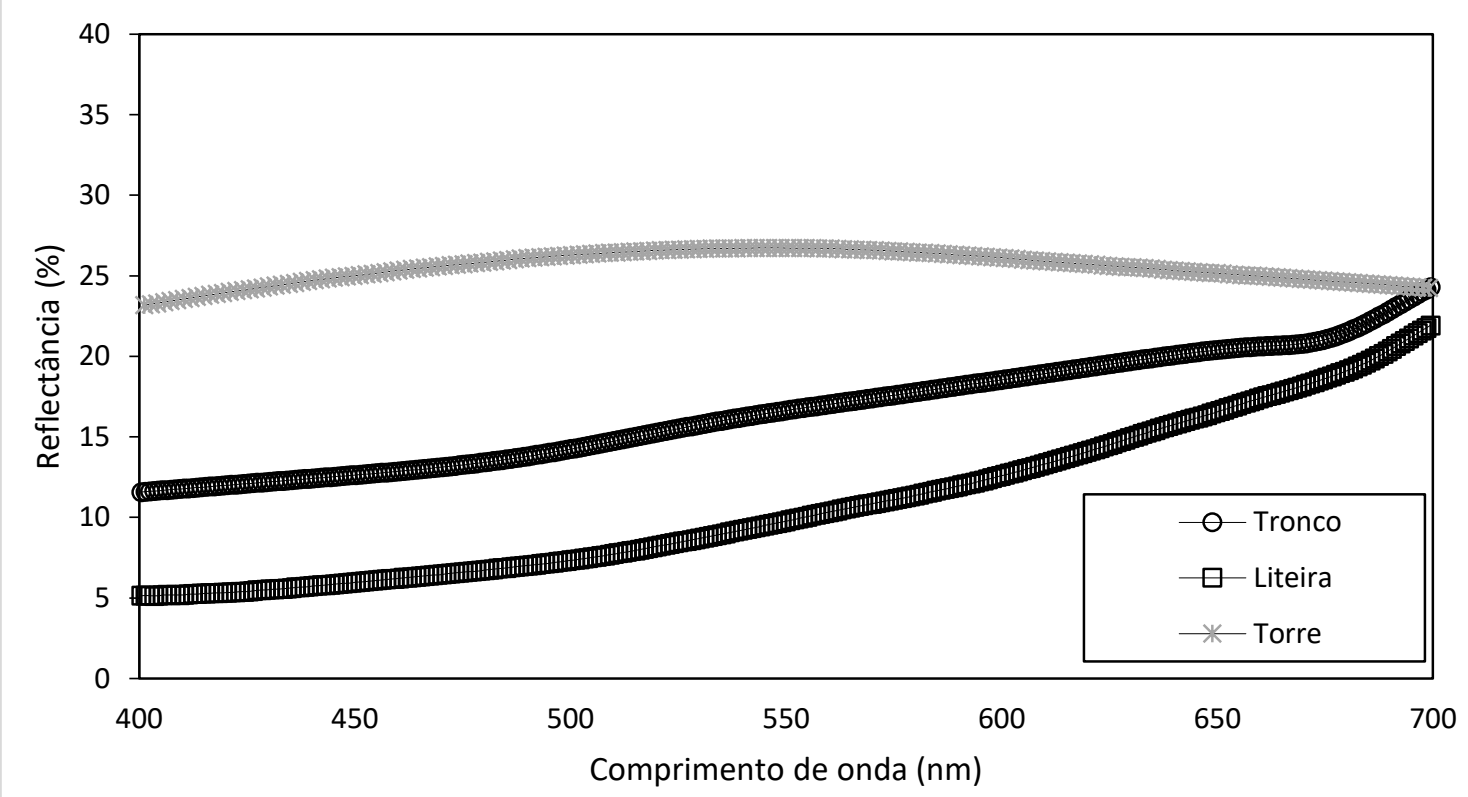

Figura 18-Reflectância espectral dos componentes da cena: tronco, liteira e torre.

\subsubsection{Caracterização da atmosfera}

O perfil vertical de aerossol adotado para este trabalho é uma variação do perfil exponencial. Esta variação traz consigo um leve aumento entre 5 e $10 \mathrm{~km}$ de altitude (Figura 19). Esse perfil corresponde ao perfil DESERV76 e está disponível no próprio DART. 


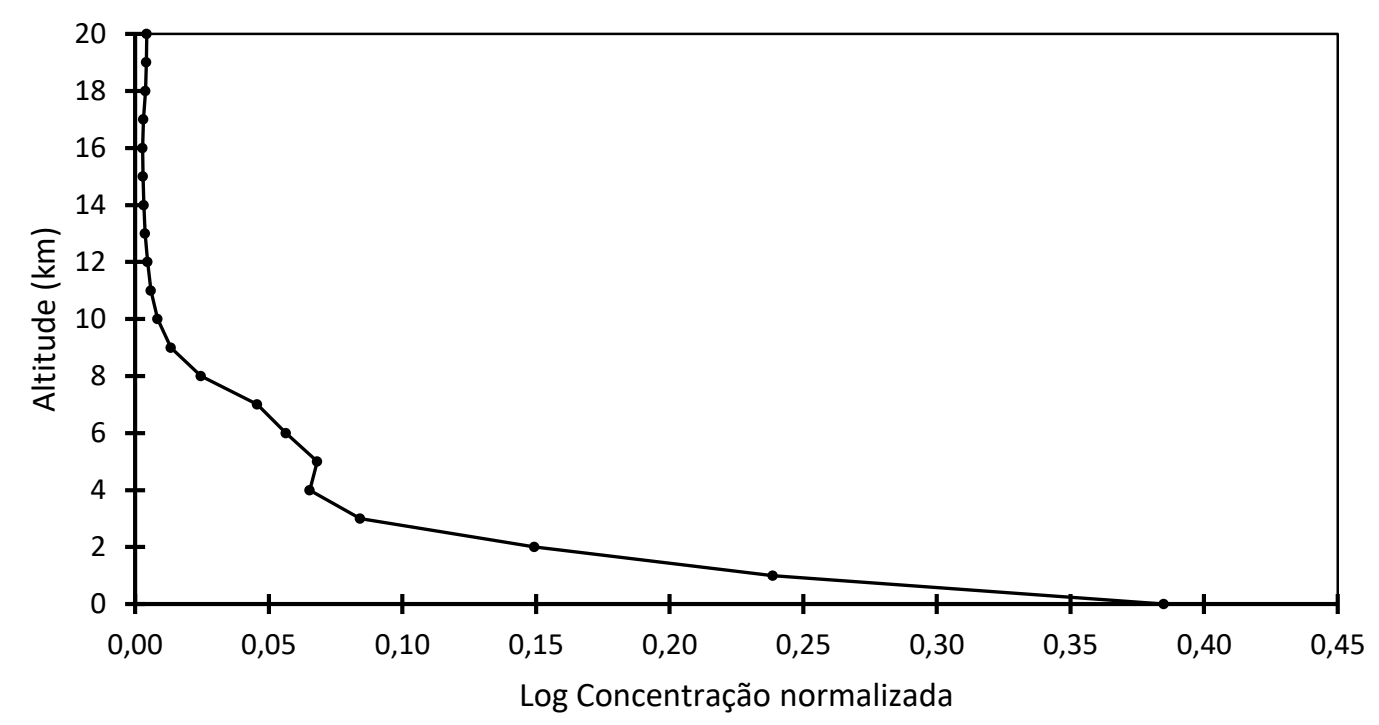

Figura 19 - Perfil vertical de concentração normalizada de aerossol referente ao modelo DESERV76.

As características ópticas do aerossol (i. e. AOD, albedo simples e fator de assimetria para espalhamento frontal) (Tabela 4) foram estimadas em trabalhos anteriores (Rosário, 2011, Rosário et al., 2011, Rosário et al., 2013). As propriedades ópticas representam a média dos aerossóis de queimada do sul da Amazônia brasileira.

Tabela 4 - Recorte espectral das propriedades ópticas do aerossol de queimada do sul da Amazônia.

\begin{tabular}{c|ccc}
$\begin{array}{c}\text { Comprimento } \\
\text { de onda }(\mathrm{nm})\end{array}$ & AOD & $\begin{array}{l}\text { Albedo } \\
\text { simples }\end{array}$ & $g_{1}$ \\
\hline 420 & 1,713 & 0,926 & 0,690 \\
440 & 1,606 & 0,924 & 0,683 \\
470 & 1,435 & 0,921 & 0,668 \\
482 & 1,367 & 0,920 & 0,661 \\
500 & 1,275 & 0,919 & 0,651 \\
550 & 1,092 & 0,916 & 0,630 \\
598 & 0,944 & 0,912 & 0,612 \\
660 & 0,768 & 0,905 & 0,583 \\
670 & 0,745 & 0,904 & 0,580 \\
690 & 0,704 & 0,902 & 0,573
\end{tabular}


Fazendo uso da função dupla de Henyey-Greenstein, a Figura 20 dispõe das funções de fase para distintos comprimentos de onda em função do ângulo de espalhamento. O fator de assimetria para cada comprimento de onda $g_{1}$ é do banco de dados próprio, referente ao aerossol de queimada da Amazônia (Tabela 4). É possível notar que o espalhamento frontal $\left(0^{\circ} \pm 30^{\circ}\right)$ é privilegiado e que há pouco espalhamento traseiro.

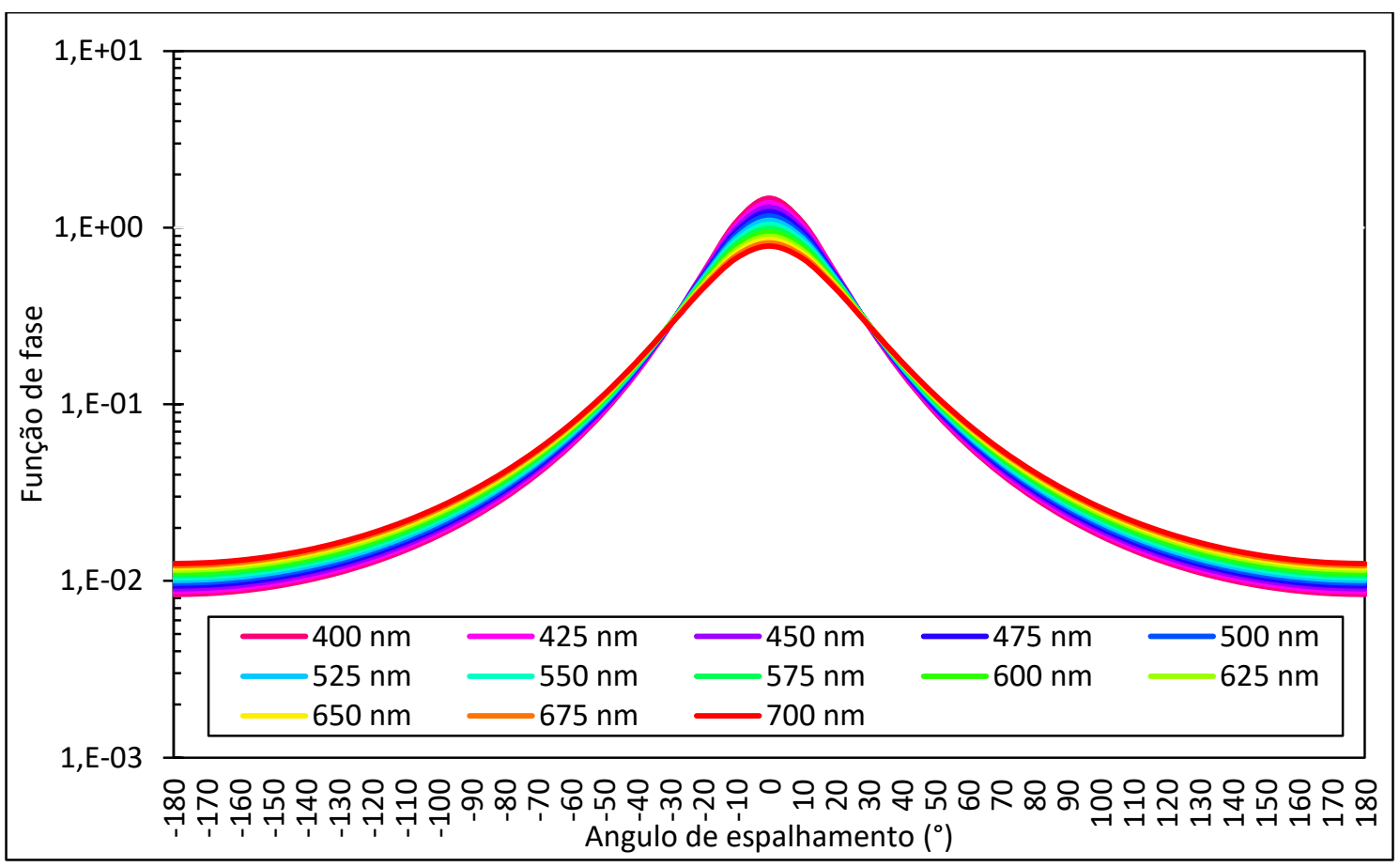

Figura 20 - Aproximação de Henyey-Greenstein uniparamétrica para a função de fase do aerossol de queimadas na Amazônia para cada comprimento de onda em função do ângulo de espalhamento.

Em todos os casos (Figura 20), o peso do primeiro termo da função de fase é $a=1$ e $\mathrm{g}_{2}=0$. Dessa forma, só o primeiro termo da função representa o espalhamento, portanto, quanto maior o fator de assimetria $g_{1}$, maior será 0 espalhamento frontal e menor o traseiro.

A parte gasosa da atmosfera compreende os perfis verticais de temperatura e pressão (Figura 21), perfil vertical de concentração dos gases (Figura 22) e as propriedades espectrais de espalhamento e absorção dos mesmos (Figura 23). Notar que há forte dependência espectral para a parcela molecular da atmosfera. Por facilidade, fez-se uso do modelo de referência TROPICAL disponível na biblioteca do código para todas as características gasosas citadas. 


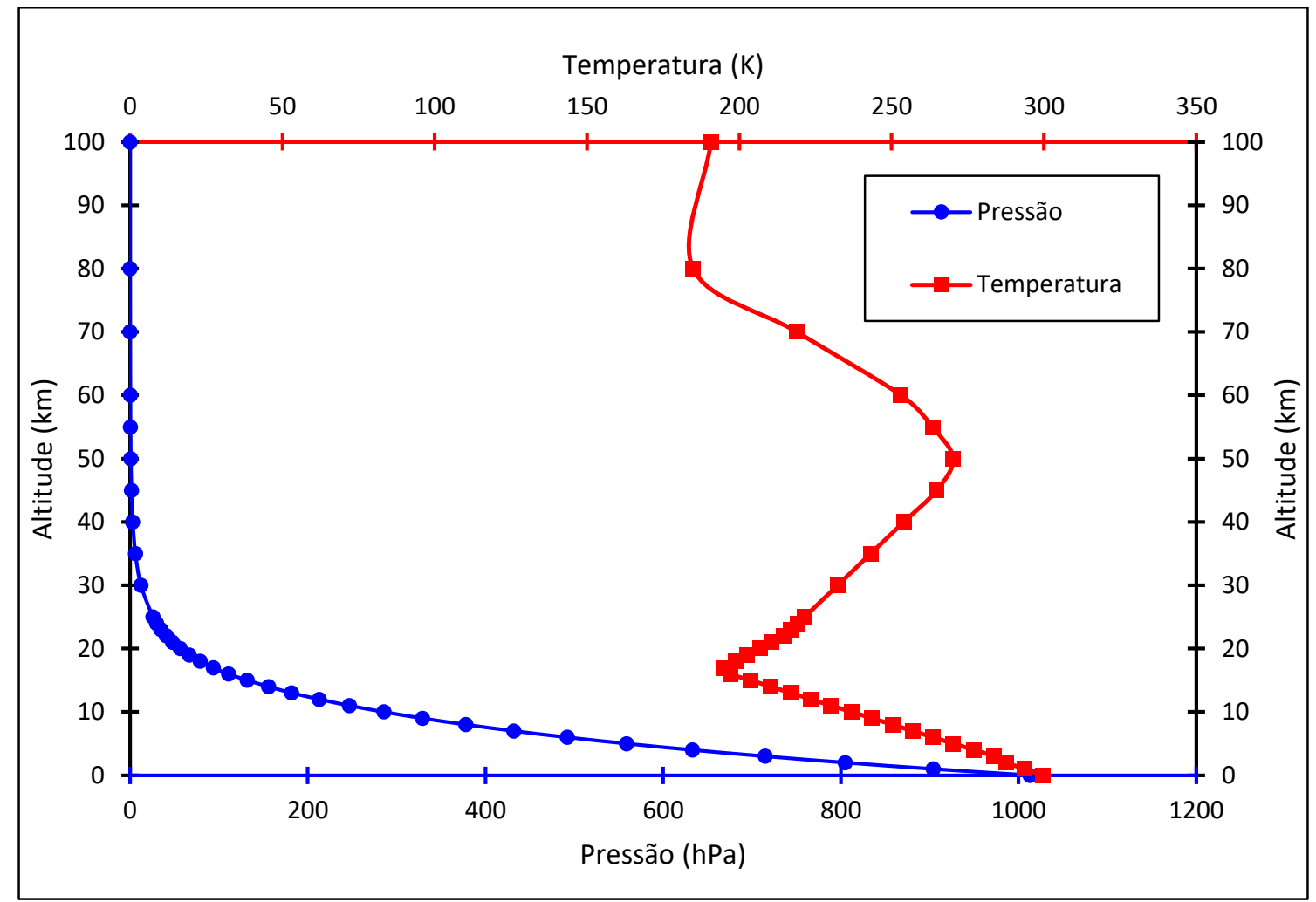

Figura 21 - Perfil vertical de temperatura e pressão da atmosfera do modelo TROPICAL da biblioteca do DART.

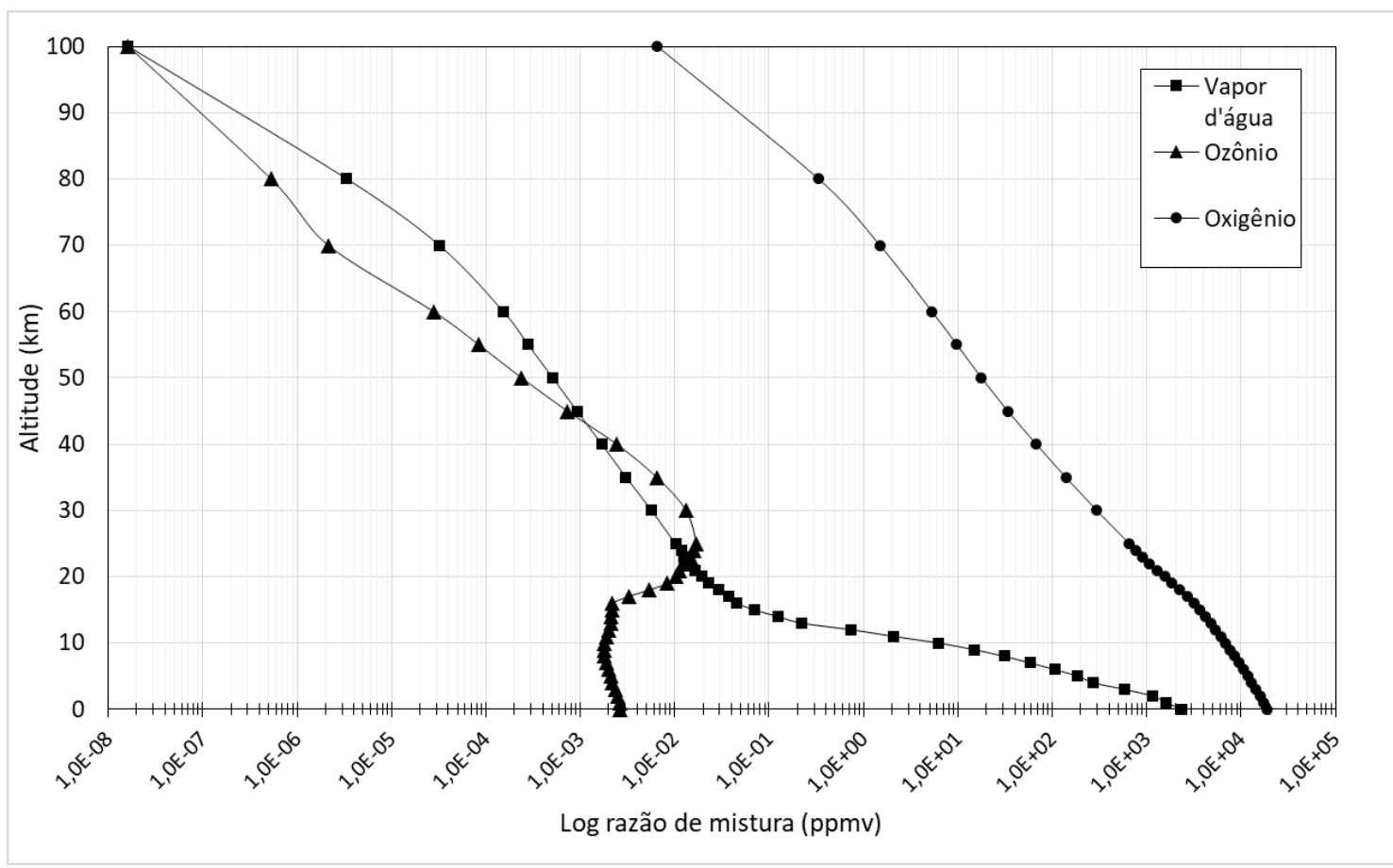

Figura 22 - Perfil vertical da concentração de alguns componentes gasosos da atmosfera do modelo TROPICAL da biblioteca do DART. 


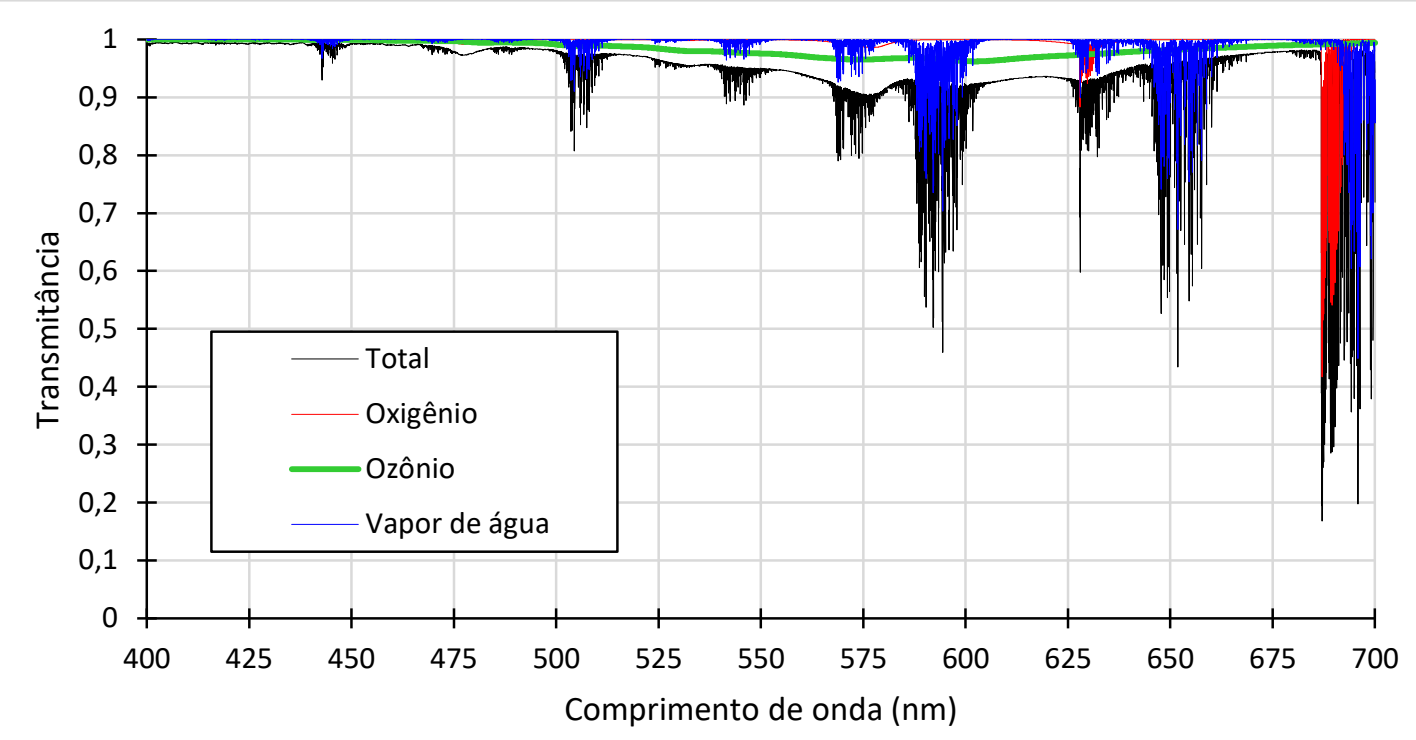

Figura 23 - Linhas de transmitância dos principais componentes gasosos da atmosfera para a região espectral da PAR, respectivos ao modelo TROPICAL da biblioteca do DART.

\subsubsection{Simulações e processamento dos dados simulados}

As rodadas foram feitas usando o método de resolução da equação de transferência radiativa padrão do modelo, o Flux-tracking (Gastellu-Etchegorry et al., 1996). O modelo calcula um total de 5 iterações (espalhamento múltiplo) e o modo de representação da cena é "cena isolada". Isto significa que um feixe de luz que se propaga para fora dos limites da cena é descartado ao cruzar a fronteira.

As alternativas ("repetitive scene" e "infinite slope") ao modo de cena isolada consistem no reaproveitamento dos feixes de radiação. $O$ reaproveitamento acontece quando um dado feixe de luz sai da cena por um lado e retorna à mesma pelo lado oposto.

Há duas opções de saída do modelo para a irradiância de dentro da cena: irradiância espectral ou transmitância. Esta última é obtida normalizando-se a irradiância em cada nível da vertical pela irradiância do topo da copa para cada pixel de área. Para melhor controle, optou-se pela saída em irradiância e calculou-se a transmitância manualmente para cada coluna de pixels da matriz que compõe a cena. 
As rodadas foram feitas para a latitude e longitude da Rebio $\left(-10,146^{\circ}\right.$; $61,908^{\circ}$ ) para um dia intermediário ao período de observações dos três sítios (dia juliano 290). As profundidades ópticas do aerossol em $415 \mathrm{~nm}$ variaram entre 0,3 e 3,0 em intervalos de 0,3.

Como o intuito deste trabalho é verificar se há um favorecimento na iluminação das camadas inferiores do dossel com o aumento da AOD, torna-se prudente escolher os ângulos de incidência solar de acordo com os sinais de maior variação de transmitância para cada nível nos sítios experimentais.

Desta maneira, agrupando-se a base de dados em função de valores de massa óptica em intervalos de 0,1, definiram-se os valores para o ângulo zenital solar de entrada para o modelo. São eles: $68,38^{\circ} ; 65,69^{\circ} ; 61,52^{\circ} ; 54,90^{\circ} ; 35,72^{\circ}$ e $9,15^{\circ}$. O equivalente em termos de massa óptica é: 2,$7 ; 2,4 ; 2,1 ; 1,7 ; 1,2 ;$ e 1,0 , respectivamente.

Com isso, pretendeu-se otimizar o tempo de processamento e o custo computacional e verificar se o modelo, através dessa metodologia, é capaz de representar os valores observados experimentalmente.

Para verificar o efeito da torre meteorológica na propagação de luz solar visível dentro do dossel, repetimos todas as rodadas, contudo excluindo-se a torre da cena e subtraindo-a da rodada de referência (simulação com torre). 
4. Resultados e discussões 


\subsection{Experimentos de Campo}

Inicialmente, os valores da profundidade óptica do aerossol no canal de $415 \mathrm{~nm}$ observados em cada sítio experimental serão analisados e discutidos.

4.1.1. Distribuição temporal da AOD

A distribuição dos valores de AOD $(415 \mathrm{~nm})$ durante o período amostral no ATTO (Figura 24) foi relativamente uniforme ao longo da manhã, com média em torno de 0,6. A largura do violino (área preenchida de cinza) indica a densidade de frequência de eventos de AOD.

Os eventos com maiores AOD aconteceram próximo do meio dia (massa óptica $=1,3$ ). Eventos com $A O D>1$ foram raros, como indicado pela largura dos violinos (área em cinza) e quantidade de pontos.

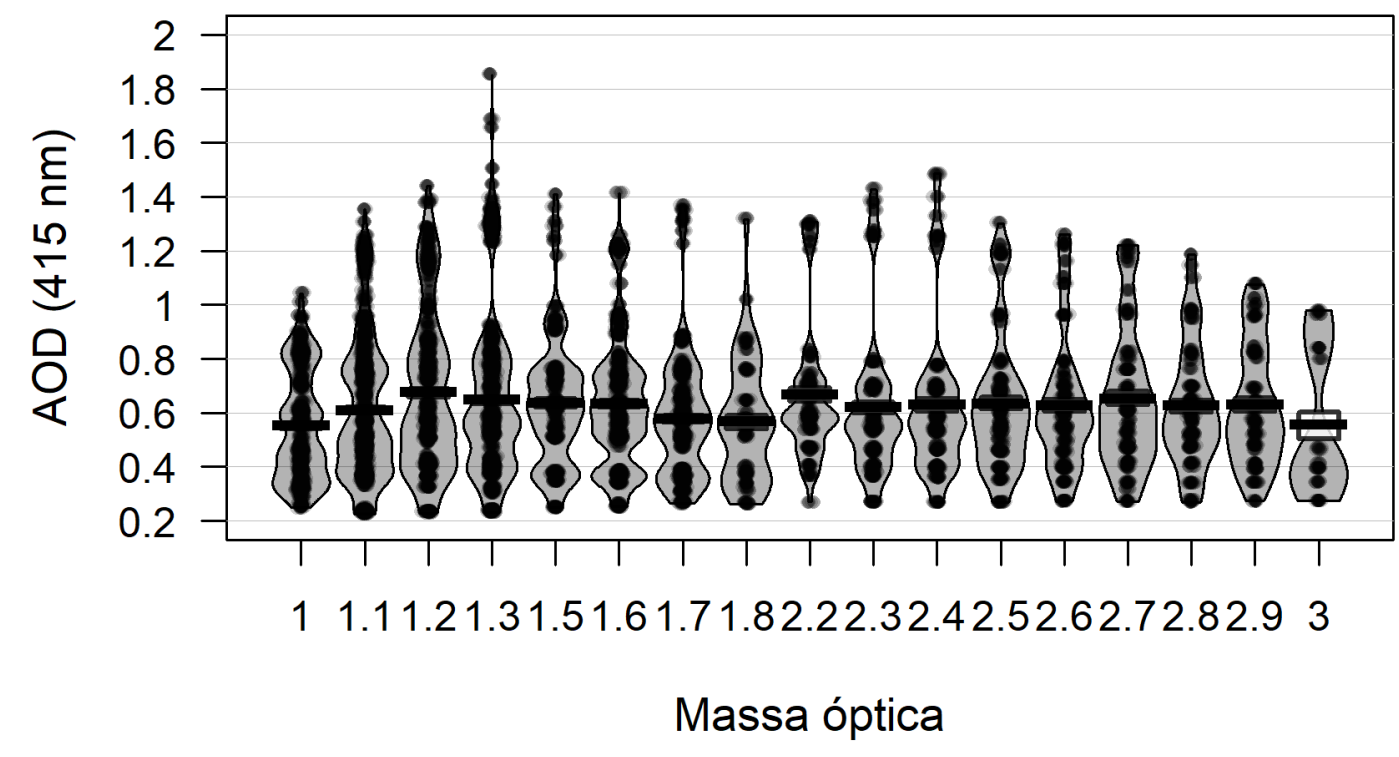

Figura 24 - Distribuição da profundidade óptica do aerossol (AOD) em $415 \mathrm{~nm}$ por intervalo de massa óptica na torre ATTO, no período matutino.

Outros fatores a serem levados em conta na análise da distribuição dos valores de AOD são: a) o período de amostragem no ATTO (vide Tabela 1 e Figura 13) e b) sua localização. As amostragens no ATTO começaram após o dia juliano 275 que, segundo da Rocha \& Yamasoe (2013), está no meio do 
período observado de altos valores de AOD (entre 1 e 3), na estação de queimadas, no arco do desmatamento.

Esses eventos (AOD > 1) foram raros para o ATTO porque, em geral, as queimadas aconteceram distante da região. Isso implica que o aerossol que foi registrado nesses eventos passou por processos de envelhecimento e, com isso, as suas propriedades ópticas (tais como o albedo simples e tamanho da partícula) sofreram alterações.

Quanto à distribuição da $A O D$ no sítio de Humaitá, algumas diferenças são notadas, embora a média da profundidade óptica do aerossol também tenha sido razoavelmente constante durante todo o período (Figura 25), assim como observado no ATTO (Figura 24).

A média da AOD ficou em torno de 0,75 (Figura 25), aproximadamente $25 \%$ maior do que a média no ATTO. Nota-se também que houve mais eventos poluídos (AOD > 1) do que os observados no ATTO, tanto em quantidade como em mais momentos do dia.

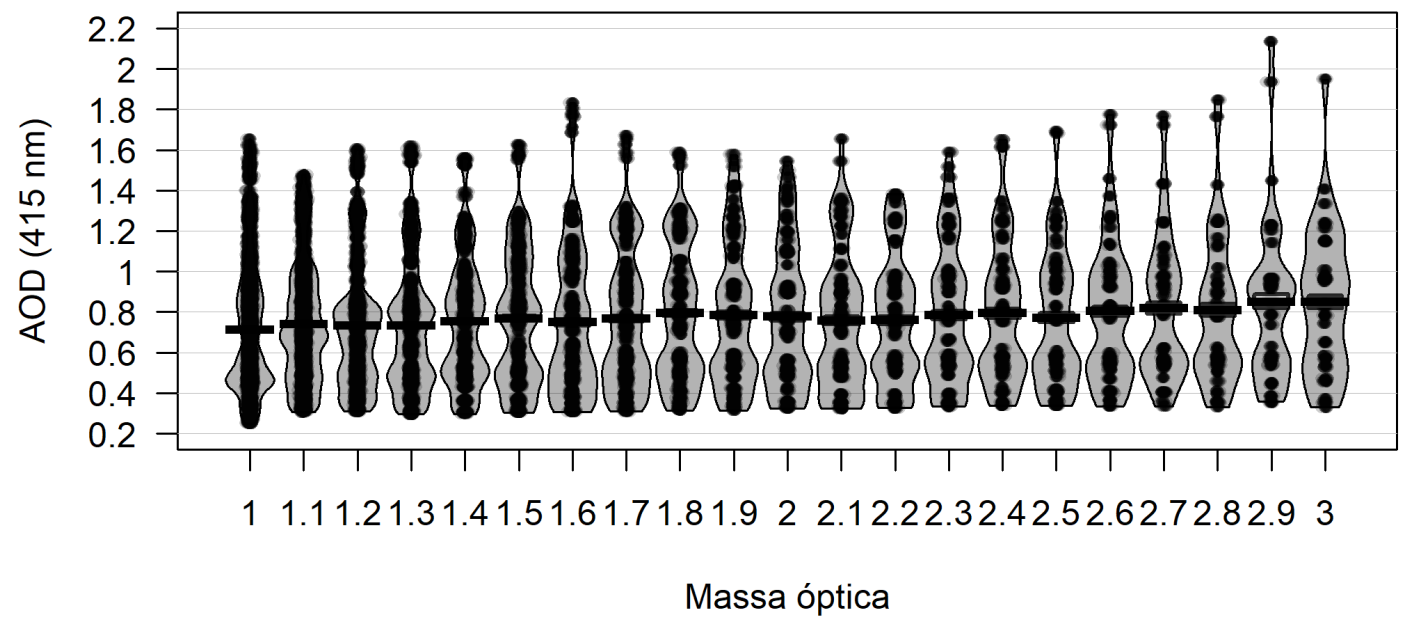

Figura 25 - Distribuição da profundidade óptica do aerossol (AOD) em $415 \mathrm{~nm}$ por intervalo de massa óptica no sítio experimental de Humaitá, no período matutino.

Visualmente é possível observar a maior frequência de eventos com AOD $>1,4$, mais raros no ATTO. Outra diferença é a presença de altos valores de $A O D$ em ângulos mais rasantes $\left(m_{\circ}>2,7\right)$. Por outro lado, as mínimas 
também foram maiores. De acordo com Yamasoe et al. (2006), as áreas queimadas eram claramente visíveis durante a realização do experimento de campo, indicando a influência de emissão de fumaça de queimadas locais tanto de vegetação de pastagem quanto de cerrado.

De todos os sítios experimentais apresentados neste trabalho, os cenários mais poluídos foram observados na Reserva Biológica do Jaru (Figura 26). Máximos de AOD (415 nm) ultrapassaram o valor de 3,5 várias vezes, porém em horários mais próximos do meio-dia (massa óptica em torno de 1).

Diferentemente dos casos anteriores (Figura 24 e Figura 25), conforme houve aumento da massa óptica, menores foram os extremos de máximos de AOD. Ao mesmo tempo, os valores mínimos foram próximos de 0,5 em todos os intervalos de massa óptica.

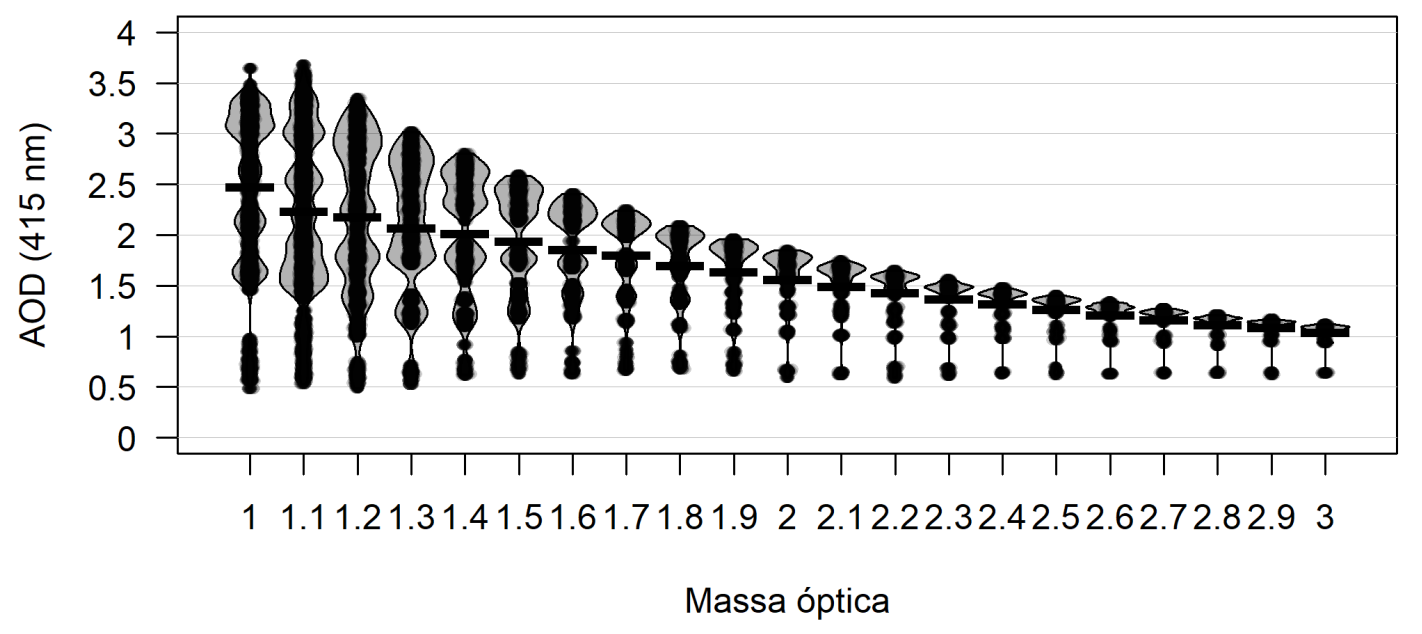

Figura 26 - Distribuição da profundidade óptica do aerossol (AOD) em $415 \mathrm{~nm}$ por intervalo de massa óptica, no sítio experimental da REBIO Jaru, no período matutino.

Dessa forma, a média da AOD em $415 \mathrm{~nm}$ para a REBIO foi 2,1. Entretanto a média da AOD não foi constante nos intervalos de massa óptica, variando de $\sim 2,5$ para $m_{\circ}=1,0$ e $\sim 1,0$ para $m_{\circ}=3,0$. Além disso, as máximas registradas apresentaram redução com o aumento da massa óptica. 
Embora o valor da AOD tenha sido maior que 1,0 nos instantes com $m_{0}>2,5$, a atmosfera, nesses instantes, tem papel de destaque na produção de radiação difusa.

4.1.2. O efeito do aerossol sobre a radiação solar incidente

Ao analisarmos a irradiância espectral descendente em superfície, no canal de $415 \mathrm{~nm}$, nos três sítios (Figura 27), fica evidente o efeito da massa óptica sobre a atenuação da radiação solar e produção de luz difusa. Nota-se, visualmente, uma concordância entre a $A O D$ e as frações direta e difusa em todos os sítios através do MFRSR em cada sítio. Podemos destacar algumas condições específicas. São elas:

Valor de AOD necessário para a condição: fração difusa 0,5

a) $\mathrm{m}_{\mathrm{o}}=1,0 \rightarrow \mathrm{AOD} \sim 0,6$

b) $\mathrm{m}_{\mathrm{o}}=1,5 \rightarrow \mathrm{AOD} \sim 0,3$

c) $\mathrm{m}_{\mathrm{o}}=2,5 \rightarrow \mathrm{AOD} \sim 0,2$

Para $m_{\circ}=3,0$, a fração direta é, praticamente, nula. Portanto, uma quantidade mínima de aerossol é necessária para ser verificada a condição fração difusa $\geq$ fração direta.

AOD necessário para a condição fração difusa fração global

a) $\mathrm{m}_{\mathrm{o}}=1,0 \rightarrow \mathrm{AOD} \sim 3,7$

b) $\mathrm{m}_{\mathrm{o}}=1,5 \rightarrow \mathrm{AOD} \sim 2,8$

c) $\mathrm{m}_{\mathrm{o}}=2,5 \rightarrow \mathrm{AOD} \sim 1,2$

d) $\mathrm{m}_{\mathrm{o}}=3,0 \rightarrow \mathrm{AOD} \sim 1,2$

O valor de AOD necessário para que o componente direto seja desprezível, isto é, a radiação se propaga sem uma direção preferencial, foi praticamente o mesmo em $m_{0}=2,5$ e 3,0. Essa abordagem visual pode não ser a mais precisa, obviamente, mas serve para se ter uma noção de quanta luz direta ou difusa chega no dossel devido à presença de fumaça e da geometria solar. 

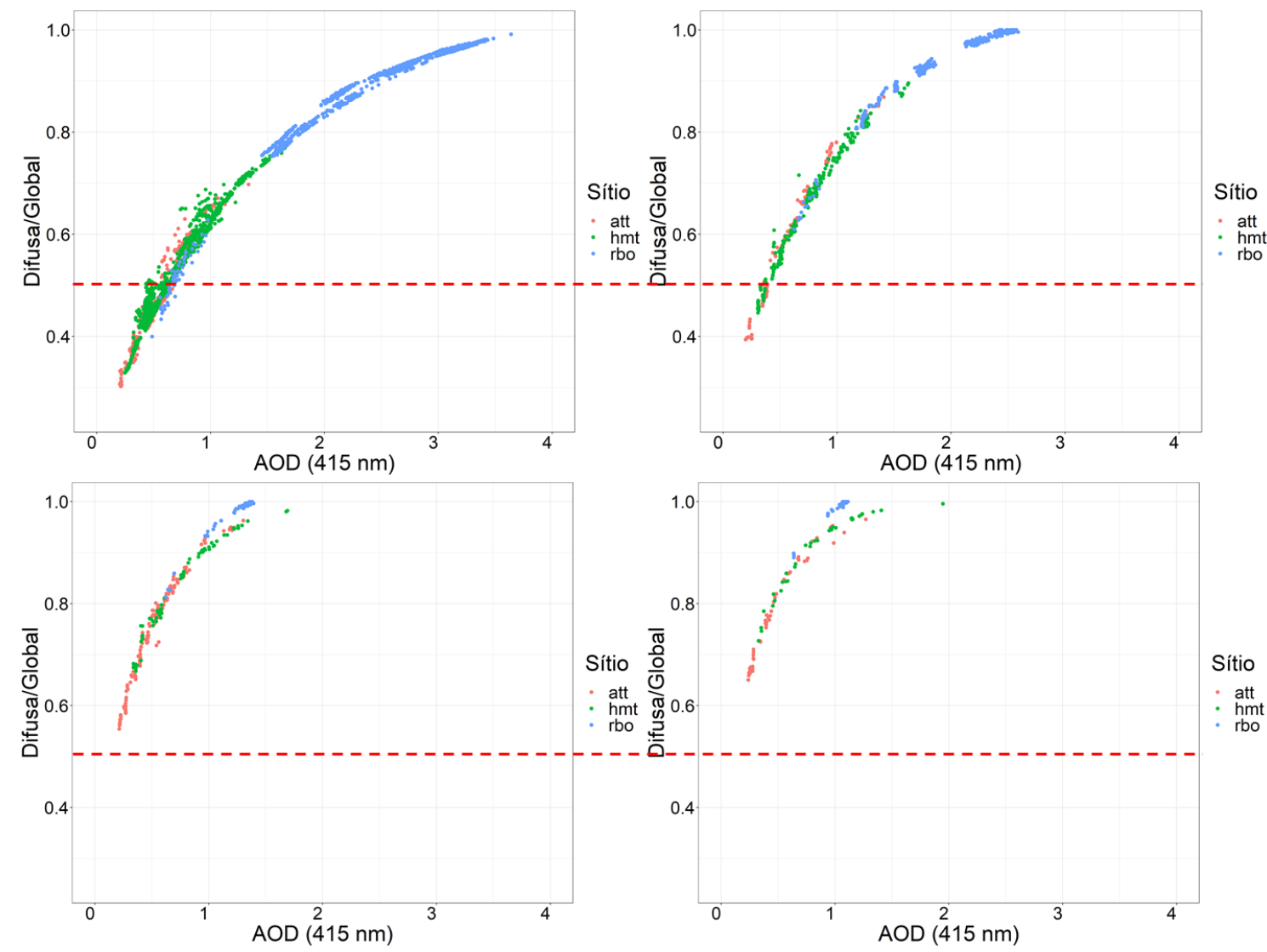

Figura 27- Razão entre a irradiância espectral difusa e a global para os três sítios experimentais em função da AOD em $415 \mathrm{~nm}$ para as seguintes massas ópticas: 1,0 (topo à esquerda); 1,5 (topo à direita); 2,5 (embaixo à esquerda); e 3,0 (embaixo à direita). $A T T O=$ att, Humaitá $=h m t$ e REBIO = rbo. A linha tracejada vermelha indica $50 \%$ na fração difusa.

Assim, no próximo tópico, será avaliado como a irradiância fotossinteticamente ativa variou, dentro do dossel, em decorrência da maior disponibilidade de radiação na forma difusa nos três sítios experimentais.

4.1.3. Variação geral da PAR dentro do dossel

A disposição dos instrumentos é muito importante para uma boa análise da transmitância de radiação dentro do dossel. Primeiro porque os agentes atenuadores dentro do dossel (e. g. galhos, troncos e folhas) não são estáticos (balançam com o vento, envelhecem). Além disso, o próprio deslocamento do disco solar no céu, no decorrer do dia, pode provocar o deslocamento da sombra devido a galhos, folhas e troncos sobre os sensores. 
Por esses motivos, a variabilidade da irradiância medida pelos sensores dispostos em perfil vertical dentro do dossel pode, em muitos casos, não ter ligação alguma com variações na atmosfera e sim com os efeitos supracitados.

O sombreamento permanente também é um grande problema na parte experimental. Uma vez que, se sombreado, o sensor não registrará nada. Todavia, em um pequeno intervalo de tempo, não se pode dizer se o dossel é muito denso ou se trata-se de um caso de sombreamento isolado.

É possível verificar se houve sombreamento em algum sensor através da Figura 28. Nela estão dispostos todos os sensores por altura $(\mathrm{m})$ para o sítio do ATTO. Os três sensores instalados mais próximos da superfície encontravam-se sistematicamente sombreados e não foram exibidos. Também é possível identificar, através dos outliers, a presença de frestas (sunflecks) em momentos específicos.

Nos quatro níveis mais altos (22 a $39 \mathrm{~m}$ ) é possível notar que quanto mais inferior é a camada, menor é o tempo de iluminação disponível. As duas camadas superiores receberam radiação durante todo o período matutino.

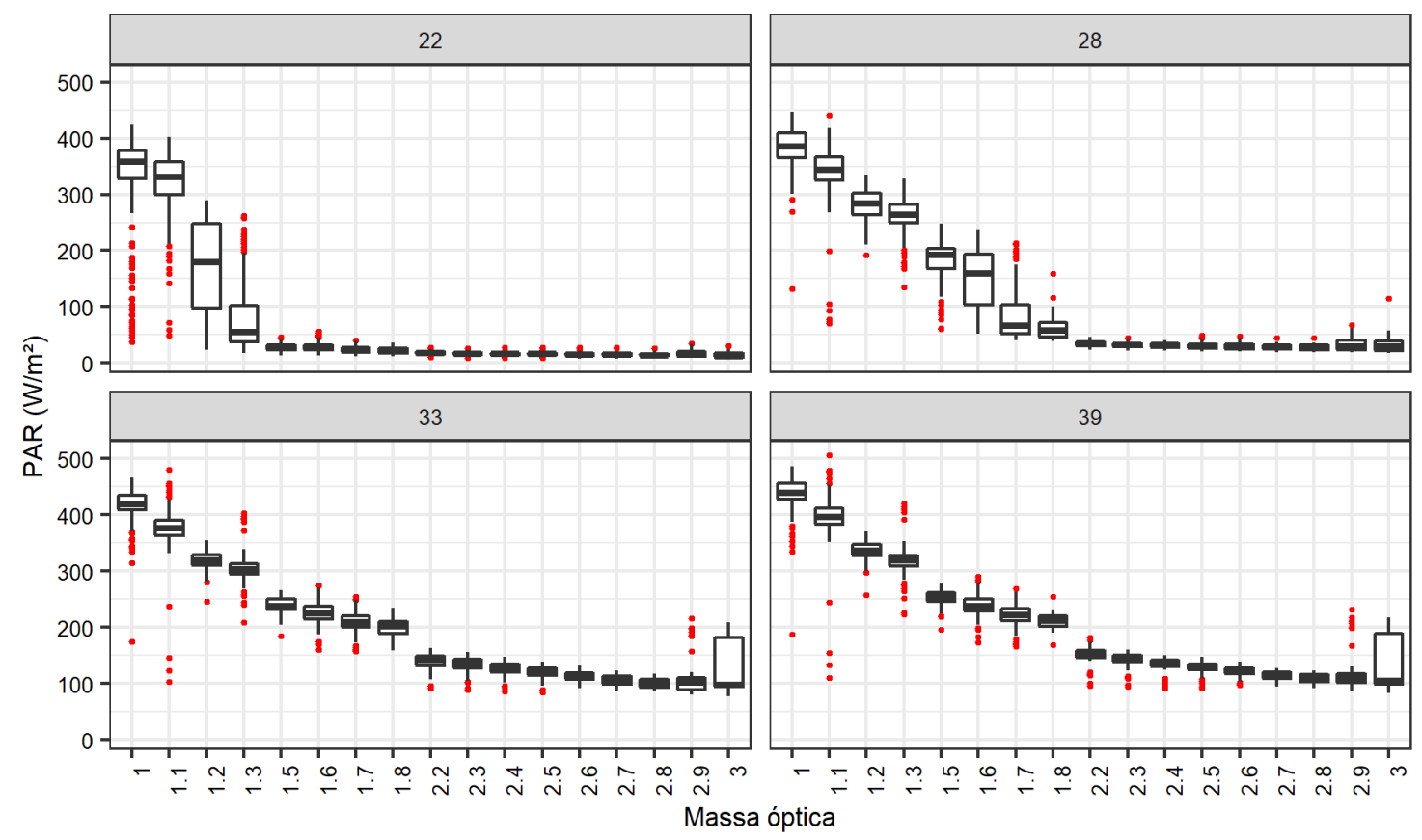

Figura 28 - Irradiância PAR incidente por intervalo de massa óptica para cada nível de altura dentro do dossel da torre ATTO. Os números acima dos quadros indicam a altura do sensor acima da superfície $(m)$, o eixo vertical é a irradiância PAR incidente $\left(W / m^{2}\right)$ e o eixo horizontal é o intervalo de massa óptica. Os sensores totalmente sombreados não foram exibidos. 
Entretanto, nos sensores localizados em 22 e $28 \mathrm{~m}$ só houve sinais de incidência PAR próximo do meio-dia solar. Nessas duas camadas também é possível notar grande variação em função de alguma(s) outra(s) variável(eis) que não a geometria solar. Esta atua muito efetivamente nas camadas superiores, enquanto nas inferiores sua atuação depende da estrutura de frestas da floresta.

Como estratégia para melhor representação horizontal e espacial da floresta, foram instalados sensores em diferentes faces, ao redor da torre meteorológica no sítio de Humaitá (conforme Tabela 2). A Figura 29 torna clara a heterogeneidade da floresta e que mesmo em uma pequena área (como é em volta da torre) há uma significativa variação da radiação solar incidente, podendo, inclusive, ser resultante de sombreamento da própria torre.

O padrão de frestas e sombreamento observado na Figura 28 no ATTO, também pode ser observado na Figura 29, em Humaitá. Note que as estruturas das torres são bastante diferentes (altura e clareira associada à presença da torre), todavia esses fatores parecem não interferir próximo da superfície.
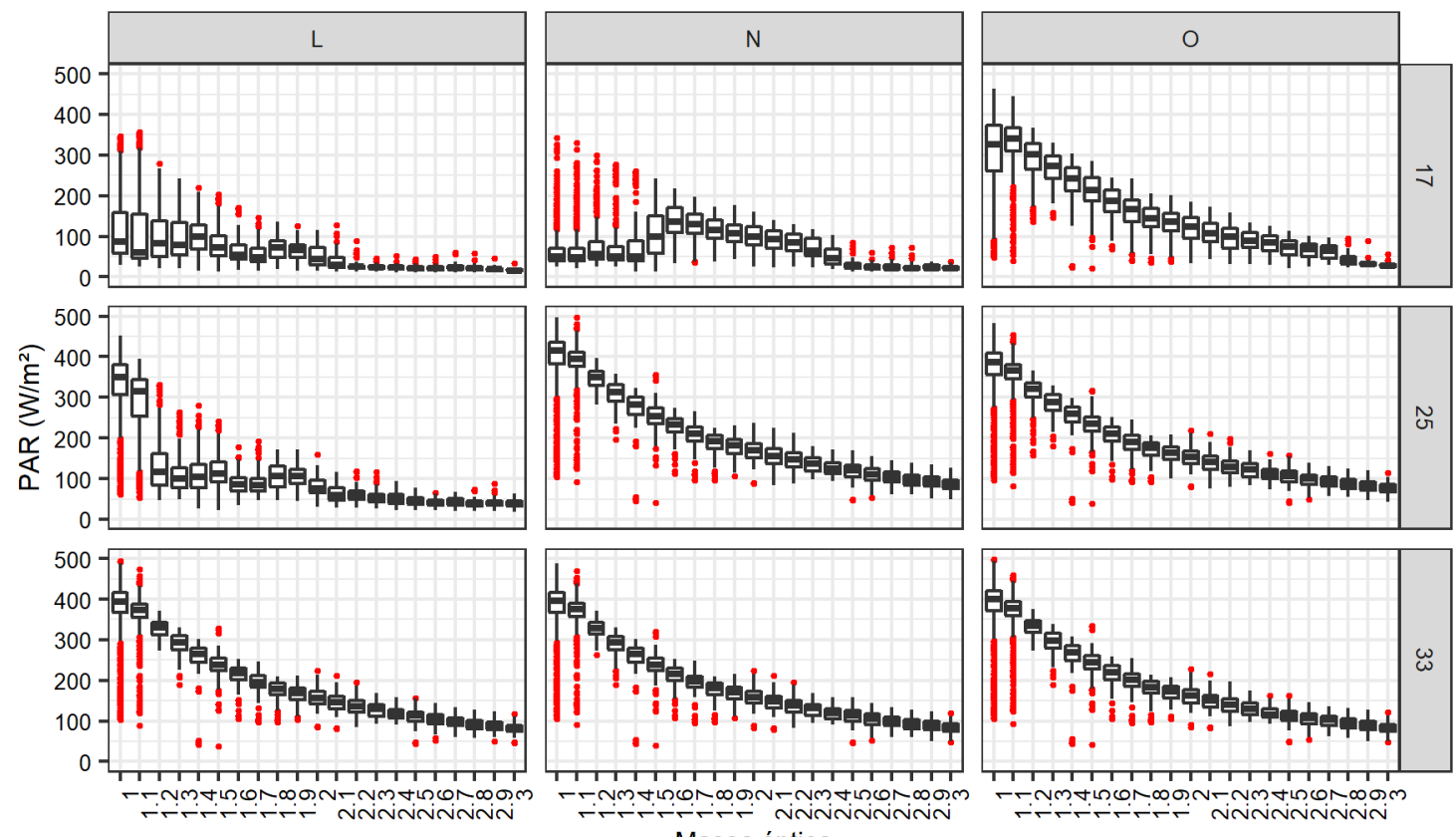

Massa óptica

Figura 29 - Irradiância PAR incidente por intervalo de massa óptica para cada nível de altura dentro do dossel em Humaitá. Os números ao lado indicam a altura acima da superfície $(m), o$ eixo vertical é a irradiância PAR e o eixo horizontal é o intervalo de massa óptica. Cada coluna representa uma das faces ( $L$ - leste, $N$ - norte, $O$ - oeste) nas quais os sensores foram instalados. Os sensores totalmente sombreados não foram exibidos. 
O movimento aparente do sol causa um efeito - discutido previamente -, de iluminação tardia nas camadas abaixo da primeira copa, ou níveis mais superiores. Esse efeito também foi observado em Humaitá.

Um detalhe a ser mencionado é que o atraso na iluminação variou conforme a posição horizontal do sensor. Isto é, na face leste da torre, este atraso foi maior, diminuiu no sentido anti-horário e pode ser melhor observado nos sensores a $17 \mathrm{~m}$ de altura.

Outras flutuações ocorreram em $17 \mathrm{~m}$ nos lados leste e norte $\left(m_{\circ}\right.$ entre 1,4 e 2,4) e também em 25 m no lado leste. Essas flutuações sem nenhum padrão aparente, possivelmente, podem estar associadas a uma copa menos estruturada ou até mesmo com aglomerados de galhos. Contudo esse tipo de análise não deixa de ser especulativa.

O experimento na REBIO foi o que apresentou os casos com maiores valores de AOD. Muito embora os casos com valores extremos de AOD (>2) não tenham sido observados homogeneamente distribuídos durante todo 0 período de análise (Figura 26), esses casos extremos também foram persistentes. Portanto, esse sítio pode, potencialmente, fornecer maiores informações sobre o efeito do aerossol na transmitância de PAR.

Contudo, embora o experimento na REBIO tenha sido o mais bem amparado em número de sensores, ele também apresentou o maior número de sensores sombreados (não exibido). Os sensores em níveis abaixo de $17 \mathrm{~m}$ de altura não registraram nenhum sinal a não ser em curtos intervalos de tempo. Em geral, esses sensores sombreados apenas apresentam sinais de iluminação próximo do meio dia solar.

Os demais sensores (níveis $17 \mathrm{~m}$ e superiores) estão dispostos na Figura 30. É possível notar que do topo da copa das árvores $(47 \mathrm{~m}$ ) até $25 \mathrm{~m}$ de altura, os sensores registraram irradiâncias muito similares. Isso significa que nessa camada não houve significativa interação das folhas com a radiação no período matutino. Isso também é refletido na falta de outliers em quase todos os casos. 

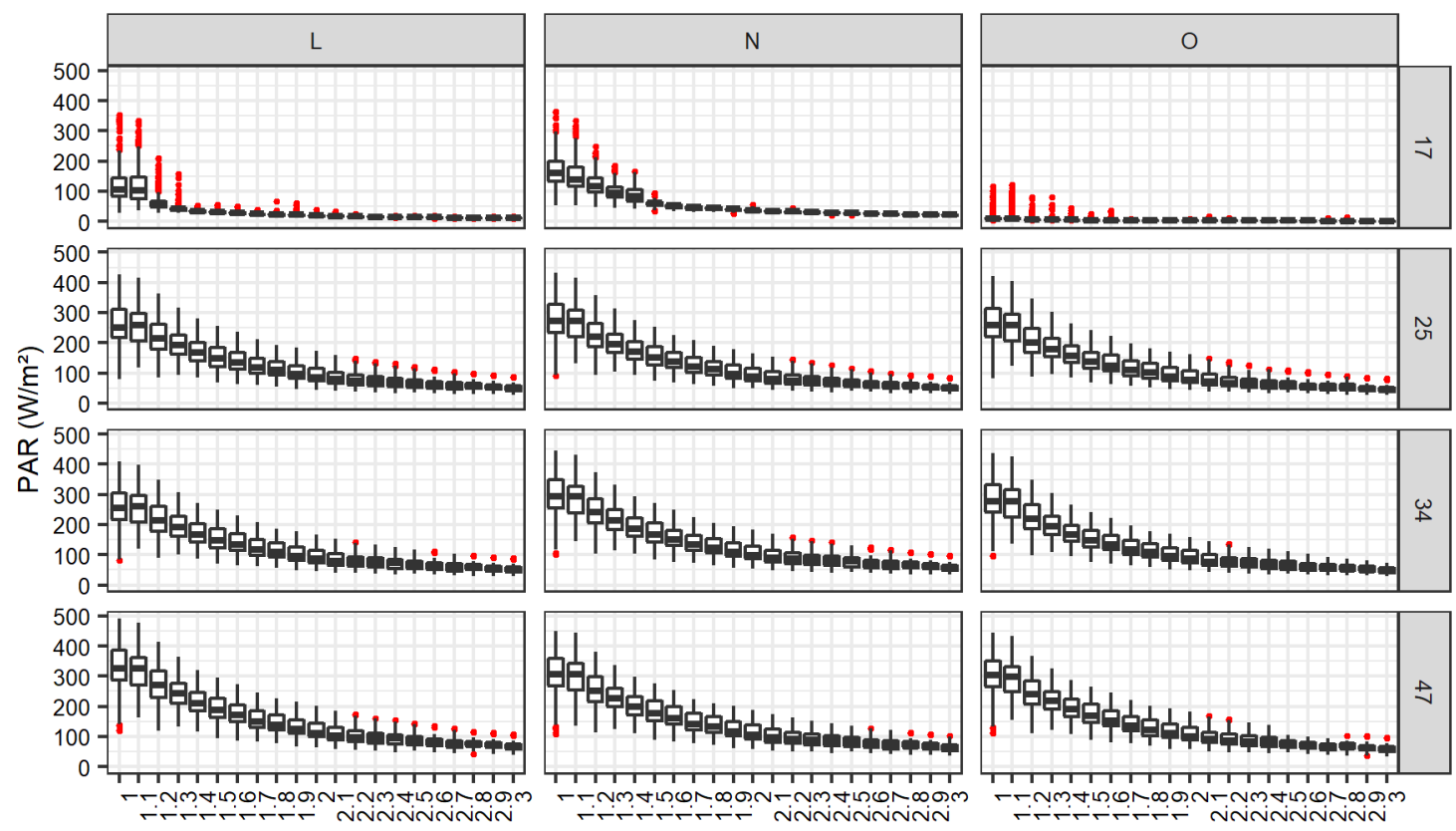

Massa óptica

Figura 30 - Irradiância PAR incidente por intervalo de massa óptica para cada nível de altura dentro do dossel na Reserva Biológica do Jaru (REBIO). Os números ao lado indicam a altura acima da superfície (m), o eixo vertical é a irradiância PAR e o eixo horizontal é o intervalo de massa óptica. Cada coluna representa uma das faces ( $L$ - leste, $N$-norte, $O$ - oeste) nas quais os sensores foram instalados. Os sensores totalmente sombreados não foram exibidos.

Os efeitos possíveis de identificar na Figura 30 são a iluminação tardia em $17 \mathrm{~m}$ e o efeito do giro anti-horário. Porém este último apenas se destaca nos lados leste e norte em $17 \mathrm{~m}$. O sensor virado para a face oeste, neste mesmo nível, esteve sempre sombreado e não revelou muita informação, uma vez que são apresentados apenas os resultados das medições do período da manhã.

Outro ponto em comum com os outros dois sítios é a maior frequência de outliers quanto mais próximo do horizonte se encontrou o disco solar. E também o efeito atenuador que a geometria impõe, isto é, quanto maior a massa óptica, menor é a variação observada na irradiância PAR incidente.

\subsubsection{Variação geral da transmitância dentro do dossel}

Comparando agora a variação da transmitância dentro do dossel, isto é, excetuando-se o nível que corresponde ao topo do dossel (acima da copa das árvores), pode-se ter uma melhor ideia do papel da geometria solar na propagação da radiação PAR. 
No nível imediatamente inferior ao topo, $33 \mathrm{~m}$ (Figura 31, para o sítio ATTO), a transmitância se mostrou praticamente estável e independente da massa óptica. $O$ efeito da geometria solar pode ser observado através da transmitância nos níveis de 22 e $28 \mathrm{~m}$. Contudo, esse efeito tornou-se mais restrito para o nível mais intermediário (22 m). Os três níveis mais inferiores não responderam à variação da posição aparente do Sol, possivelmente por estarem sistematicamente à sombra de troncos ou galhos.

Quanto menor a massa óptica, maior é a fração direta da luz e mais perpendicularmente incide essa componente, em relação à superfície do solo. Desta forma, sensores mais altos acusaram essa variação do ângulo de incidência de luz solar primeiro, portanto, apresentaram maior tempo de influência deste, efeito da iluminação tardia. Isso pode explicar a diferença nos valores de transmitância a partir de massa óptica =1,6 para $28 \mathrm{~m}$ e 1,2 para 22 m (Figura 31).
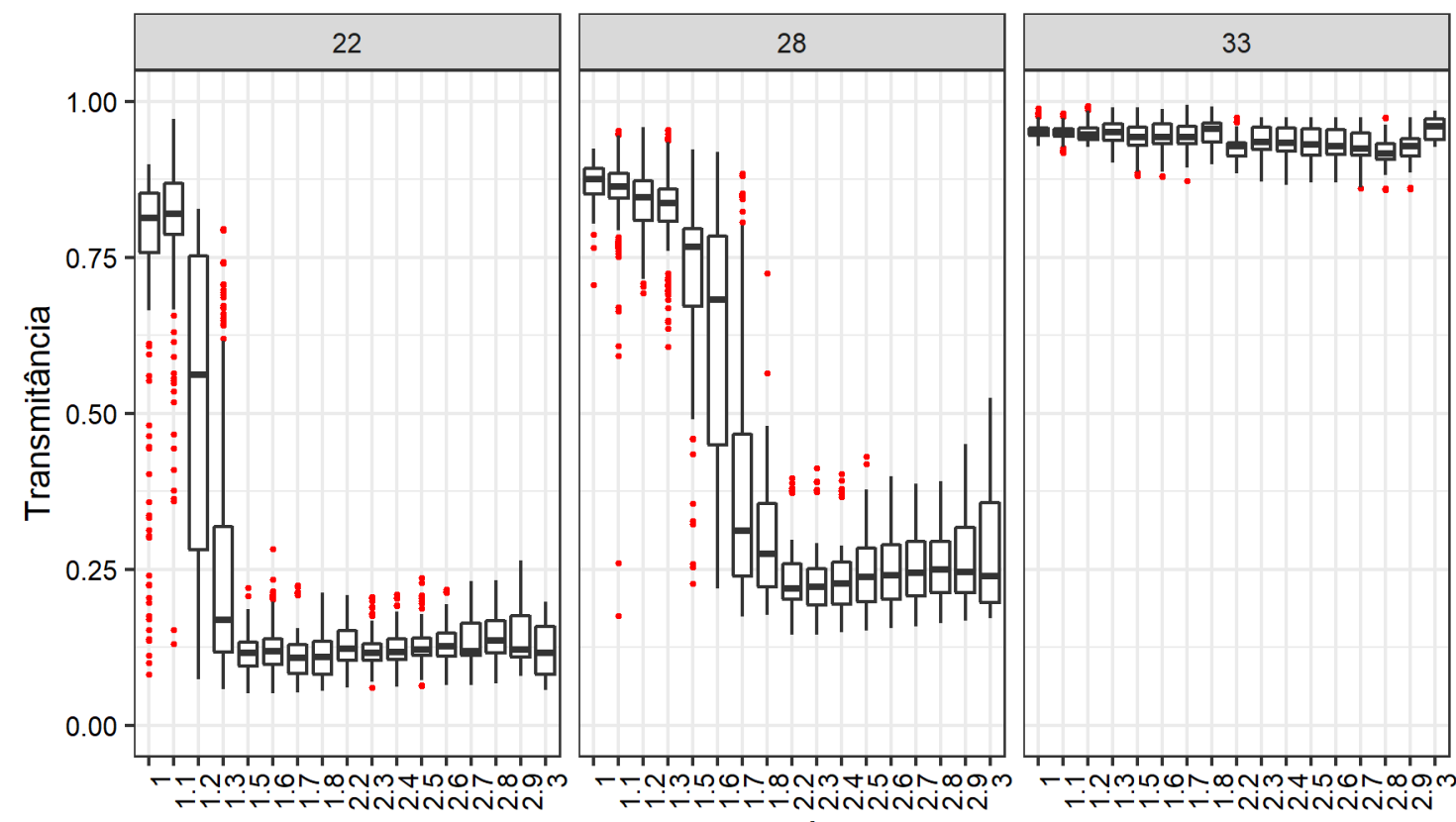

Massa óptica

Figura 31 - Transmitância PAR por intervalo de massa óptica para cada nível de altura dentro do dossel da torre ATTO. Os números acima das caixas indicam a altura acima da superfície $(m)$, o eixo vertical é a transmitância PAR incidente e o eixo horizontal é o intervalo de massa óptica.

Em 33 m (Figura 31), a transmitância é mais uniforme e estável. Por estar mais perto do topo da copa, há uma menor camada de folhas e, portanto, ocorre menos interação da matéria com a luz. 
A heterogeneidade da floresta proporciona diferentes condições de transmitância. Por exemplo, em Humaitá (Figura 32) houve maior variação da transmitância PAR para os instrumentos instalados do lado Norte da torre em função da geometria solar ou por outros fatores.

Ressaltando que a variação em função da geometria é observada na posição da caixa no eixo horizontal e a variabilidade associada a outros fatores, é compreendida como o tamanho da caixa.

A frequência de outliers positivos nos dois níveis mais interiores do dossel indica maior presença de gaps/frestas. A maior densidade de outliers ocorreu com o sol próximo do zênite (entre $m_{\circ}=1,0$ e 1,5 ) o que favoreceu a entrada de luz direta.

Portanto a presença de luz direta pode estar associada à maior variação nas observações. A clareira decorrente da presença da torre também pode ser um fator a se considerar como um facilitador desse efeito de passagem de luz direta para dentro do dossel.

As observações de transmitância feitas em Humaitá podem ser visualizadas na Figura 32. O comportamento da transmitância difere significativamente dos apresentados na Figura 31, para o ATTO.

A transmitância determinada a partir das medições efetuadas pelo sensor imediatamente inferior ao topo do dossel $(25 \mathrm{~m})$ apresentou comportamento constante e estável, sem grandes variações com o ângulo zenital solar, para as faces norte e oeste. Para a face leste, houve muita variação e aparentemente sem nenhuma forte relação com as variáveis já mencionadas.

A transmitância estimada a partir do sensor do lado leste da torre a $17 \mathrm{~m}$ de altura também apresentou variação sem correlação visual com os padrões anteriores. Por outro lado, a transmitância associada ao sensor a $17 \mathrm{~m}$ de altura, no lado norte, apresentou variação entre $m_{\circ}=1,5$ e 2,4. A configuração das caixas indica um padrão com dois regimes intercalados. Esse tipo de padrão diferiu dos anteriores e também pode levantar uma hipótese sobre uma possível relação com a AOD. 

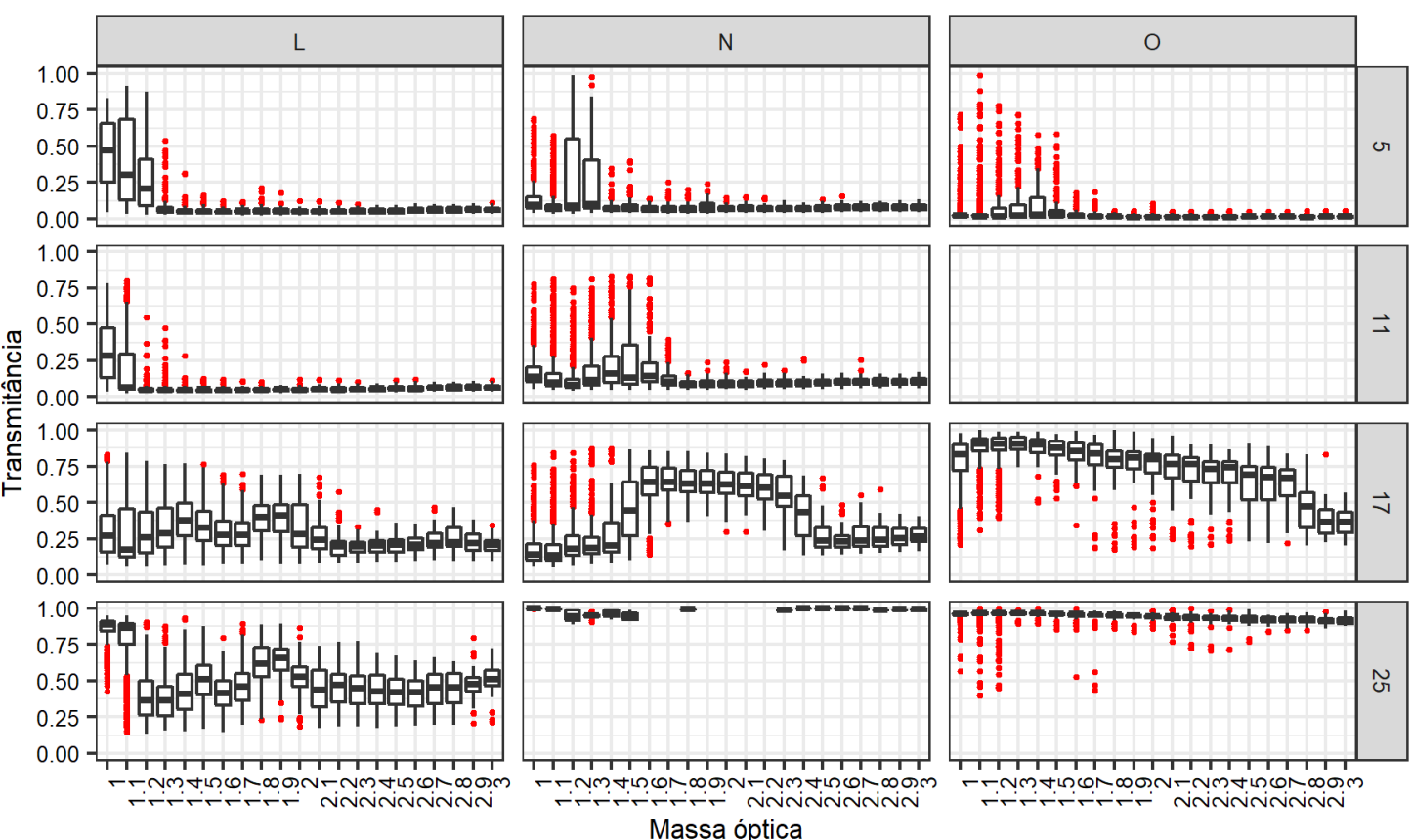

Massa óptica

Figura 32 - Transmitância PAR por intervalo de massa óptica para cada nível de altura dentro do dossel no sítio de Humaitá. Os números na lateral indicam a altura acima da superfície $(m), o$ eixo vertical é a transmitância PAR incidente e o eixo horizontal é o intervalo de massa óptica. As colunas indicam em qual lado da torre está o sensor, norte $(N)$, leste $(L)$ e oeste $(O)$.

A maior presença de outliers em menores valores de massa óptica foi uma constante em todos os sensores, em todas as faces da torre, inclusive. Outliers positivos são mais frequentes em níveis mais baixos e vice-versa. Esses outliers são tanto potenciais indicadores de frestas momentâneas, como de sombreamento.

No sítio experimental da REBIO, excetuando-se o sensor do topo, temos os seis sensores mais altos (três em cada nível - 25 e $34 \mathrm{~m}$ ) sem nenhum tipo de sombreamento. Todavia, os mesmos estão numa situação tal que quase não houve grandes variações (Figura 33), em comparação com os dados dos outros sítios.

A transmitância dos dois primeiros níveis imediatamente abaixo do topo do dossel (25 e $34 \mathrm{~m}$ ) apresentou comportamento semelhante em todos os lados da torre. Nesses níveis, os valores do lado norte foram sempre maiores que os do lado leste, e o lado leste apresentou maior variabilidade nos dados do que o lado norte. O lado oeste apresentou tendência decrescente e não aparentou ter um padrão no tamanho das caixas em função da posição solar. 

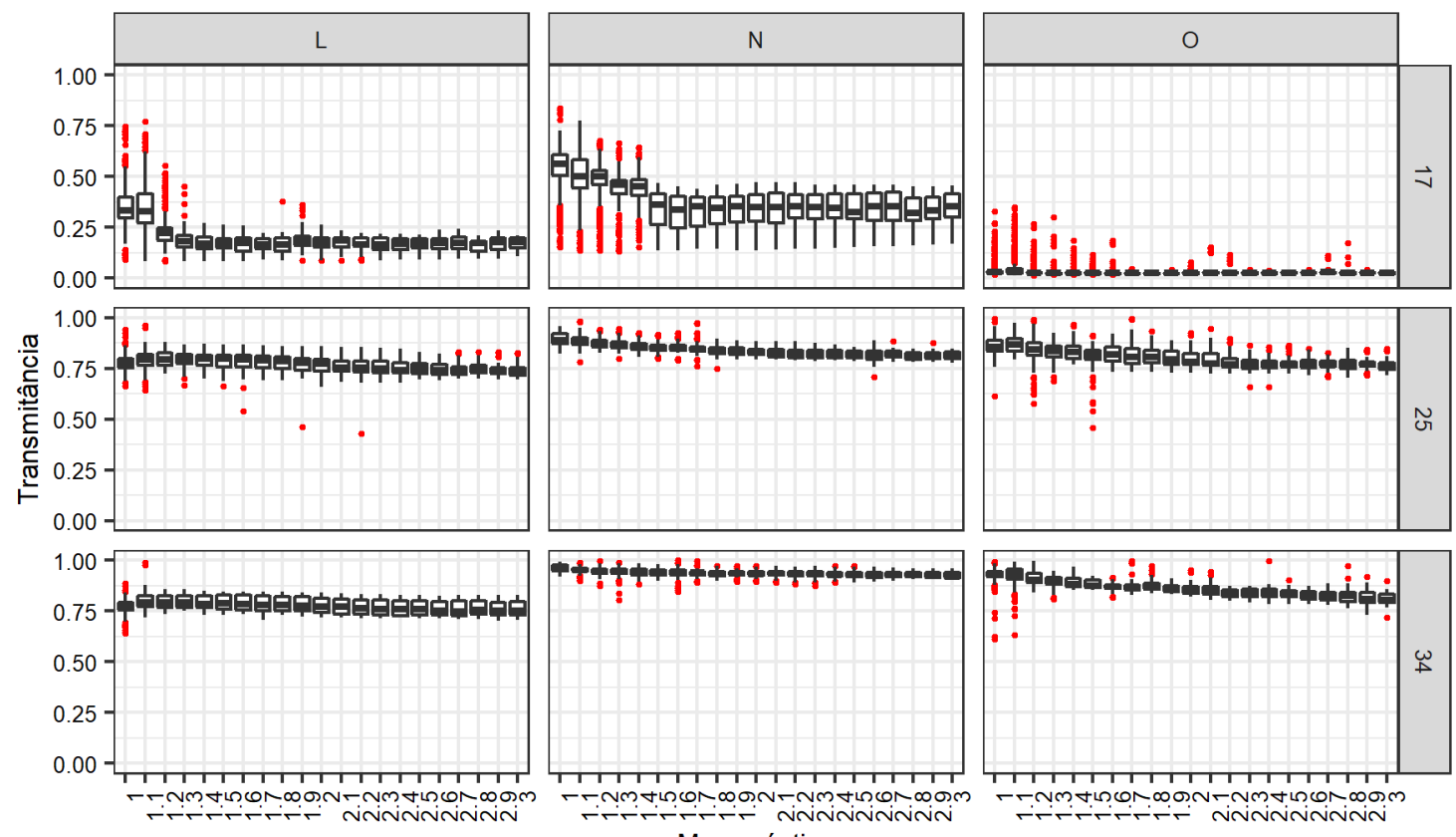

Massa óptica

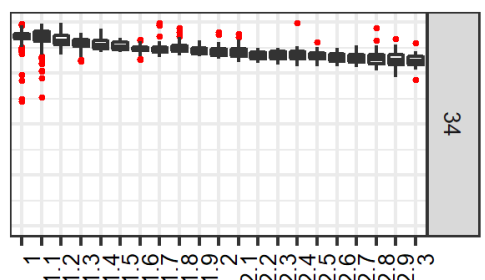

Figura 33 - Transmitância PAR por intervalo de massa óptica para cada nível de altura dentro do dossel da Reserva Biológica do Jaru (REBIO). Os números na lateral indicam a altura acima da superfície $(\mathrm{m})$, o eixo vertical é a transmitância PAR incidente e o eixo horizontal é o intervalo de massa óptica. As colunas indicam em qual lado da torre está o sensor, norte (N), leste (L) e oeste (O).

Em 17 m, para mo $>1,5$ a transmitância se manteve estável no lado norte e leste, porém com maior variabilidade no lado norte. Para mo menor que 1,5, a transmitância da face norte foi, em média, duas vezes maior que a transmitância da face leste. Quanto mais interno (mais baixo) o sensor, mais restrita foi a influência do ângulo zenital solar.

\subsubsection{Relações entre transmitância PAR dentro do dossel e AOD}

Com o intuito de eliminar possíveis dados que representassem sunflecks, sombreamentos devidos a galhos ou ramos de folhas, entre outras flutuações, restringiu-se o banco de dados para aqueles que se ajustaram dentro do intervalo interquartil. I. e., aquela região acima do percentil 0,25 e abaixo de 0,75, representando $50 \%$ dos dados em torno da medida de centralidade (mediana).

A transmitância, como visto anteriormente, também variou em função da geometria solar. Todavia, por simplicidade, serão apresentados apenas os casos caracterizados por uma mudança no regime do padrão da transmitância em algum dos níveis de medição. 
No experimento do ATTO (Figura 34), com o sol próximo do zênite $\left(m_{\circ}=1\right)$, a maior presença de aerossóis não afetou significativamente a transmitância de PAR dentro do dossel. Vale destacar que as linhas na Figura 34, representam o ajuste linear aos dados para melhor visualizar a sua tendência e a área adjunta indica o intervalo com 95\% de confiança.

$\mathrm{Na}$ camada, relativamente, mais inferior $(22 \mathrm{~m})$, a maior presença de aerossóis na atmosfera implicou numa pequena diminuição da transmitância Uma redução menos acentuada foi notada no nível de $28 \mathrm{~m}$, e estabilidade no nível imediatamente abaixo do topo $(33 \mathrm{~m})$. Os resultados observados nos sensores abaixo de $22 \mathrm{~m}$ não foram exibidos pois, por estarem sombreados não apresentaram nenhum sinal.

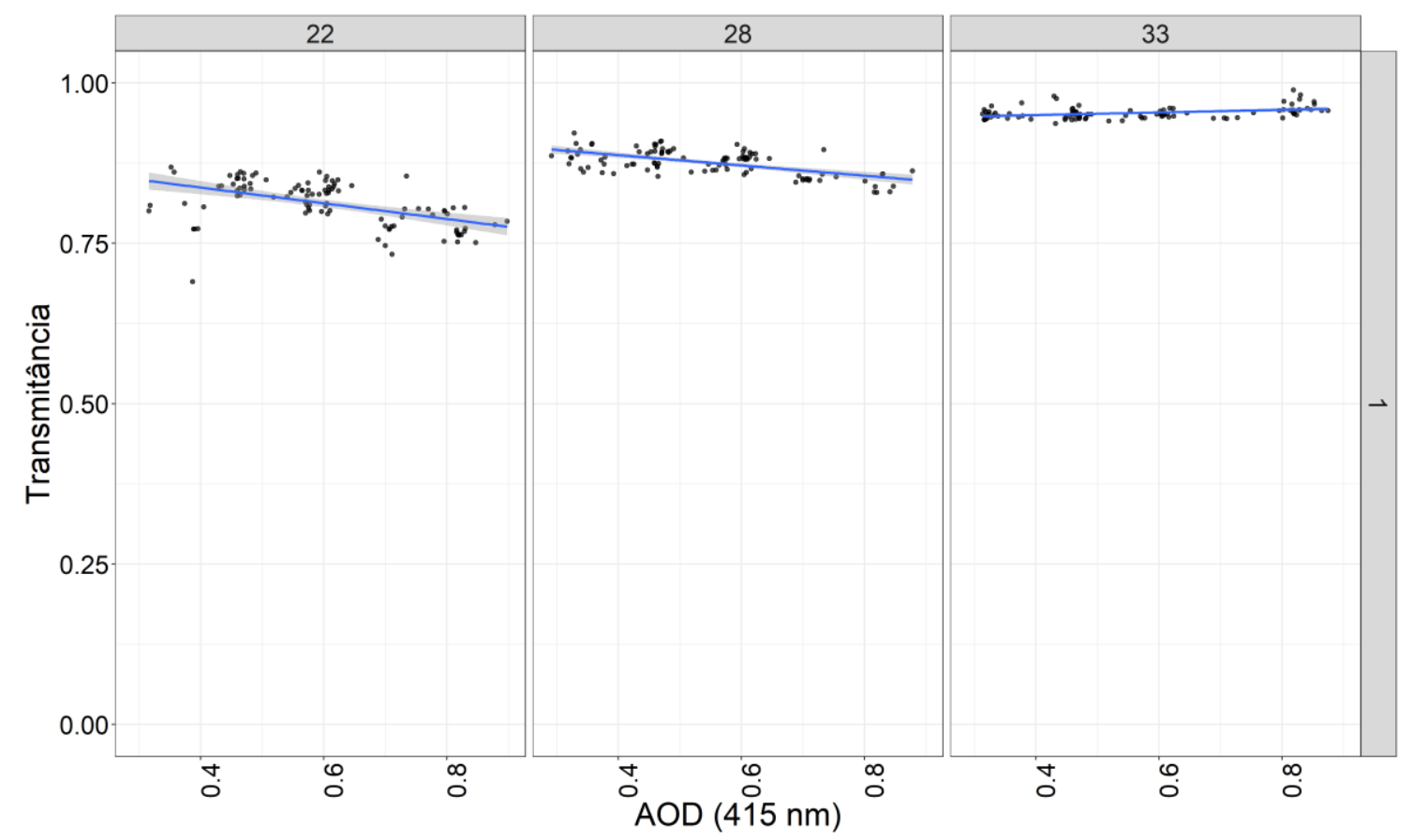

Figura 34 - Relação entre a transmitância e a profundidade óptica do aerossol (415 nm) nos três níveis mais altos, excetuando-se o nível do topo $(39 \mathrm{~m})$ em casos com massa óptica $=1$. Sítio experimental: ATTO. As linhas representam o ajuste linear aos dados (pontos) e a área ao redor da reta representa o intervalo com $95 \%$ de confiança.

Aproximadamente às 11:30 da manhã (horário local), que corresponde ao intervalo de massa óptica $m_{0}=1.3$ (Figura 35), se estabeleceu uma nova relação entre a transmitância e a profundidade óptica do aerossol. Uma tendência positiva é observada em $22 \mathrm{~m}$ de altura.

Os demais níveis superiores permaneceram com as mesmas características da figura anterior, com a diferença que a tendência negativa em 
$28 \mathrm{~m}$ se apresentou mais acentuada, comparativamente. A estabilidade no sensor a $33 \mathrm{~m}$, certamente está associada à semelhança nas condições de exposição com o sensor do topo.

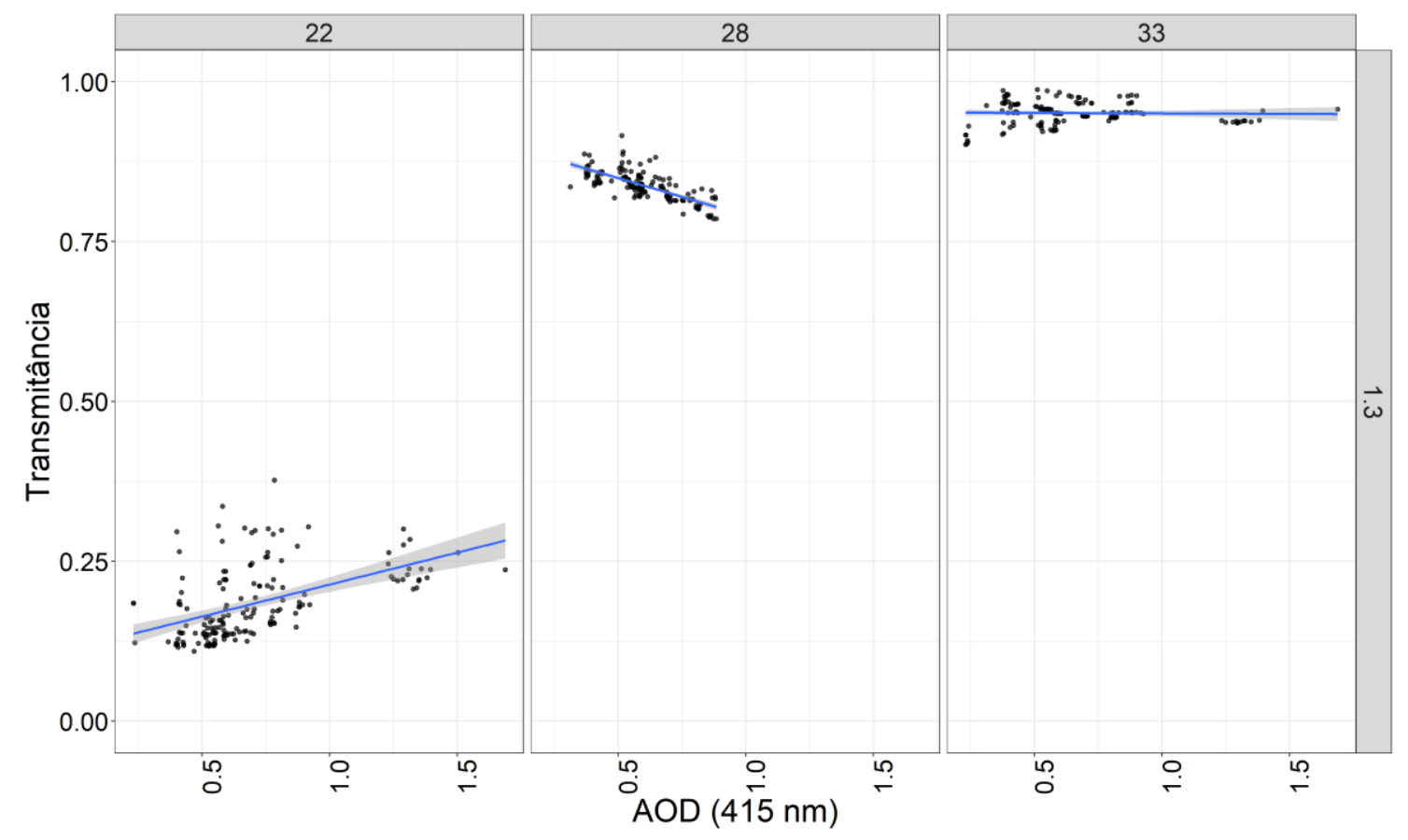

Figura 35 - Relação entre a transmitância e a profundidade óptica do aerossol (415 nm) nos três níveis mais altos excetuando-se o nível do topo $(39 \mathrm{~m})$ em casos com massa óptica $=1,3$. Sítio experimental: ATTO.

A transmitância é calculada para uma camada a partir da radiação incidente no topo da copa, desta forma, o sensor no topo sempre terá valor 1. Como observado na Figura 28, o padrão de variabilidade de incidência PAR é, em 33 m, muito similar ao observado no topo (39 m). Portanto, a disposição dos sensores é um fator importante para a observação da relação entre a transmitância PAR e a AOD.

Quando o ângulo zenital solar estava em aproximadamente $56^{\circ}\left(m_{0}=1,8\right)$, os sensores a 28 e $22 \mathrm{~m}$ de altura registraram aumento na transmitância em função da AOD (Figura 36). O nível a $33 \mathrm{~m}$ de altura permaneceu estável sob quaisquer condições de AOD.

Se, por um lado, um dado sensor recebe uma quantidade de radiação muito semelhante à que chega no topo, então a transmitância deste será muito 
próxima de 1, como discutido anteriormente. Isso é facilmente observado nos sensores próximos ao topo.

Por outro lado, sensores que estão em regiões mais abaixo, em relação ao topo do dossel, são os mais susceptíveis a sombreamento. Desta forma, os resultados sugerem que quando o sensor está dentro do dossel (e. g. sensor a 28 m na Figura 36), ele registra incremento da transmitância PAR com a AOD, devido à maior disponibilidade de radiação na forma difusa, ao passo que quando há mais radiação solar direta, a tendência é negativa (mesmo sensor na Figura 35 e Figura 34).

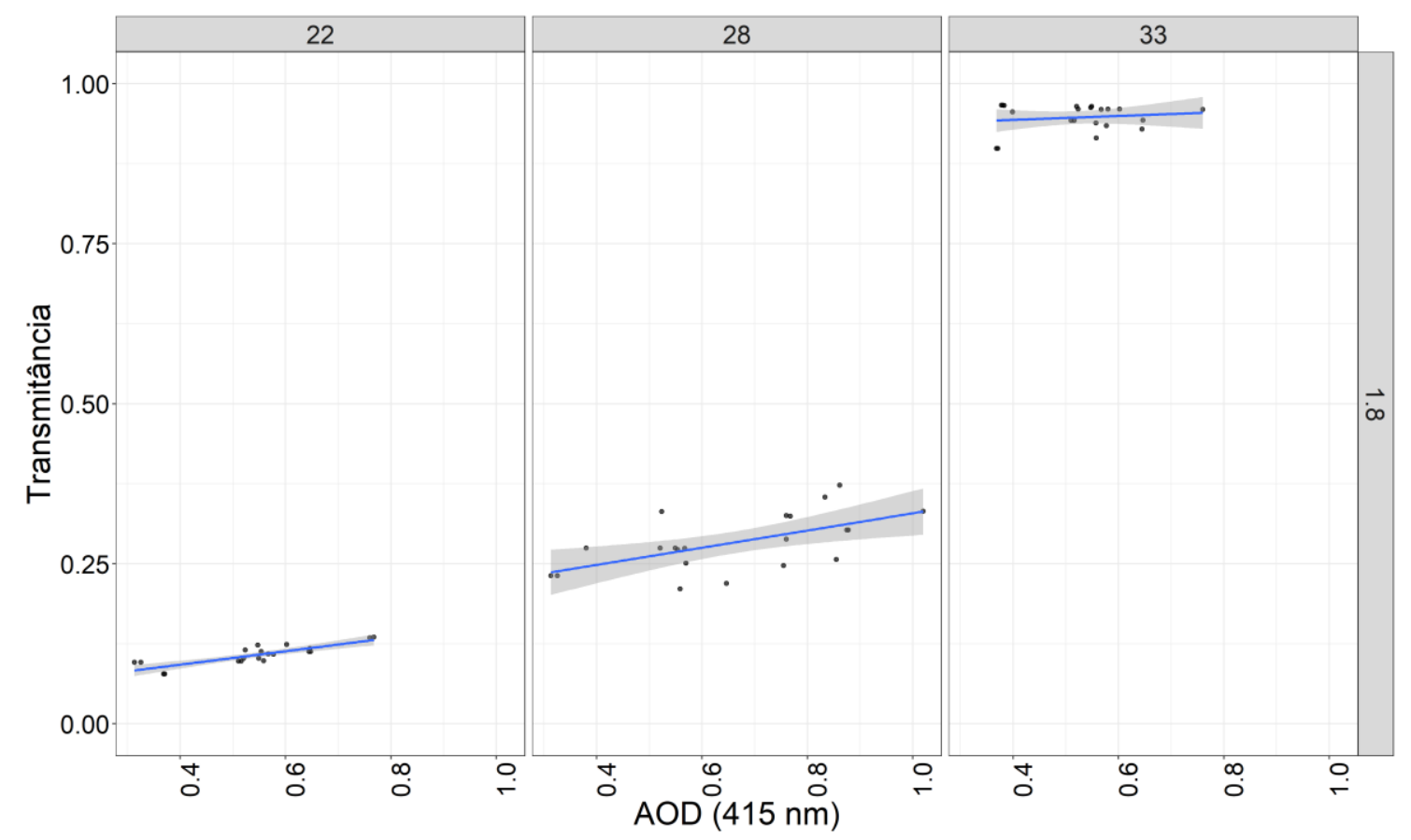

Figura 36 - Relação entre a transmitância PAR e a profundidade óptica do aerossol (415 nm) nos três níveis mais altos excetuando-se o nível do topo $(39 \mathrm{~m})$ em casos com massa óptica = 1,8. Sítio experimental: ATTO.

No sítio de Humaitá, o sensor a $5 \mathrm{~m}$ de altura, na face leste da torre (Figura 37), é marcado por um grande ruído. Os outros sensores no mesmo nível estão sombreados e não apresentaram nenhuma resposta com as mudanças de AOD ou ângulo zenital solar (Figura 32). O mesmo pode ser dito dos sensores a $11 \mathrm{~m}$ de altura.

Para facilitar a discussão dos resultados na sequência, será utilizado o termo sensor iluminado para descrever os sensores que estejam na condição similar aos sensores a oeste da torre meteorológica, em 17 e $25 \mathrm{~m}$ de altura 
(Figura 37). I. e., mesmo em níveis abaixo do topo das árvores, não estão sob as sombras das mesmas.

Note que esta condição não é apenas dependente da altura, mas também da conjuntura geometria solar + estrutura das árvores (posição dos galhos, folhas e troncos). Logo, em consequência dessas condições, o sensor deve apresentar tendência negativa com o aumento da AOD ou permanecer constante , caso ele esteja um nível imediatamente abaixo do sensor instalado acima da copa das árvores.

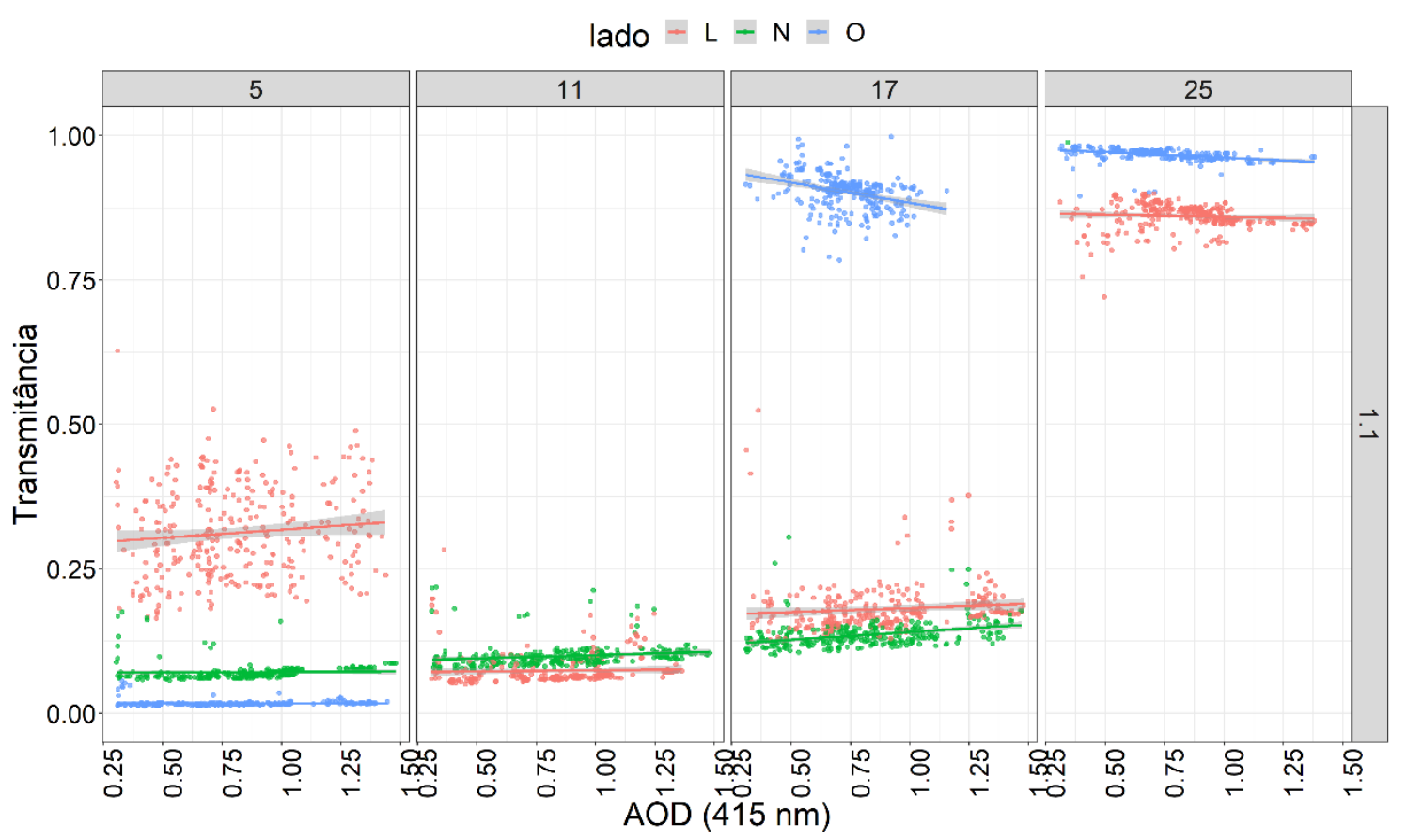

Figura 37-Relação entre a transmitância e a profundidade óptica do aerossol (415 nm) em casos com massa óptica = 1,1 para cada nível de sensor separando os pontos pelos lados nos quais os sensores estão voltados em relação à torre. Verde: lado norte, azul: lado oeste e rosa: lado leste. Sítio experimental: Humaitá.

Em todo o período de análise, o sensor a $17 \mathrm{~m}$, da face norte (Humaitá), apresentou resposta negativa ao aumento da AOD ou ficou completamente sombreado (sem variação e com valores próximos a 0 ). Apenas com $m_{0}=1,5$ ele apresentou incremento na transmitância com o aumento da AOD (Figura 38).

Novamente, para $m_{0}<1,5$, o sensor da face norte apresentou valores de transmitância menores que os apresentados pelo sensor, no mesmo nível, do lado leste. Por outro lado, para $\mathrm{m}_{\mathrm{o}} \geq 1,5$, apresentou valores maiores $\mathrm{e}$, em alguns casos, até 2 ou mais vezes maiores. 
Estes fatos são importantes para enfatizar a heterogeneidade da floresta que, para o mesmo nível, poucos metros ao lado, o regime da transmitância pode ser completamente diferente, como é o caso dos sensores instalados no lado oeste, que apresentaram valores de transmitância sistematicamente maiores que os dos lados leste e norte, tanto em 17 quanto em $25 \mathrm{~m}$, para as três massas ópticas ilustradas nas Figura 37 a Figura 39.

Como já mencionado, conforme a $m_{\circ}$ aumenta, a produção de radiação difusa é facilitada pelo aumento do caminho óptico. Por isso a tendência positiva da transmitância com a AOD é maior (Figura 39). O número de sensores com aumento também aumenta, pois, com o sol próximo do horizonte, a sombra alcança níveis mais altos.

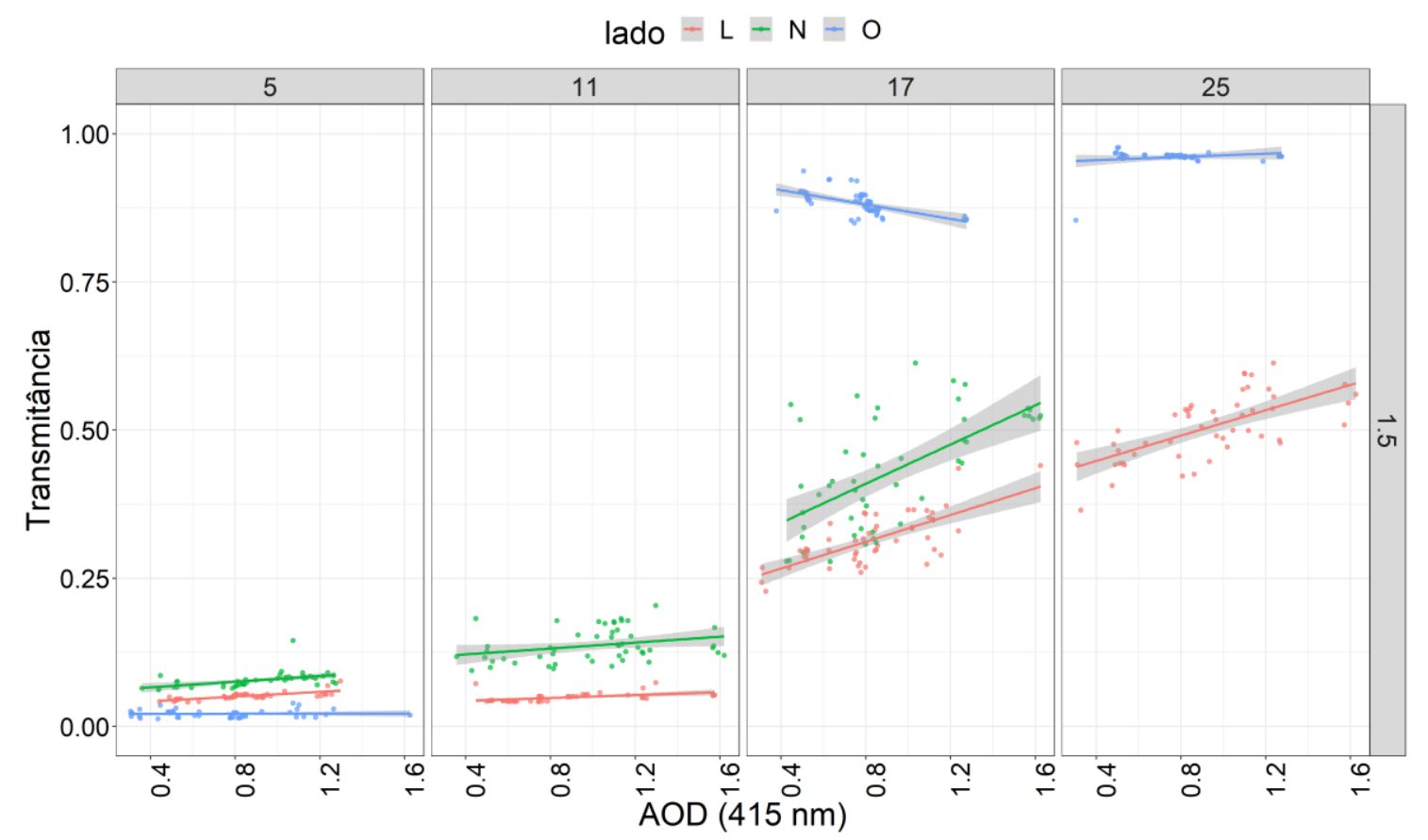

Figura 38 - Relação entre a transmitância e a profundidade óptica do aerossol (415 nm) em casos com massa óptica $=1,5$ para cada nível de sensor separando os pontos pelos lados nos quais os sensores estão voltados em relação à torre. Verde) lado norte, azul) lado oeste e rosa), lado leste. Sítio experimental: Humaitá. 


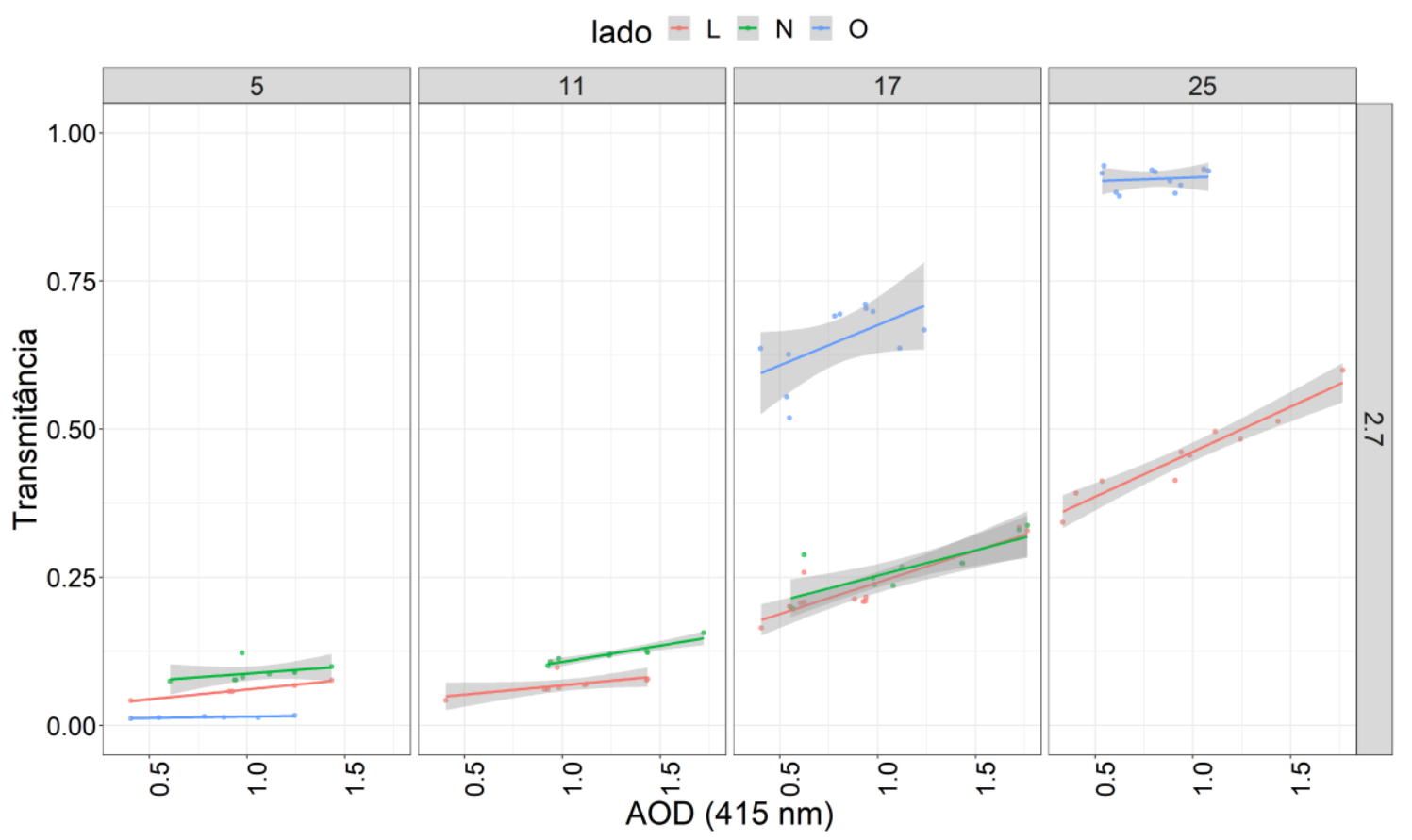

Figura 39 - Relação entre a transmitância e a profundidade óptica do aerossol (415 nm) em casos com massa óptica = 2,7 para cada nível de altura de instalação do sensor, separando os pontos pelos lados nos quais os sensores estão voltados em relação à torre. Verde) lado norte, azul) lado oeste e rosa), lado leste. Sítio experimental: Humaitá.

Na Figura 39 também é possível notar que o maior incremento na transmitância foi observado no nível mais alto. E que conforme os níveis ficaram mais profundos, esse aumento com a AOD tendeu a diminuir.

Na Reserva Biológica do Jaru (REBIO) foram observados os maiores casos de AOD (Figura 26). Disto, temos a oportunidade de avaliar a transmitância em situações em que há majoritariamente radiação difusa presente em momentos de baixa massa óptica (Figura 40), o que não foi possível nos outros sítios.

Para a maioria dos casos dos sítios discutidos anteriormente, a filtragem dos dados foi satisfatória. Entretanto, quanto menor a massa óptica, maior foi a presença de ruído, principalmente com $m_{0}=1$, uma vez que quanto menor a massa óptica, maior é o tempo de amostragem possível, para uma mesma variação de massa óptica.

Também foi observada maior variação em casos com AOD baixo. Isso pode estar associado a maior fração de radiação direta e, consequentemente, maior presença de sunflecks. 
Conforme a AOD aumentou, as flutuações em torno da curva de ajuste linear tendeu a diminuir sistematicamente em todos os sensores de todos os níveis (vide Figura 40, em especial para os sensores norte e leste a $17 \mathrm{~m}$ de altura).

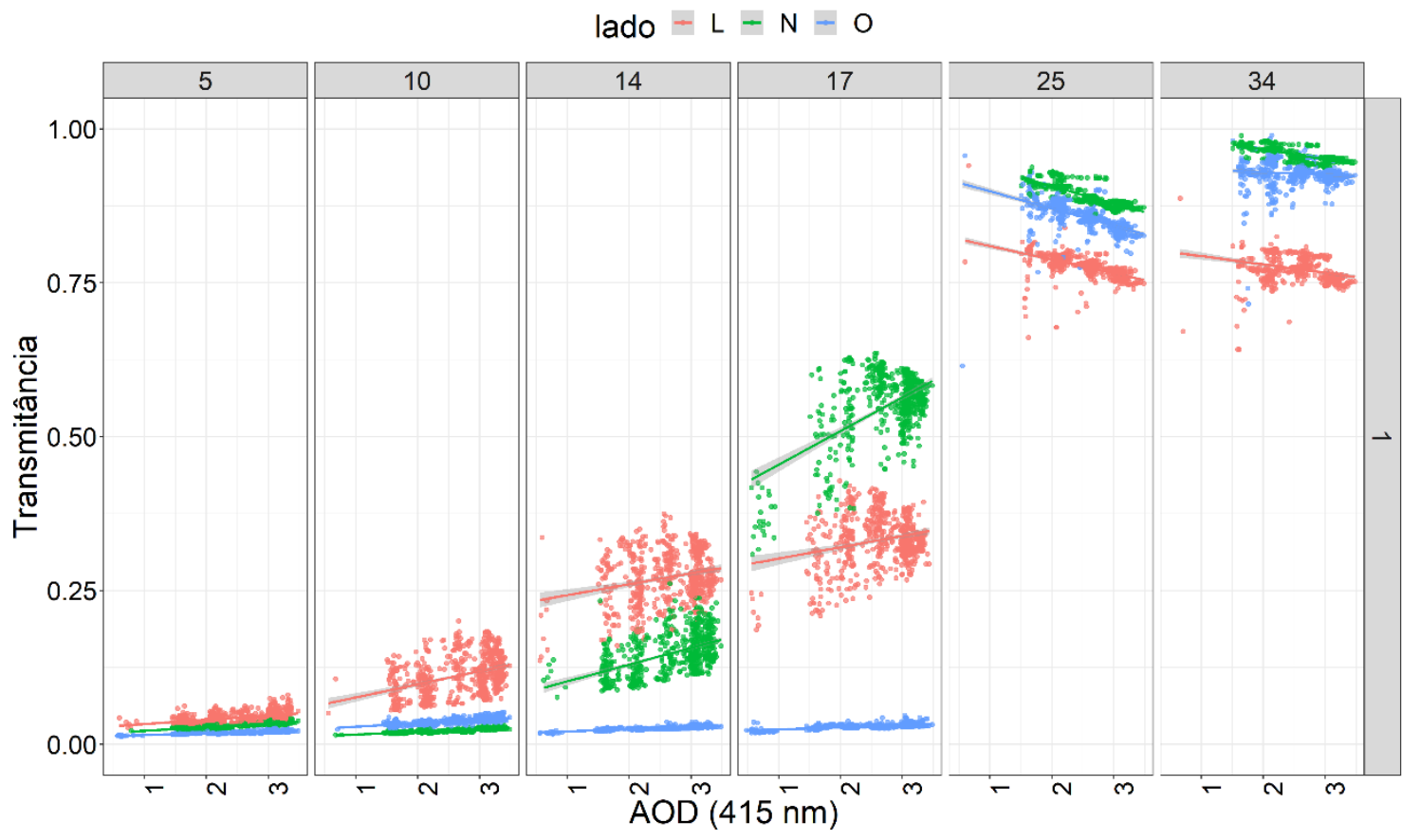

Figura 40 - Relação entre a transmitância e a profundidade óptica do aerossol (415 nm) em casos com massa óptica = 1,0 para cada nível de sensor separando os pontos pelos lados nos quais os sensores estão voltados em relação à torre. Verde) lado norte, azul) lado oeste e rosa), lado leste. Sítio experimental: REBIO.

Os dois níveis mais altos ( 25 e $34 \mathrm{~m}$ ) podem ser caracterizados como sensores iluminados. Todos os sensores nesse nível apresentaram tendência de queda na transmitância com o aumento da AOD. Há também uma certa proximidade nos valores (em especial para os lados norte e oeste) indicando condições de homogeneidade horizontal na iluminação PAR nestes níveis e lados.

A transmitância na REBIO apresentou padrões muito semelhantes em todos os intervalos de massa óptica analisados quando comparados com 0 padrão da Figura 40. A título de exemplo é apresentada a Figura 41. Dos resultados apresentados na Figura 41 os que mais se destacaram são os dos sensores das faces norte e leste no nível intermediário $(17 \mathrm{~m})$. Ambos se destacaram pela sua grande resposta positiva de aumento com o aumento da AOD. 


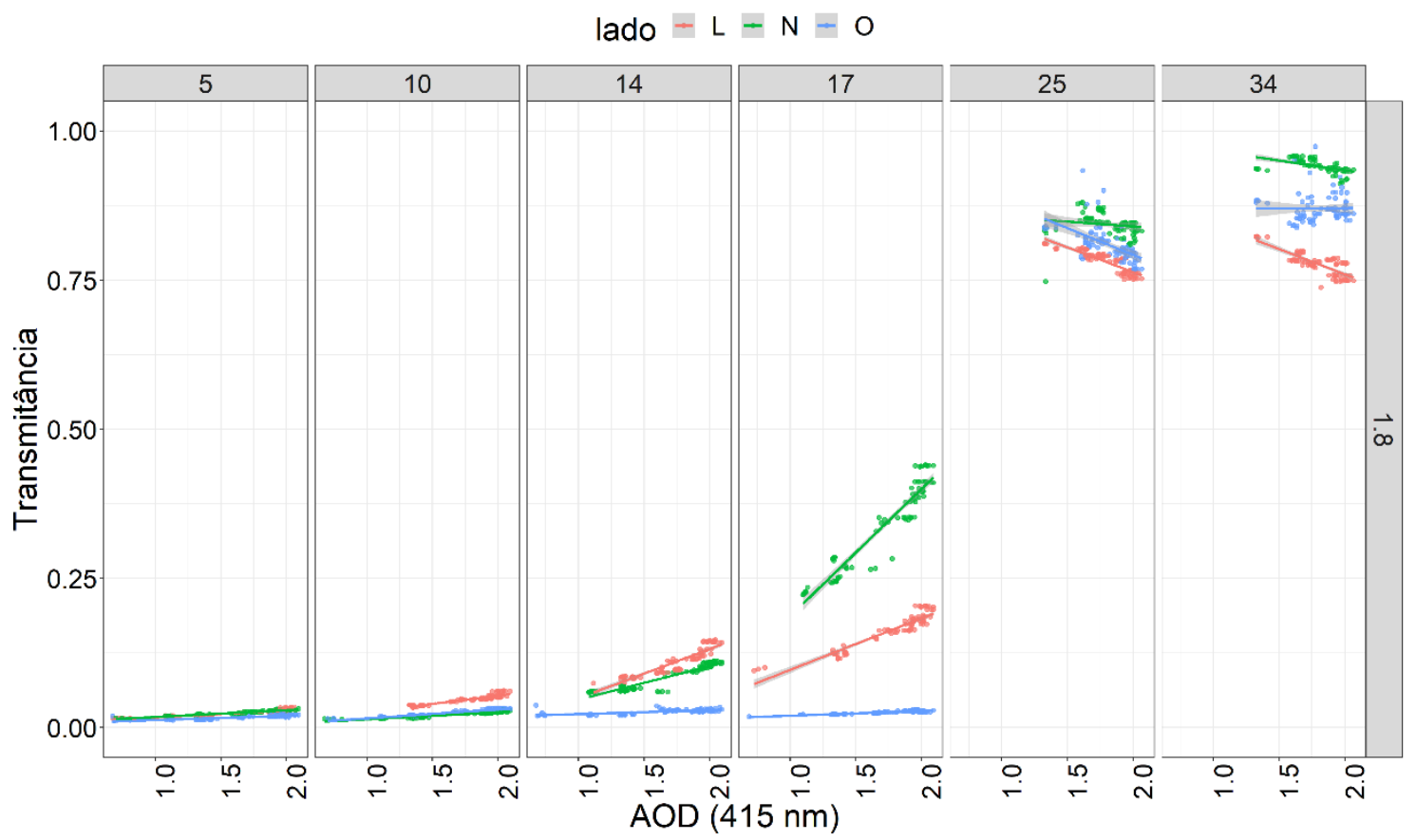

Figura 41 - Relação entre a transmitância e a profundidade óptica do aerossol (415 nm) em casos com massa óptica = 1,2 para cada nível de sensor separando os pontos pelos lados nos quais os sensores estão voltados em relação à torre. Verde) lado norte, azul) lado oeste e rosa), lado leste. Sítio experimental: REBIO.

Em relação à filtragem de dados, o maior corte, em relação ao intervalo de AOD, foi observado nos níveis mais altos ( 25 e $34 \mathrm{~m}$ ). Dois outros pontos importantes a serem mencionados são, i) a grande maioria dos dados filtrados encontram-se na região de $A O D<1,0$; ii) a quantidade de dados filtrados aumenta conforme o ângulo zenital solar se tornou mais rasante.

Possivelmente a descontinuidade nos dados de AOD (Figura 26) foi um fator para a classificação dos valores de transmitância com $A O D<1,0$ como outliers (Figura 33) e, consequentemente, haver um maior corte nesta região. Como a ocorrência de $A O D<1$ diminui com o aumento da $\mathrm{m}_{\circ}$, a descontinuidade dos dados também aumenta. Isso explica os pontos i) e ii).

\subsection{Resultados simulados numericamente com o DART}

Todos os resultados aqui apresentados foram simulados para a cena com a presença da torre meteorológica. Apenas os resultados sobre o impacto da torre na transmitância PAR possuem simulações com cena sem a presença da torre. 


\subsubsection{Análise do efeito de borda}

No modelo de transferência radiativa 3D DART é possível observar a entrada e saída de radiação lateralmente (Figura 42), i. e., transporte horizontal de radiação. Entretanto, quando a cena é representada como "cena isolada", isso faz com que o modelo entenda que o feixe de radiação que sai da cena "morra". Ou seja, o feixe de luz que sai do sistema não retorna mais.

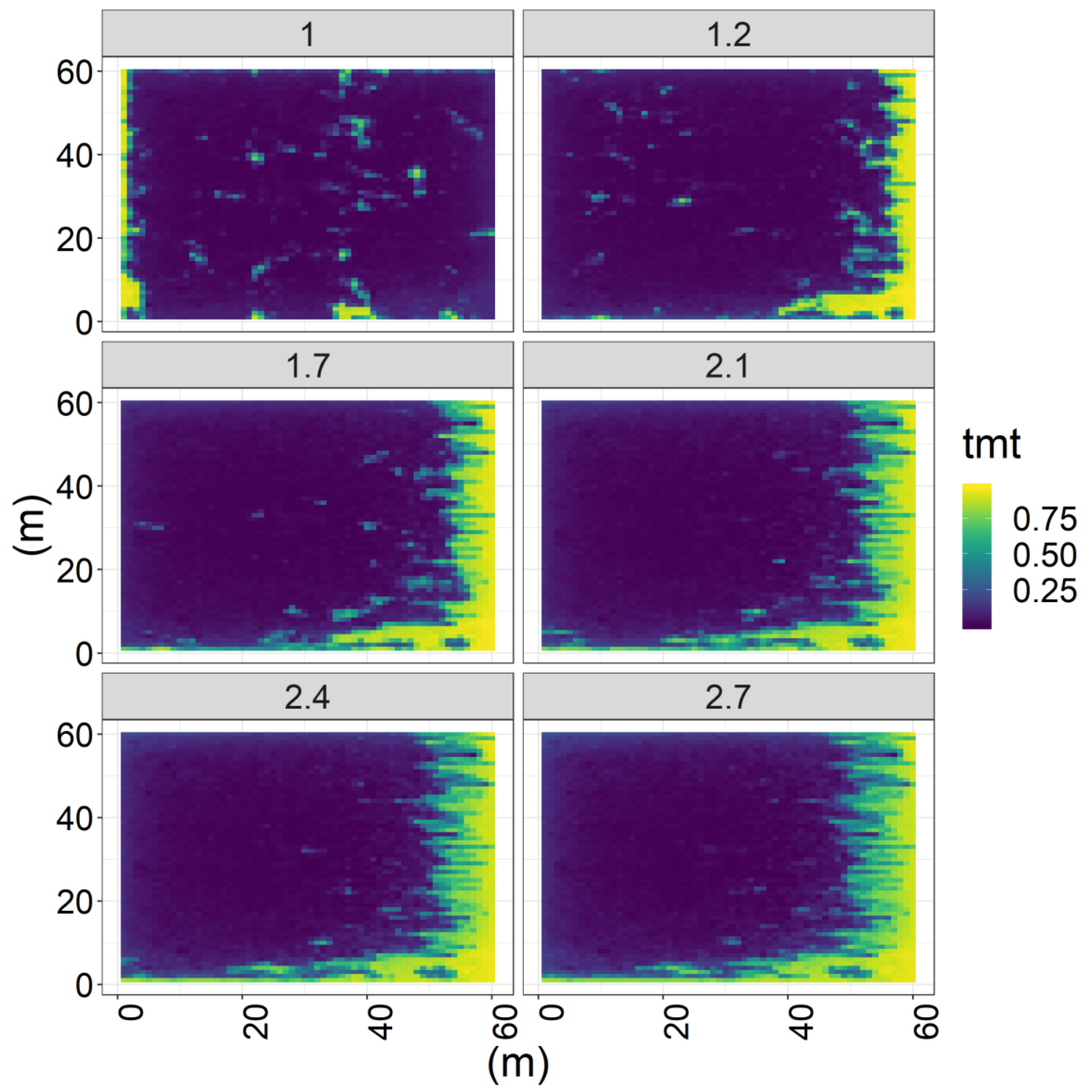

Figura 42 - Efeito de borda: contaminação da cena pela radiação que incide pela região lateral da cena simulada considerando o método "cena isolada". O efeito de borda é destacado pela região em amarelo e indica a direção predominante de incidência solar. O número acima de cada quadro indica a respectiva massa óptica. Neste caso, o observador está olhando para o nadir, e o sol está a leste (manhã), isto é, à direita do observador. 
Isso é vantajoso para o nosso caso pois, nas outras opções (repetitive scene e infinite slope), há um reaproveitamento dessa radiação emergente, como retroalimentação do modelo. Isso faz com que se tenha uma cena muito mais iluminada nos níveis inferiores e que interações de um lado sejam observadas do outro lado.

Um problema desse tipo de método é a borda associada. No caso do trabalho em tela, o objetivo é simular uma pequena região de uma floresta extensa. Portanto, subentende-se que a área florestada seja maior que a apresentada. Note que, na Figura 42, para massa óptica maior ou igual a 1,2, o disco solar estava à direita da cena, pois a simulação foi feita para representar o período da manhã, com o observador olhando para o norte. Assim, o lado direito (leste) encontrou-se artificialmente mais iluminado que o lado esquerdo. Esse cenário seria representativo de uma floresta que tem uma clara divisão com uma zona desmatada (uma estrada por exemplo) do lado leste. Para evitar essa iluminação artificial, não representativa do caso real, fez-se um recorte da área central, em torno da torre, de $13 \mathrm{~m}$ de lado.

\subsubsection{Radiação solar incidente simulada no topo do dossel}

O período amostral dos três sítios somam mais de 100 dias. Para representar todo esse período, as simulações numéricas foram feitas para as coordenadas geográficas da estação da REBIO Jaru num dia intermediário (dia juliano 290) ao período de coleta de dados dos três sítios (Tabela 1).

De maneira geral, o modelo conseguiu representar bem a fração difusa da radiação solar incidente no topo do dossel (Figura 43). Note que, muito embora o modelo tenha, sistematicamente, subestimado a fração difusa, ela ainda é muito próxima das curvas observadas. Na maioria dos casos, o erro não foi maior que $5 \%$ (Figura 44).

Alguns padrões podem ser identificados ao observar as diferenças entre os valores simulados e os observados (erro relativo) (Figura 44), tais como, tendências e semelhanças entre alguns dos sítios. Por exemplo, o comportamento do erro em Humaitá e no ATTO são semelhantes. 
Para estes sítios, os maiores erros (> 0,05 - valores absolutos) foram observados em cenas com $A O D<1,0$. Essas diferenças são mais acentuadas, principalmente, nos casos com $m_{\circ}=1$ e 1,2. Observou-se também uma tendência de diminuição do erro relacionado ao aumento da massa óptica e a AOD. A tendência do erro com a AOD é melhor observada em Humaitá.

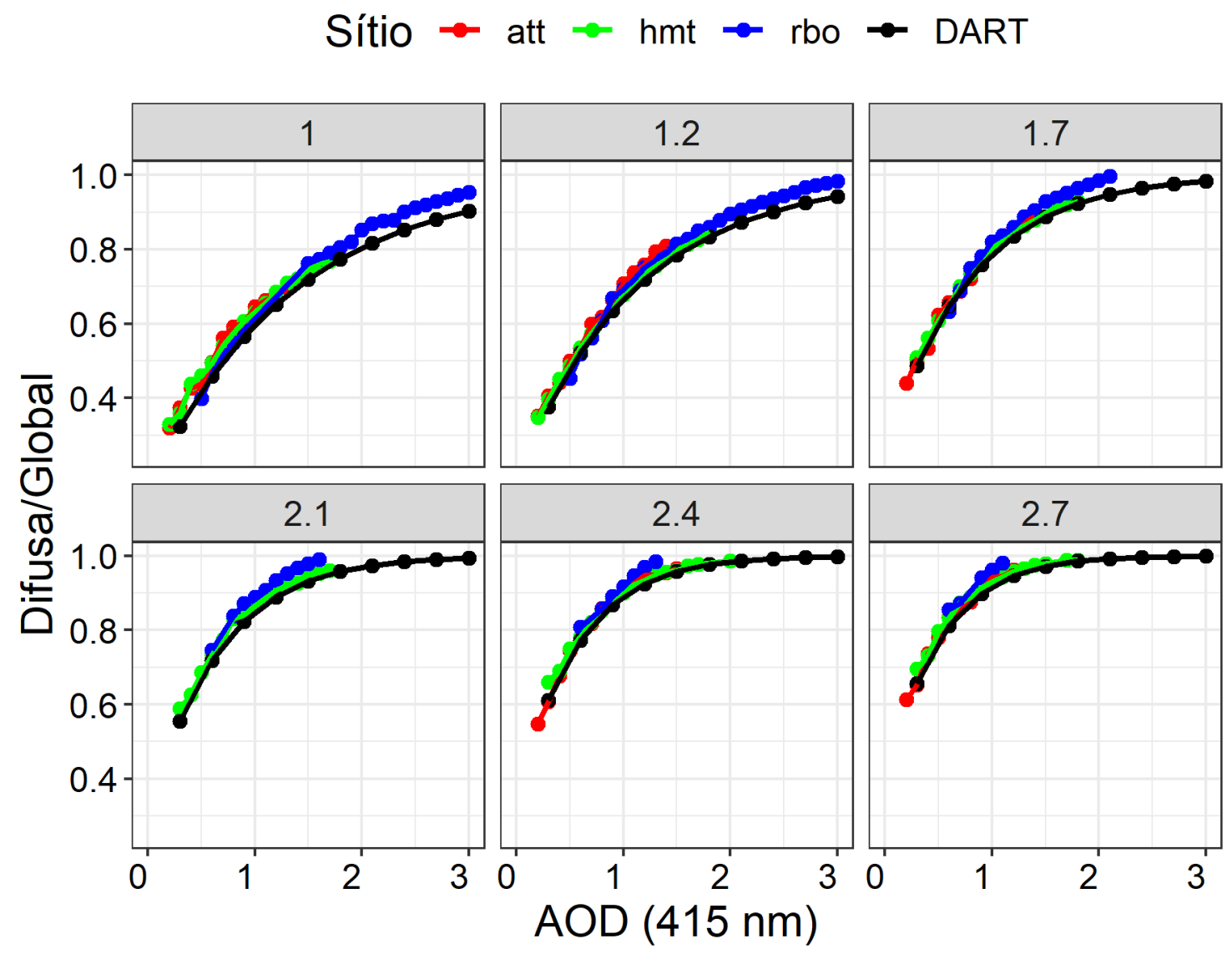

Figura 43 - Razão entre a irradiância espectral difusa e a global em $415 \mathrm{~nm}$ para os três sítios experimentais em função da AOD $(415 \mathrm{~nm})$. A massa óptica para cada rodada está indicada acima de dos quadros. ATTO = att (vermelho), Humaitá $=h m t$ (verde), REBIO = rbo (azul) e DART (preto).

A REBIO, por outro lado, não apresenta uma clara tendência em relação à massa óptica. Contudo, para $m_{0}=1,0$, existe uma tendência positiva do erro em função da $A O D$. Esse padrão não foi claramente observado nos outros ângulos. Porém, para $A O D>1,5$, um erro constante em torno de $-0,05$ foi observado em todos os casos.

O erro (desvio padrão) médio para o ATTO, Humaitá e REBIO foram, respectivamente, $-0,03(0,03) ;-0,03(0,02)$ e $0,04(0,02)$. Note que, muito embora as coordenadas para a simulação tenham sido referentes à REBIO, o maior erro 
médio foi para o mesmo sítio. Contudo, a distribuição da AOD para cada sítio (Figura 24, Figura 25 e Figura 27) é algo que temos que levar em consideração sobre esse valor. $O$ fato da REBIO ter um maior espectro de AOD, implica em mais erros de entrada para o cálculo da média.

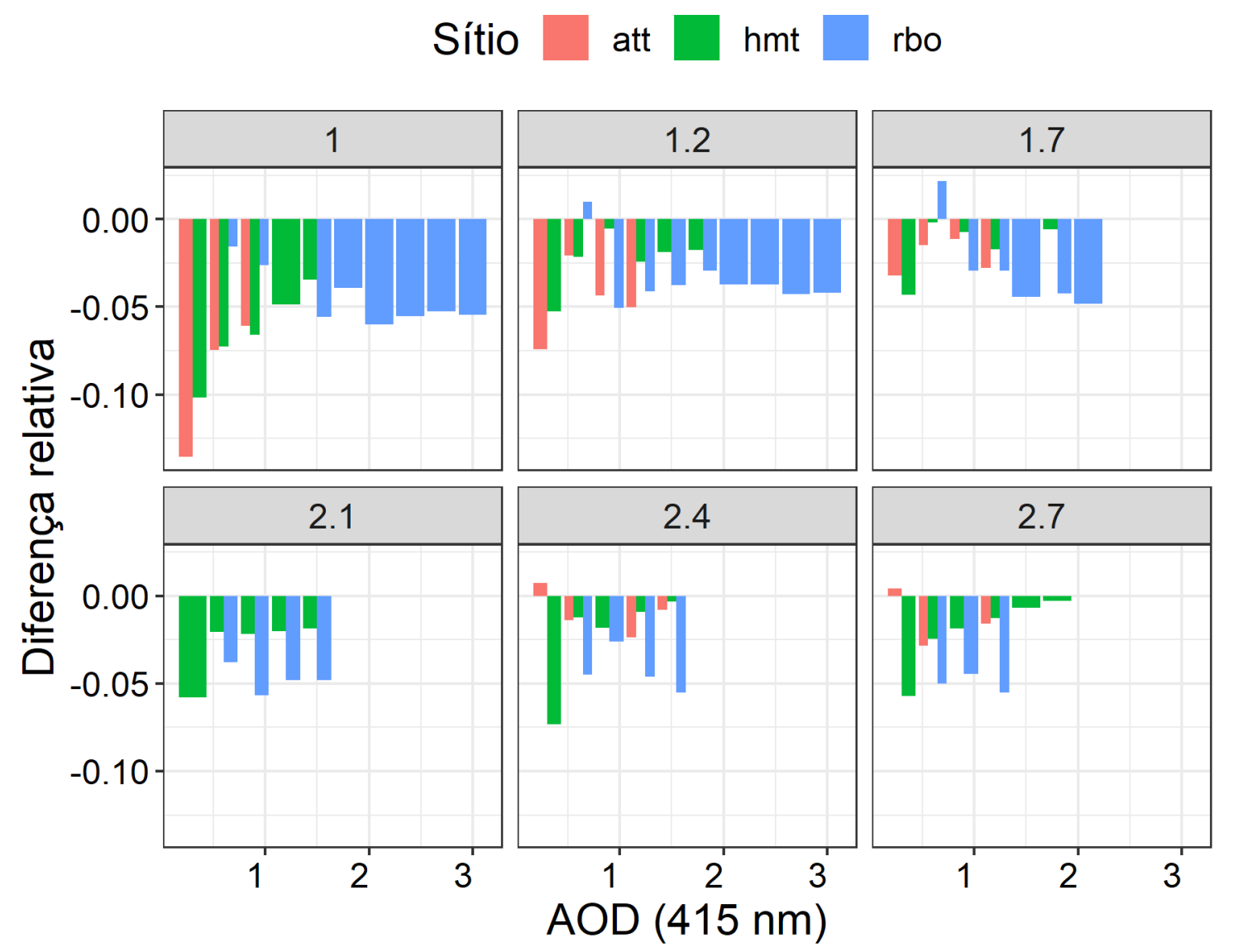

Figura 44 - Diferença relativa entre a irradiância espectral em $415 \mathrm{~nm}$ simulada pelo DART e as respectivas observações no ATTO (att), em Humaitá (hmt) e na REBIO (rbo). As diferenças foram normalizadas pelas irradiâncias observadas referentes a cada sítio. Os números acima de cada quadro indicam a massa óptica correspondente.

\subsubsection{Variação geral da PAR dentro do dossel}

Pelo fato da cena ter sido simulada com $1 \mathrm{~m}^{3}$ de resolução, há pontos a cada metro de altura. Isso proporciona uma maior riqueza de detalhes e permite a observação de fenômenos de pequena escala que serão abordados a seguir.

A variação da radiação fotossinteticamente ativa descendente na área central da cena está representada na Figura 45. Através dela, pode-se ver 0 
perfil vertical de maior frequência (linha sólida dentro das caixas) e as regiões deste perfil onde há maior variabilidade dos dados entre 30 e 40 metros.

A modelagem oferece a possibilidade de isolar as variáveis. Portanto essa variabilidade observada na camada entre 30 e 40 metros de altura deve estar associada exclusivamente às diferentes condições de AOD e a estrutura física da floresta.

Uma vez que a floresta é estática (não muda suas componentes de lugar), assim como as propriedades ópticas de todos os elementos (aerossóis, folhas etc.) são constantes, não há nenhum outro elemento que possa interferir na radiação incidente além da quantidade de aerossóis na atmosfera e a posição aparente do sol.

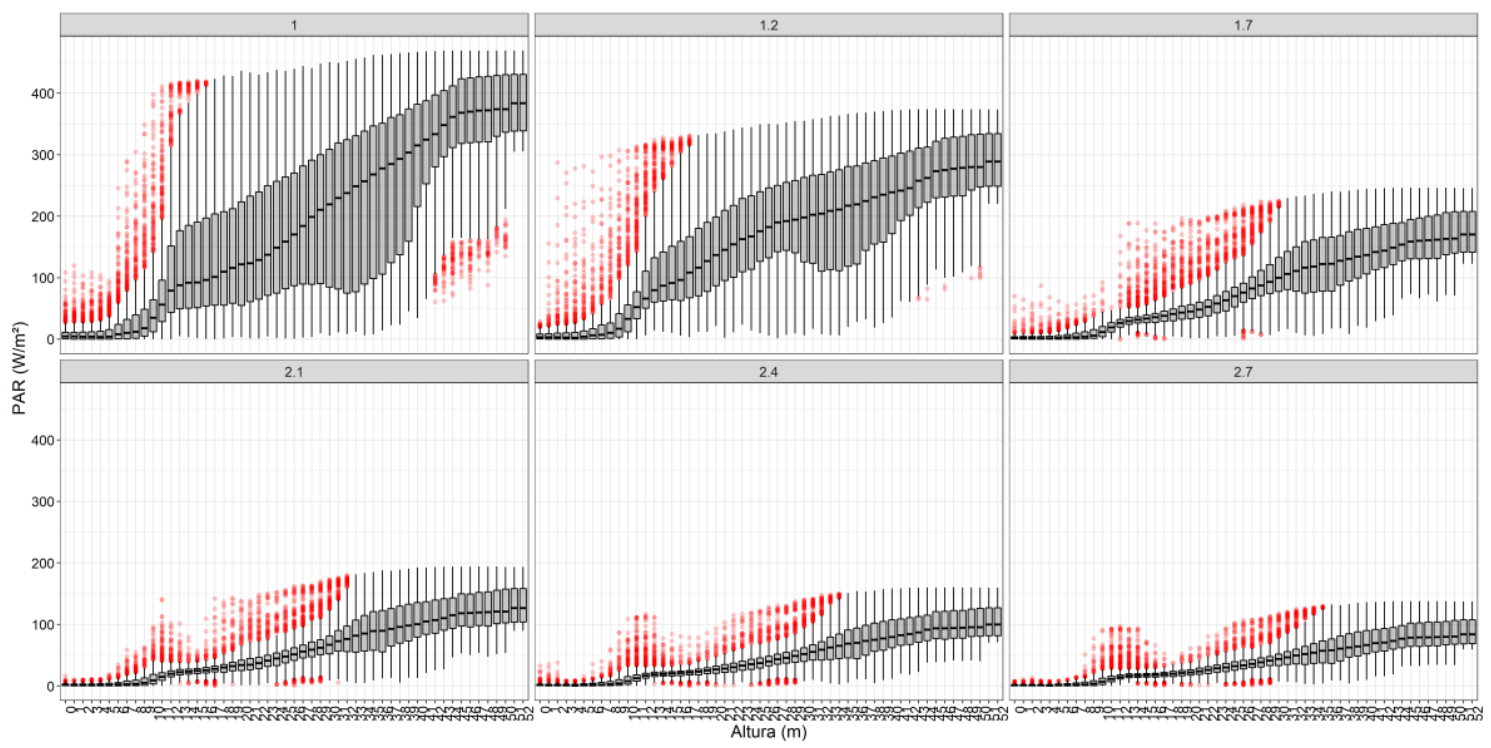

Figura 45 - Perfil vertical da irradiância PAR simulada dentro do dossel para cada condição de massa óptica. Os números acima das caixas indicam a massa óptica, o eixo vertical é a irradiância PAR descendente $\left(\mathrm{W} / \mathrm{m}^{2}\right)$ e o eixo horizontal é a altura $(\mathrm{m})$.

A Figura 45 mostra que em todas os ângulos existem pixels completamente sombreados. Esses pixels podem ser apenas pixels de ar dentro do dossel sombreados, como também pode ser parte do tronco de alguma árvore, pois estes são completamente opacos. Além disso, os valores estão dentro da variabilidade média medida nos sítios experimentais (Figura 28, Figura 29 e Figura 30). 
4.2.4. Variação geral da transmitância dentro do dossel

Similar à Figura 45, a Figura 46 mostra grande variabilidade nos valores de transmitância PAR no recorte central da cena simulada. Uma característica que é observada em todos os casos de mo, é a grande atenuação que ocorre abaixo de $10 \mathrm{~m}$ de altura.

A camada de grande variabilidade $(30$ e $40 \mathrm{~m})$ é ressaltada na transmitância. O tamanho das caixas (indicativo da variabilidade), diminui com o aumento da massa óptica. Partindo da discussão anterior dos resultados experimentais, podemos inferir que o modelo representou bem a transição da floresta para um estado de maior homogeneidade de iluminação pela maior fração de radiação difusa associada à massa óptica.

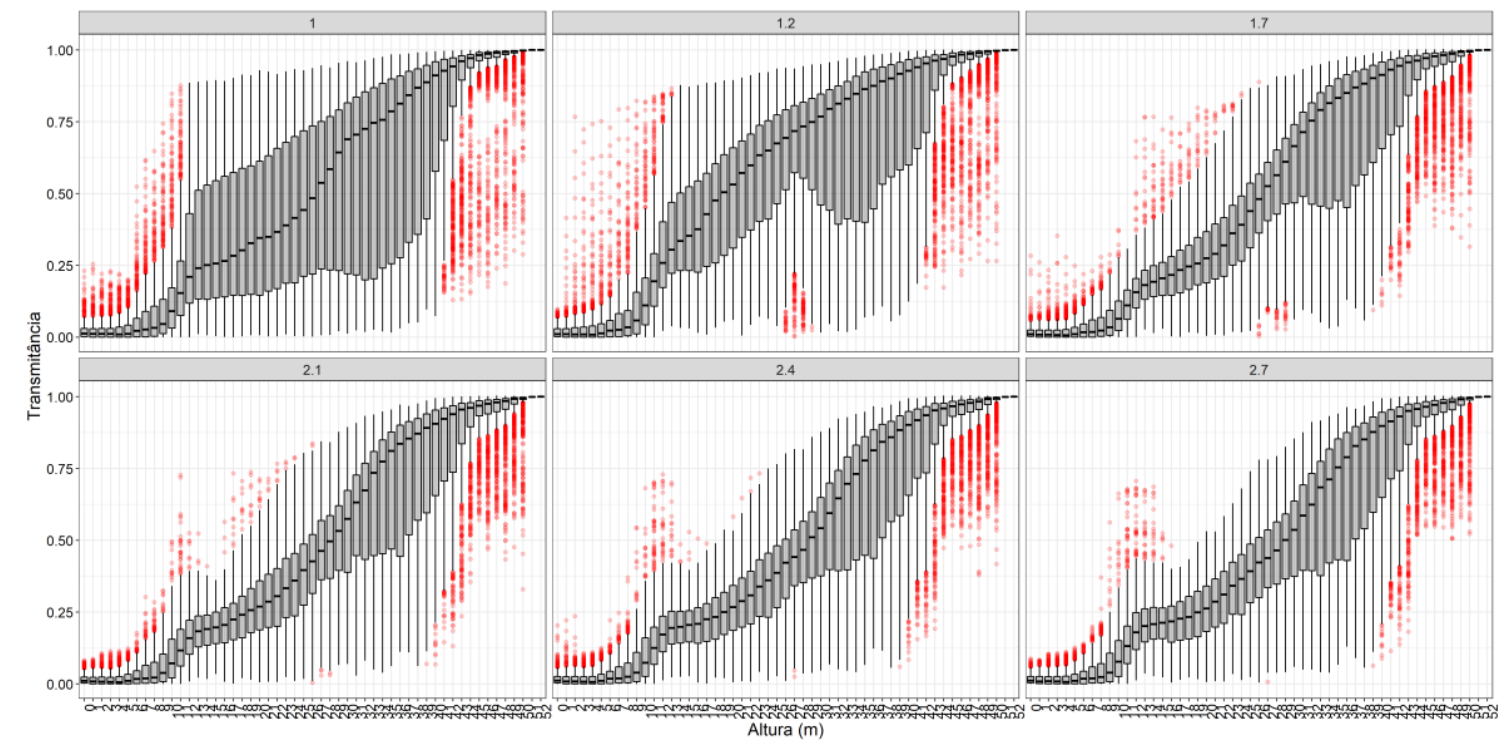

Figura 46 - Perfil vertical de transmitância PAR simulada dentro do dossel para cada condição de massa óptica. Os números acima das caixas indicam a massa óptica, o eixo vertical é a transmitância PAR descendente normalizada pela PAR incidente no topo do dossel para cada coordenada e o eixo horizontal é a altura $(m)$.

Os outliers também são semelhantes aos resultados observados (Figura 31, Figura 32 e Figura 33), positivos nos níveis inferiores e negativos nos superiores. Há uma camada com outliers sempre presentes entre 10 e 15 m.

A presença desses outliers positivos pode estar associada a sunflecks como também a alguma eventual clareira maior. Ter conhecimento da presença desses pontos é importante para uma maior lucidez na interpretação em casos 
pontuais. Também é importante para a avaliação da representatividade das pequenas estruturas 3D pelo modelo e dos seus efeitos sobre a transferência de radiação dentro do dossel.

\subsubsection{Heterogeneidade horizontal da transmitância}

Segundo a Figura 46, a camada localizada a $30 \mathrm{~m}$ de altura não tem nenhum outlier positivo (isto é, pontos vermelhos acima das caixas cinza) em nenhuma das geometrias do disco solar consideradas nas simulações. Desta forma, não há indicativo de frestas/sunflecks. Para uma melhor investigação da presença das frestas, a Figura 47 e Figura 48 mostram um corte horizontal a 30 metros da superfície sob diversas condições de AOD e mo.

Em ângulos de incidência mais perpendiculares $\left(m_{\circ}=1\right)$, podemos observar que há diversas frestas dentro da copa das árvores. Isso ressalta que o modelo conseguiu representar as estruturas que dão condição a esse fenômeno.

Por outro lado, com o aumento da massa óptica, pode ser observado o crescimento da sombra projetada. Tomemos como fator de comparação, os casos com $A O D=0,3$. Temos que, para $m_{\circ}=1,7$ já é possível observar de forma clara pixels em amarelo que indica transmitância (tmt) alta $(>0,75)$ (frestas).

À medida em que a massa óptica aumenta, pode-se ver o deslocamento e alongamento das frestas na mesma direção da projeção das sombras. Contudo, o efeito da AOD faz com que o contraste entre as sombras e essas frestas se esvaia. 

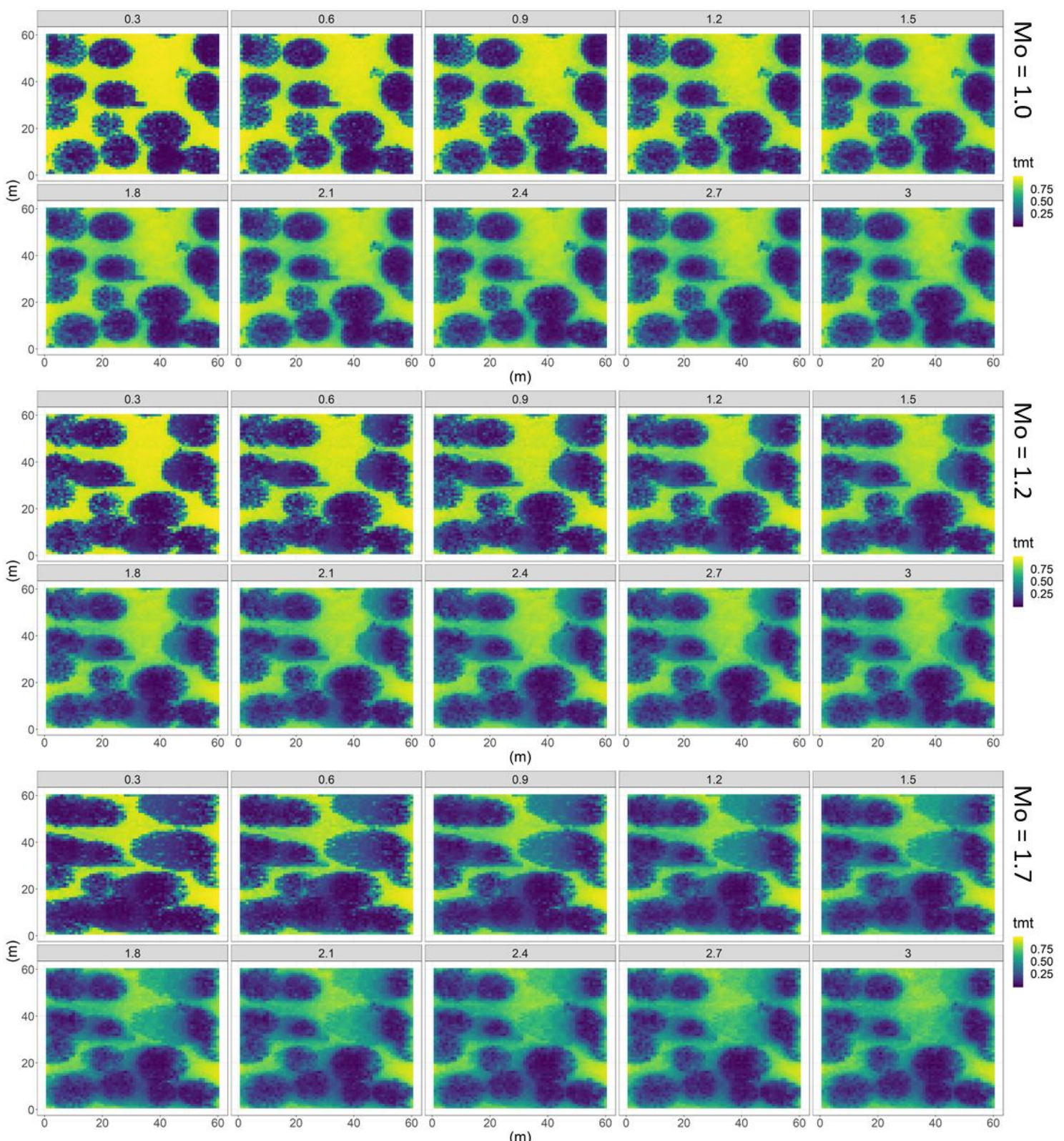

Figura 47-Corte horizontal da cena simulada a $30 \mathrm{~m}$ de altura sob diversas condições de $A O D$ $(415 \mathrm{~nm}$ ) (indicada pelos números acima dos quadros) e diferentes geometrias solares (indicada na legenda ao lado). As cores representam a transmitância (tmt) para cada pixel na altura mencionada.

A diminuição desse contraste indica que a cena está ficando homogeneamente iluminada. Disto, entende-se que a presença e os possíveis efeitos das frestas são reduzidos pelo aumento da fração difusa da radiação. Ao mesmo tempo em que as áreas mais iluminadas escurecem e vice-versa. 

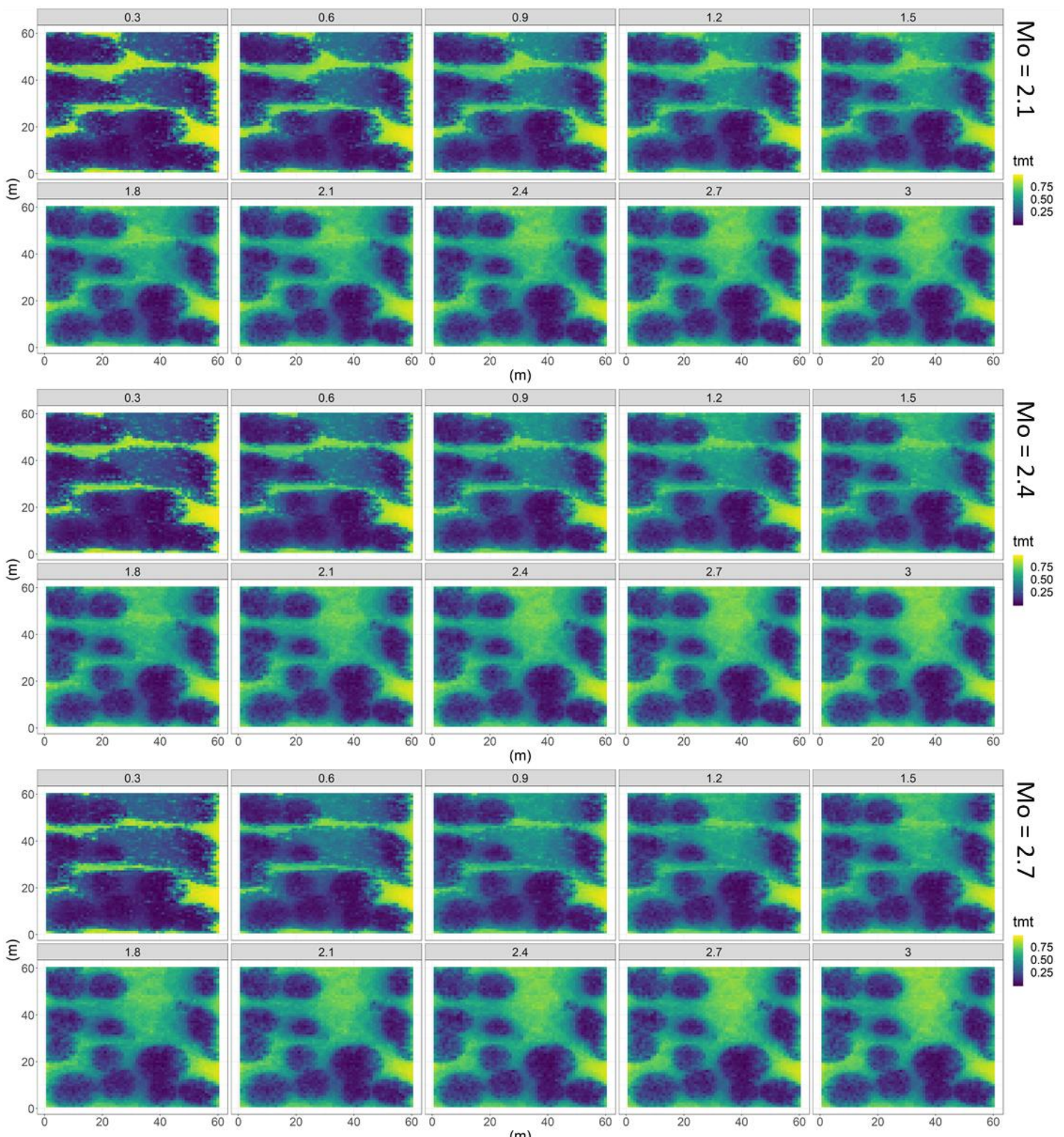

Figura 48 - Corte horizontal da cena simulada a $30 \mathrm{~m}$ de altura sob diversas condições de $A O D$ $(415 \mathrm{~nm}$ ) (indicada pelos números acima dos quadros) e diferentes geometrias solares (indicada na legenda ao lado). As cores representam a transmitância para cada pixel na altura mencionada. Continuação da figura anterior

A partir da Figura 46, a decisão de apresentar a cena completa, e não apenas o recorte central, foi feita para que se entenda o contexto geral. Em outras palavras, é mais fácil entender de onde está vindo a sombra para a região central de interesse. 
Note que a projeção da sombra facilita a análise, pois é uma consequência das árvores geradas pelo modelo. Já a clareira na borda é resultado de uma área vazia sem nenhuma árvore (efeito de borda discutido anteriormente).

4.2.6. Análise da transmitância PAR simulada no perfil vertical da floresta

Ao analisar a variação vertical da transmitância PAR simulada numericamente dentro do dossel da floresta, através da Figura 49, podemos primeiramente identificar a posição das silhuetas das árvores e, bem no centro da imagem, a silhueta da torre meteorológica.

Novamente, a imagem mostra a visão do observador olhando para o norte. Desta forma pode-se facilmente identificar o movimento aparente do sol de leste para oeste. Esse movimento é notado claramente através das diferenças das sombras projetadas em função do ângulo zenital solar (representado pela massa $\left.m_{\circ}\right)$.

Entre 1,7 $\leq m_{\circ} \leq 2,7$ não há grandes diferenças visuais na posição das sombras. Porém em $m_{0}=1,2$ pode ser observado um padrão na sombra da torre projetada a oeste. O padrão é caracterizado por sombras mais escuras intercaladas. Essas sombras são das escadas da torre que se alinham a cada 4 blocos por conta da rotação descrita na metodologia.

À medida em que a $A O D$ aumenta, a definição das sombras diminui e apresenta um aspecto esfumaçado. $O$ contraste diminui, assim como observado nas Figura 47 e Figura 48. Realçando essas diferenças (absolutas) entre AOD, a Figura 50 aponta em verde o aumento na transmitância em função do aumento da AOD e em vermelho o oposto. 
tmt $\begin{array}{lllll}4 & 0 & 0 & 0 \\ 0 & 0 & 0 & 0\end{array}$
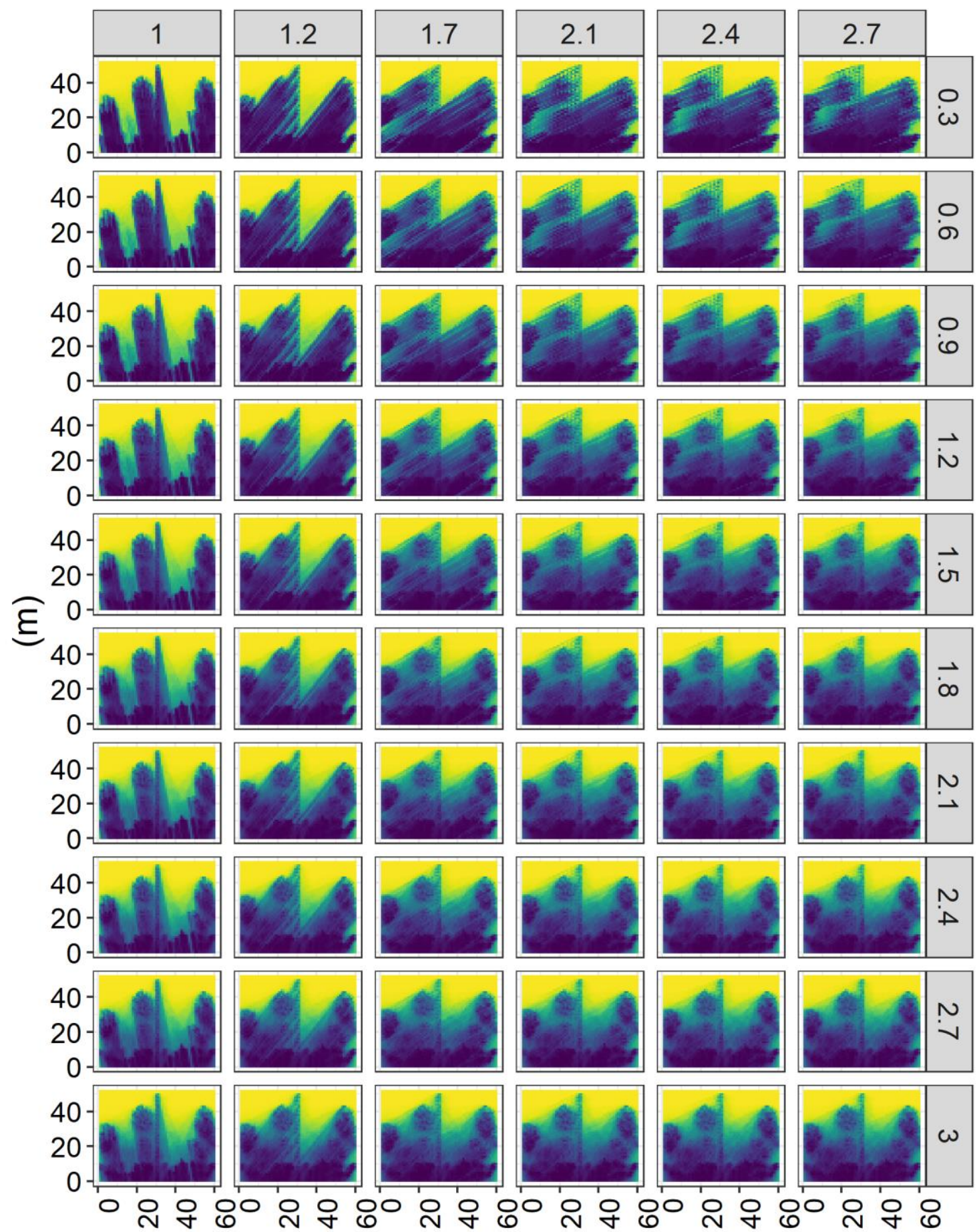

$(\mathrm{m})$

Figura 49 - Corte vertical da cena simulada na região central sob diversas condições de $A O D$ $(415 \mathrm{~nm}$ ) (indicada pelos números acima dos quadros) e diferentes geometrias solares (indicada pelos números à direita dos quadros). As cores representam a transmitância para cada pixel. $O$ eixo vertical é a altura e o horizontal representa a distância entre a borda oeste e a leste, ambas em metro. 

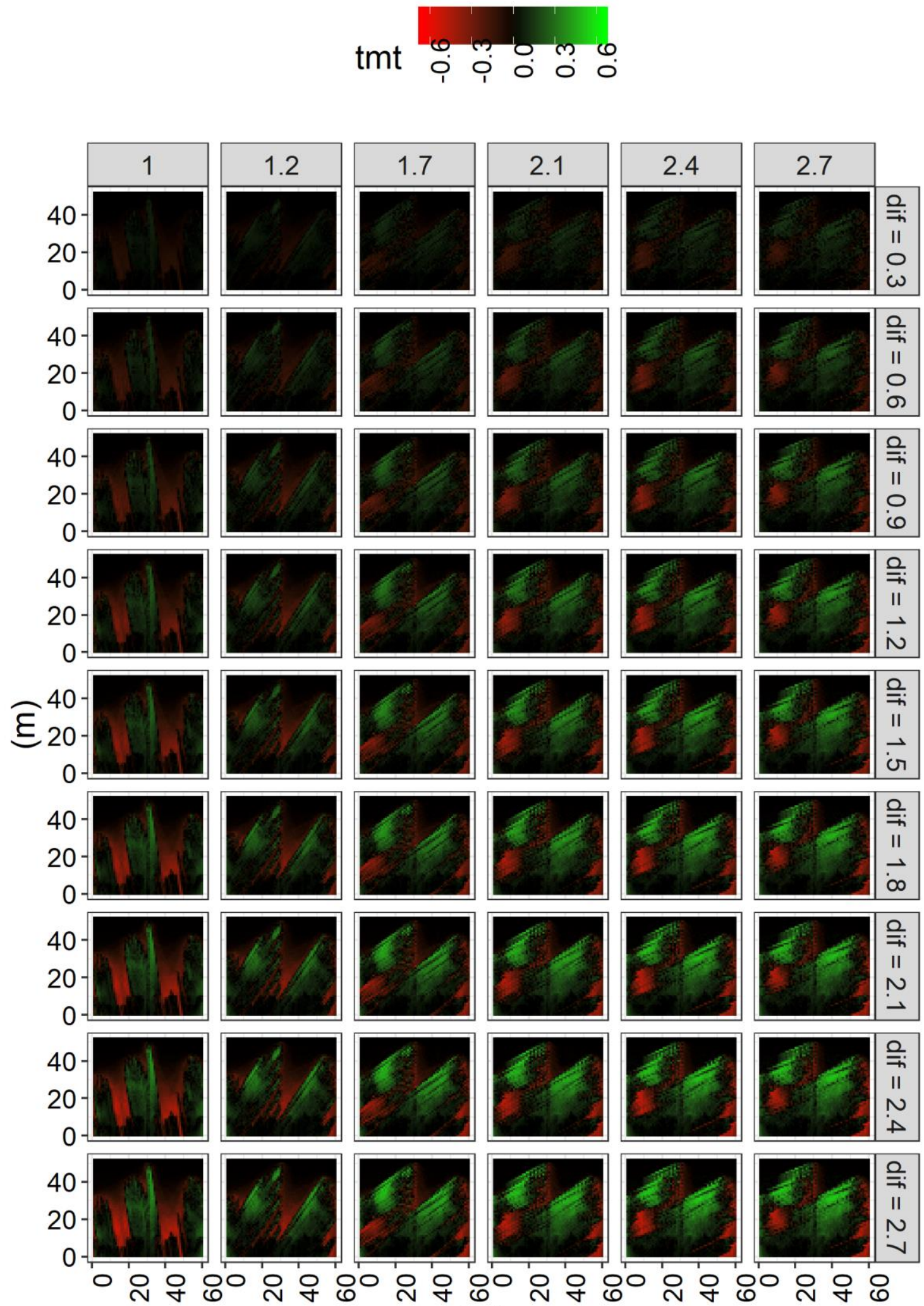

$(\mathrm{m})$

Figura 50 - Corte vertical da cena simulada na região central sob diversas condições de $m_{0}$ (indicada pelos números acima dos quadros) e diversas comparações de AOD (indicada pelos números à direita dos quadros). As cores representam a diferença absoluta da transmitância de $A O D>0,3$ menos a transmitância para $A O D=0,3$. $O$ eixo vertical representa a altura e a horizontal a distância entre a borda oeste e a leste, ambas em metro. 
Fica claro então que assim como na esquematização do efeito fertilizante da luz difusa (Figura 2), o aumento da luz difusa aumenta a iluminação nas regiões sombreadas enquanto que as regiões iluminadas (regiões acima das sombras projetadas) recebem majoritariamente a radiação solar direta.

Quanto maior a diferença entre a AOD, maior é a diferença absoluta entre as transmitâncias (Figura 50), maior é o ganho da transmitância. E que, como o incremento é limitado à região sombreada, quanto mais próximo do horizonte estiver o sol, maior será a sombra e, portanto, maior será o efeito da radiação difusa na transmitância.

\subsubsection{Transmitância pontual}

Selecionando pontos aleatórios ao redor das quatro faces da torre, podemos verificar a alta variabilidade da transmitância PAR dentro do dossel associada à heterogeneidade da vegetação, conforme apresentado na Figura 51. Ao mesmo tempo, podemos conferir, de maneira simplificada, se há maior flutuação relacionada a valores baixos de AOD como observado experimentalmente (e. g. Figura 40).

O efeito positivo da radiação difusa pode ser observado na Figura 51 quando as curvas se organizam de maneira crescente (em termos de AOD) para a direita do gráfico (sentido crescente do eixo horizontal).

O lado oeste é marcado por um grande ruído que perdura de $m_{0}=2,7$ até $m_{o}=1,2$. Esse grande ruído é causado pela sombra da escadaria da torre (vide Figura 49). As curvas para esse lado somente se tornam mais estáveis em $m_{0}=$ 1,0 , que é justamente o momento em que a sombra começa a ser projetada para o lado leste, como demonstrado na Figura 49.

Também é verificada maior oscilação da curva de $A O D=0,3$ (azul) em comparação com AOD = 3 (amarela). Essas oscilações bruscas observadas com baixo AOD representam os padrões de sombra (pontos mais baixos) versus sunflecks (mais próximo do topo do dossel) comparado com o efeito esfumaçado em situação de alto AOD. 


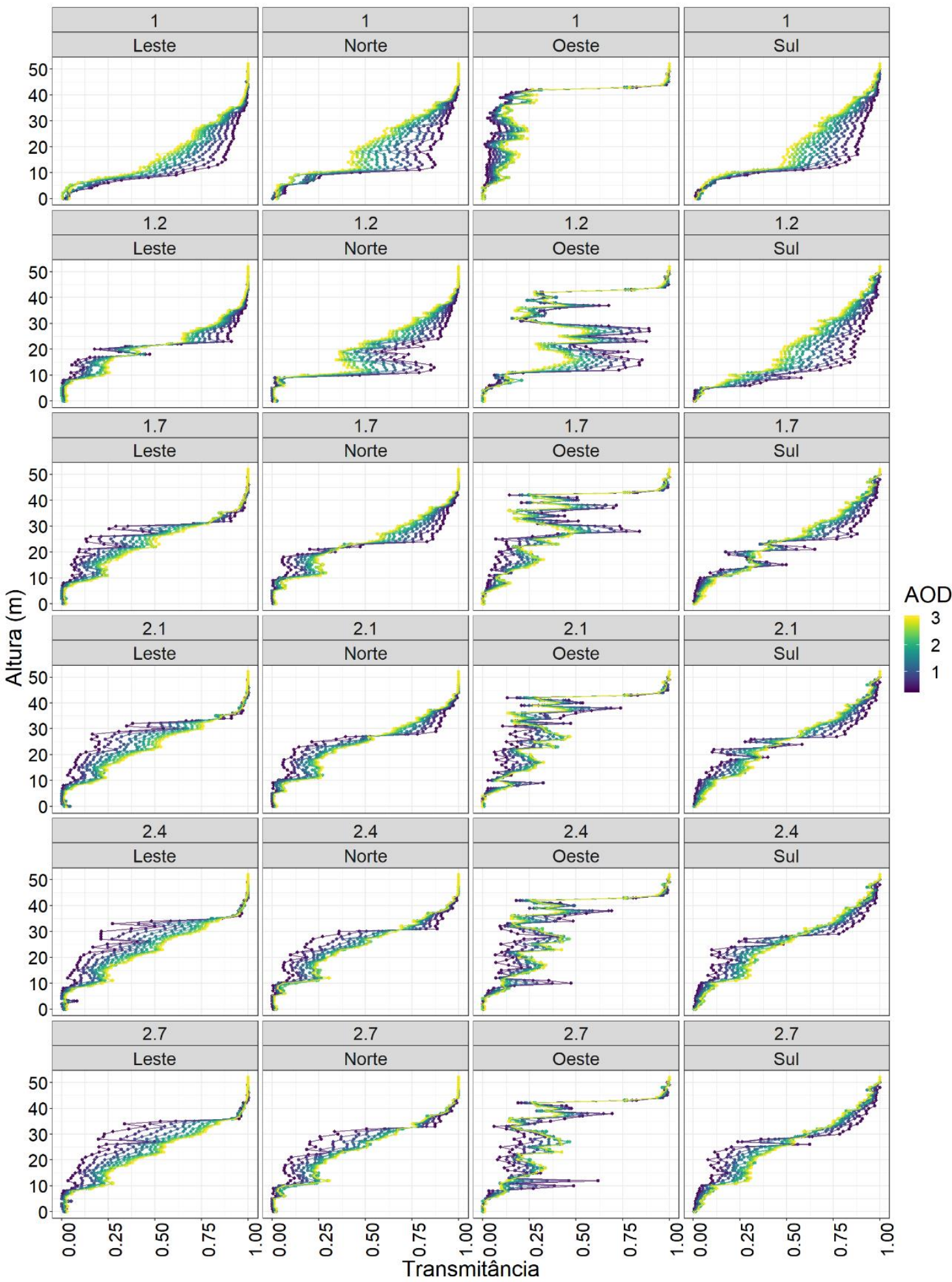

Figura 51 - Perfil vertical da transmitância PAR em quatro pontos distintos da cena simulada em diferentes condições de $A O D$ em $415 \mathrm{~nm}$ (cores), sendo que o valor de $A O D=0,3$ é representado pela cor azul mais escura (limite inferior da escala de cores) e $m_{0}$ (indicada pelo número acima de cada quadro). O eixo vertical indica a altura $(m)$ e o eixo horizontal a transmitância. 
Vemos na Figura 49 que há perfis divididos entre efeito positivo e negativo. Por exemplo, no lado sul para $m_{\circ}=2,4$, com divisão em aproximadamente $30 \mathrm{~m}$ de altura. Lembrando que efeito positivo significa que houve aumento da transmitância com o aumento da AOD e negativo se houve redução.

O efeito negativo sempre aparece na parte superior pois está associado à parte iluminada, isto é, o aerossol atenua a componente direta. A altura na qual ocorre a divisão pode diferir de ponto para ponto, visto que é totalmente dependente do objeto que projeta a sombra, e como há uma grande variedade de altura das árvores, essas diferenças são comumente observadas. Por exemplo, para $m_{0}=1,7$ o lado leste tem ponto de divisão em aproximadamente $35 \mathrm{~m}$ de altura, ao passo que, do lado norte, o ponto de divisão está mais abaixo em $~ 20 \mathrm{~m}$.

\subsubsection{Impacto da torre na transmitância}

Para analisar o efeito da torre, foram realizadas rodadas extras com as exatas mesmas condições das rodadas anteriores, porém excluindo a torre da área central da cena (Figura 52). Então, selecionamos os pixels referentes aos os 10 metros centrais da cena com torre e da área correspondente sem torre. Feito isto, subtraiu-se a simulação com torre da simulação sem torre para isolar o seu efeito sobre a transmitância PAR dentro do dossel.

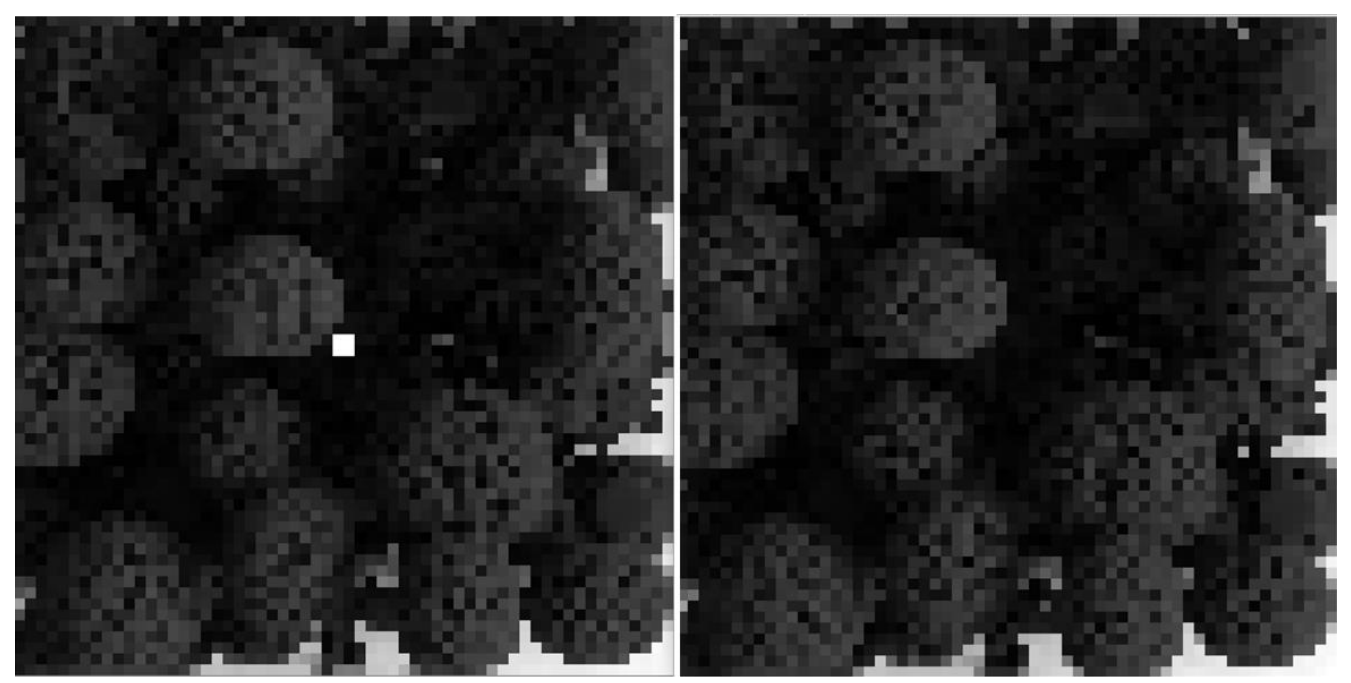

Figura 52 - Imagens de nadir da cena simulada A) com torre e B) sem torre. 
Como visto anteriormente (Figura 48 e Figura 49), o aumento da AOD tende a tornar a iluminação do perfil vertical da floresta cada vez mais homogênea e a geometria solar define a região onde ocorrerá o efeito positivo da radiação difusa. A média da transmitância dos dez metros centrais (Figura 53) também apresenta as mesmas características.

Para contextualizar as diferenças da cena com torre e sem torre, analisaremos a Figura 53. Com isso podemos entender o que está acontecendo em cada um dos momentos (massa óptica), isto é, que tipo de efeito foi observado (positivo ou negativo) e qual a influência da torre nestes.

A Figura 53 é uma sequência onde podemos notar a redução da região de atuação positiva do efeito da luz difusa. Para $m_{\circ}=2,7(1,7)$, podemos ver essa região entre 10 e $35 \mathrm{~m}$ (10 e $27 \mathrm{~m}$ ) de altura. Quando $\mathrm{m}_{\circ}=1$, não há o efeito da luz difusa, uma vez que a sombra projetada, neste momento, é mínima.

$A O D$

$\begin{array}{llll}0.3 & 0.6 & 0.9 & 1.2\end{array}$
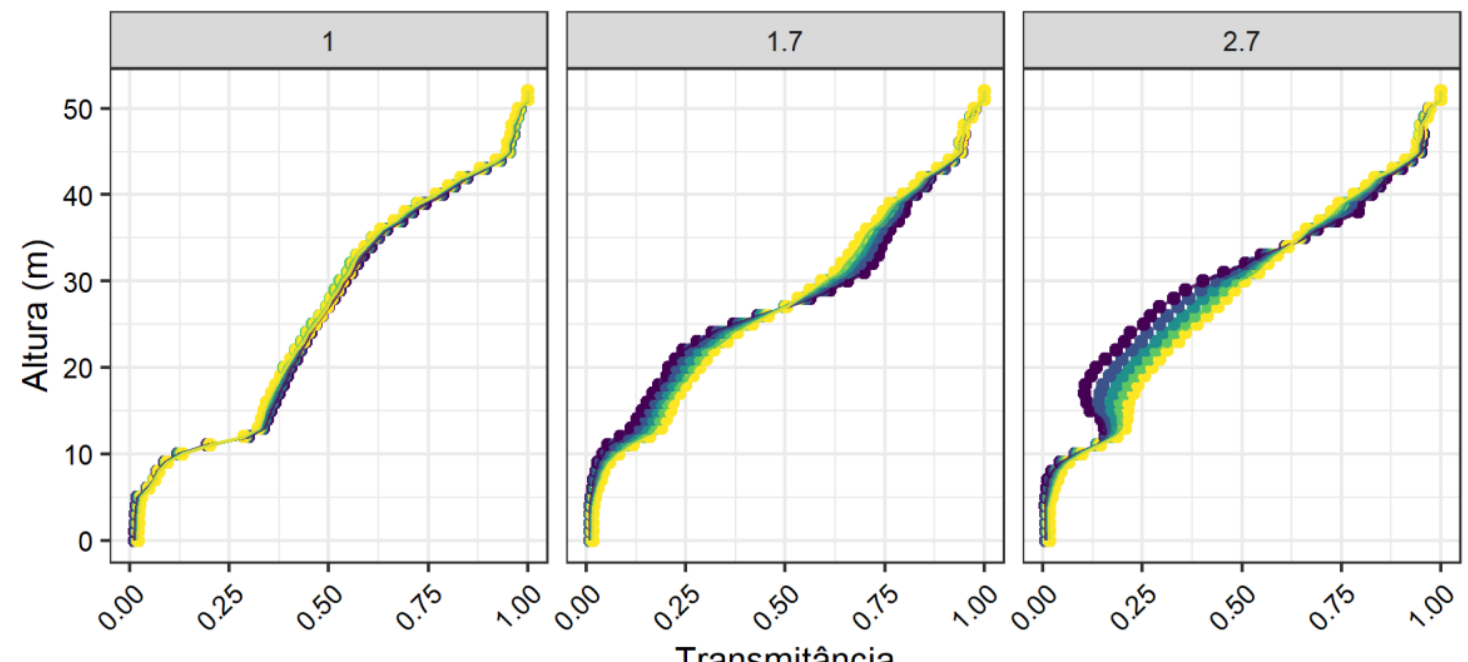

Figura 53 - Transmitância PAR média do perfil vertical da área central simulada em diferentes ângulos para distintas condições de $A O D(415 \mathrm{~nm})$. Cena com torre.

A Figura 54 ilustra a média da diferença da transmitância entre as cenas e destaca o efeito da torre em diferentes geometrias solares e a influência da AOD. De maneira geral, do topo da copa até aproximadamente $32 \mathrm{~m}$ não há influência da AOD em nenhum caso. Com incidência solar oblíqua (massa óptica $>1,1)$, o perfil pode ser estratificado em 3 : 
- Topo até $~ 32 \mathrm{~m}$

- $32 \mathrm{~m}$ até $\sim 8 \mathrm{~m}$

- $8 \mathrm{~m}$ até a superfície $\rightarrow$ sem influência da AOD

$\rightarrow$ com influência da AOD

$\rightarrow$ redução da influência da $A O D$ e perfil constante

Em geral, a torre atenua a incidência de luz em todo o perfil dentro do dossel quando comparada com a cena sem torre. Isso é verificado através dos valores negativos (Figura 54). O papel da AOD, isto é, da fração da radiação na forma difusa, nesse processo é mais complexo. Com ângulos rasantes $\left(m_{\circ}=2,7\right)$, a região intermediária (32 a $8 \mathrm{~m}$ de altura) tem, em termos absolutos, maiores diferenças entre diferentes AOD. Porém, as diferenças são menores com AOD baixo $\left(m_{0}=2,7\right)$.

Talvez isso aconteça porque há mais obstáculos para a luz quando o sol é rasante $\left(m_{0}=2,7\right)$, uma vez que a radiação tem que atravessar um maior caminho de árvores e folhas. Quando a AOD é baixa, a maior parte da radiação chega na forma direta, por isso tem menor propagação para o interior do dossel, consequentemente a diferença é menor.

\section{AOD}

$\begin{array}{llll}0.3 & 0.6 & 0.9 & 1.2\end{array}$
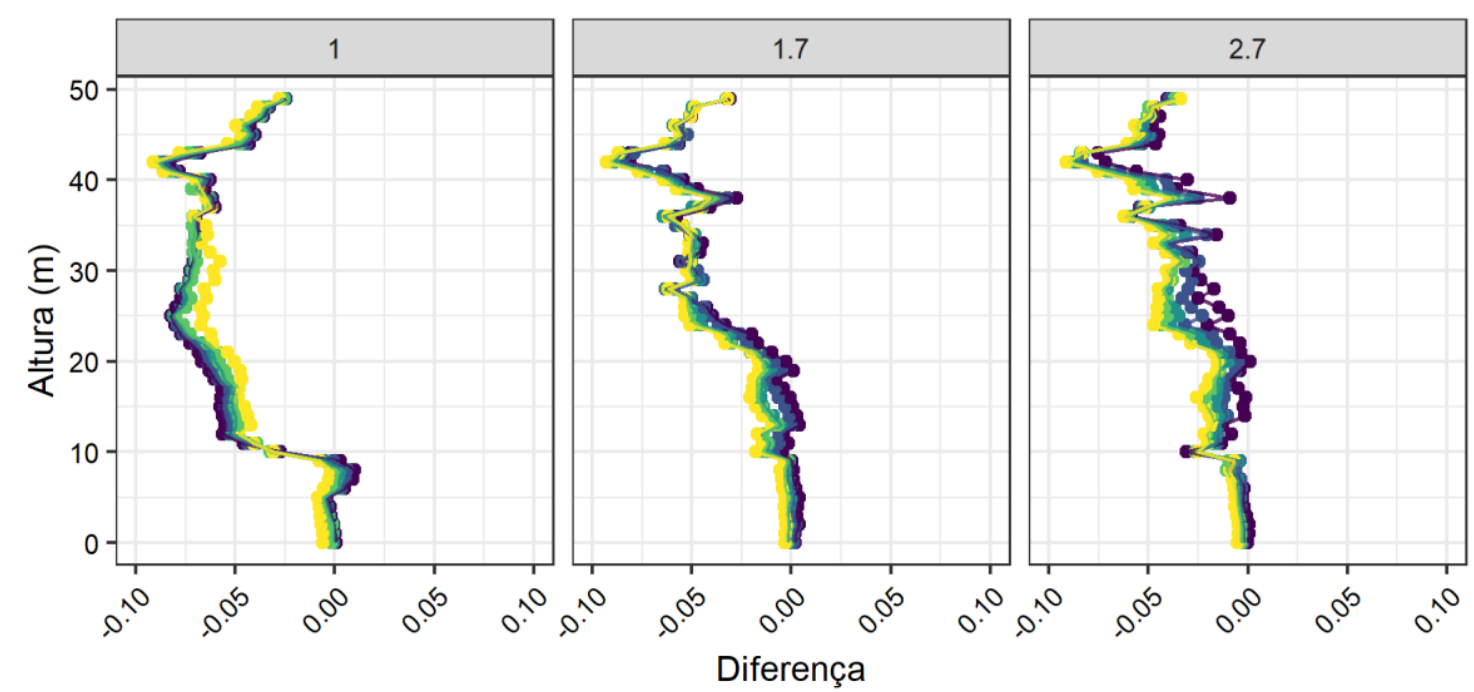

Figura 54 - Diferença entre a transmitância da área central $(10 \times 10$ m) da cena com torre e sem torre. 
A maior atenuação causada pela torre foi observada quando o sol está quase a pino $\left(m_{0}=1,1\right)$. Para essa geometria solar a AOD contribui para a mitigação dos efeitos da torre. De maneira que quanto maior a AOD menores foram as diferenças simuladas. Isso se deve, novamente, a maior homogeneidade da cena nessas condições de iluminação.

A variabilidade espacial dessa diferença pode ser observada na Figura 55, sob algumas condições de geometria e AOD. Pode-se observar que, predominantemente, as diferenças observadas são negativas e coincidem com a projeção da sombra da torre. Em todos os ângulos, com o aumento da AOD tem-se uma diminuição na diferença entre as cenas.
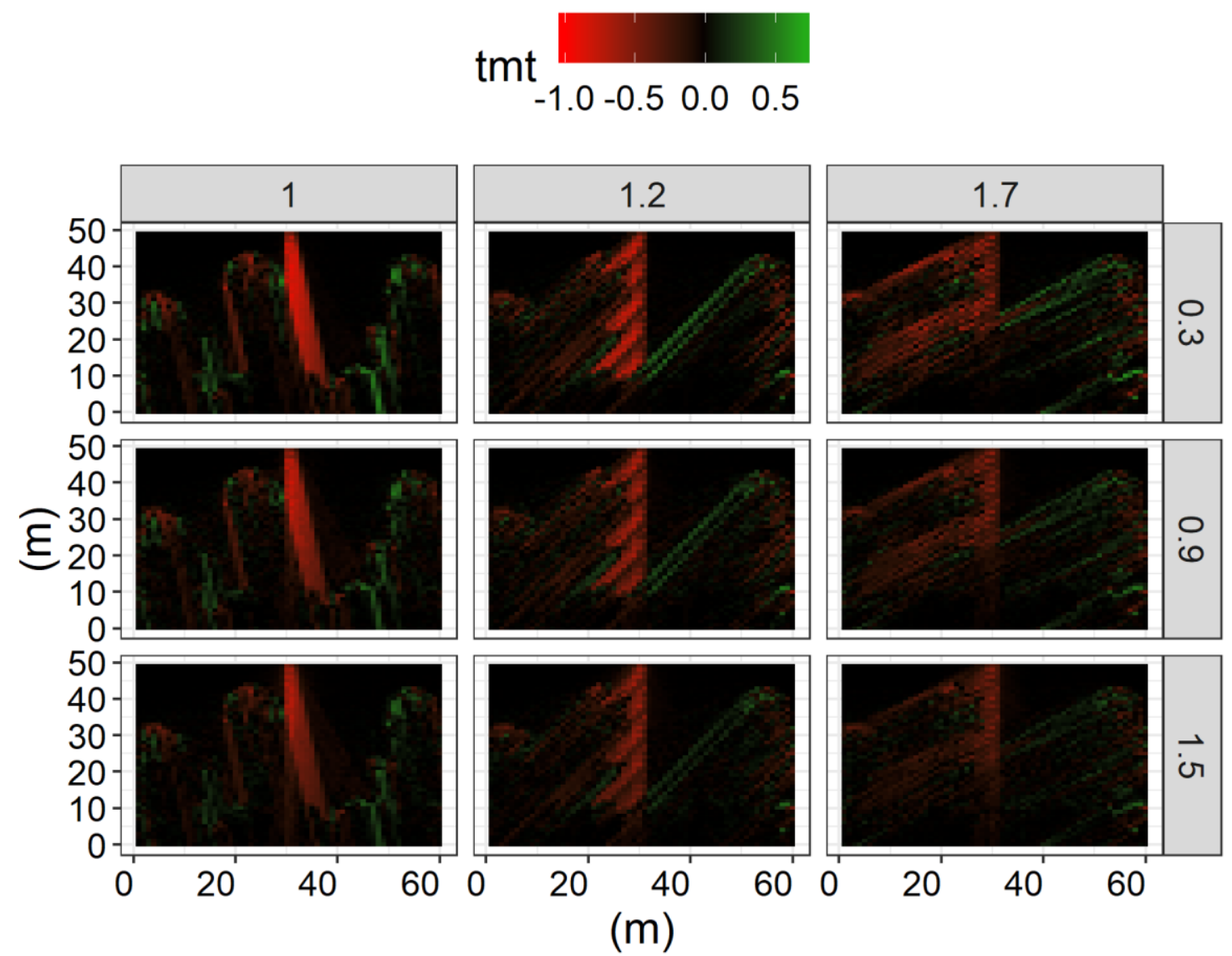

Figura 55 - Corte vertical no centro da cena $(30 \mathrm{~m})$ da variabilidade espacial da diferença entre a transmitância da cena com torre e sem torre em diferentes condições de AOD (415 nm) e massa óptica. Os números acima dos quadros indicam a massa óptica e os números nas laterais indicam a $A O D$. 
Com o aumento da AOD, aumenta-se também a propagação de radiação difusa dentro do dossel. Com efeito, a falta de preferência de orientação de incidência de luz (luz difusa) propicia camadas iluminadas mais homogeneamente. Isso faz com que as diferenças diminuam ao redor da torre (Figura 55).

As diferenças, na área central em destaque (Figura 56), dos valores de irradiância PAR que chegam até a superfície das cenas com e sem torre ao meio dia (horário local), é mais um fator que ressalta que o efeito de atenuação da luz pela torre se limita à sua área de sombreamento. Nesse caso houve uma redução de mais de $40 \%$, aproximadamente. Os valores mais altos nas duas cenas (em vermelho) indicam que há gaps (falhas) no dossel que permitem que grande parte da irradiância atinja a superfície.
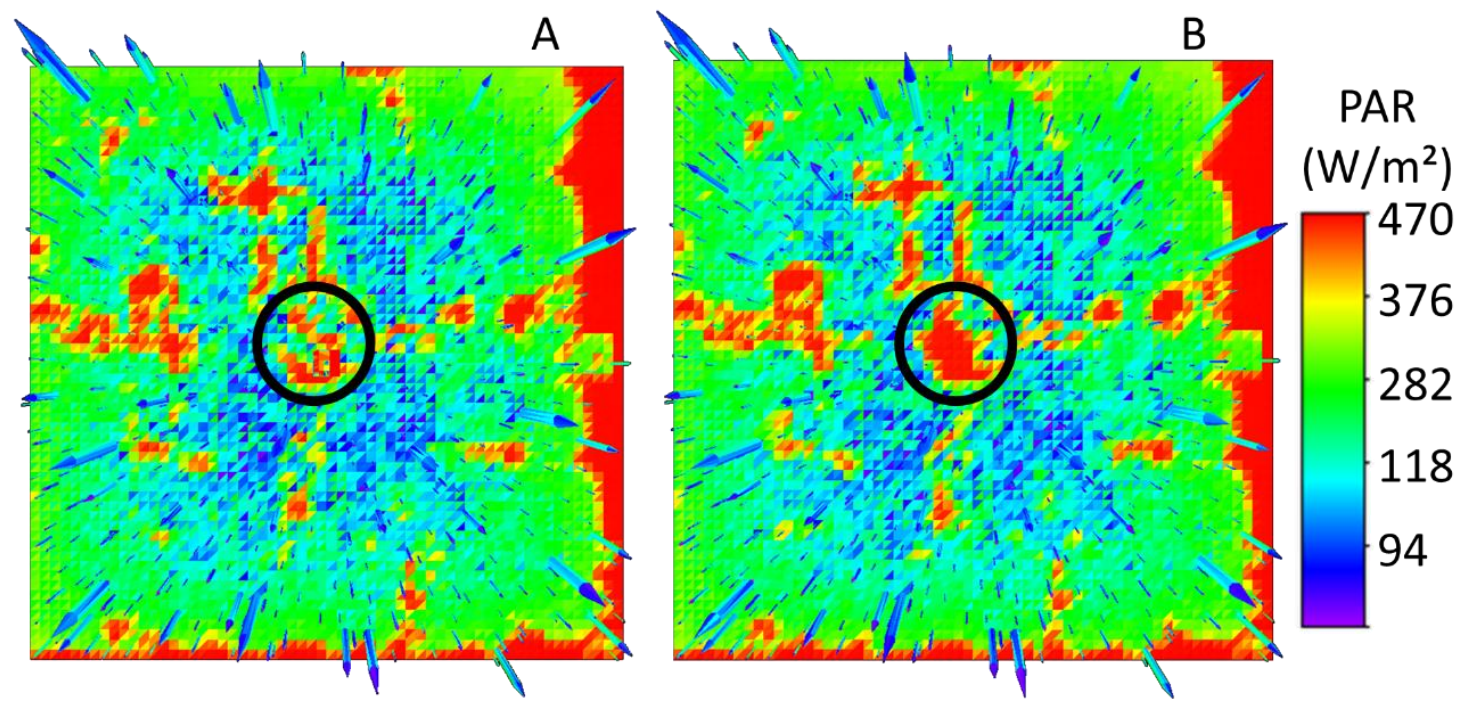

Figura 56 - Irradiância PAR que atingiu a superfície do solo e troncos em cena A) com torre e B) sem torre para $m_{0}=1$.

A torre também pode vir a sofrer com processos de envelhecimento e ambientais que podem alterar seu albedo. Como por exemplo, criação de musgo ou até mesmo acúmulo de poeira.

Determinar essas variações na torre é muito difícil e também não se sabe o impacto das mesmas nas medições. Para investigar essas questões, alteramos drasticamente o valor adotado para o albedo da torre e comparamos em termos de diferença absoluta. 
A Figura 57 apresenta as diferenças absolutas da transmitância simulada para a torre com fator multiplicativo para o albedo em todo o intervalo espectral de análise (400 a $700 \mathrm{~nm}$ ) da torre de alumínio 0,7 (valor adotado em todas as simulações com torre analisadas anteriormente) menos a cena com fator multiplicativo 0,2 .

A diferença observada é pequena, com máximo de 0,02 . O efeito da variação do albedo da torre é espacialmente concentrado. As maiores diferenças são observadas na própria torre. Também é possível notar o efeito no mesmo lado de incidência solar.

As diferenças aumentam com a AOD e, conforme o sol está mais próximo do horizonte (i. e. massa óptica alta), as diferenças que estavam concentradas na metade de cima da torre, se redistribuíram em praticamente toda sua extensão. 

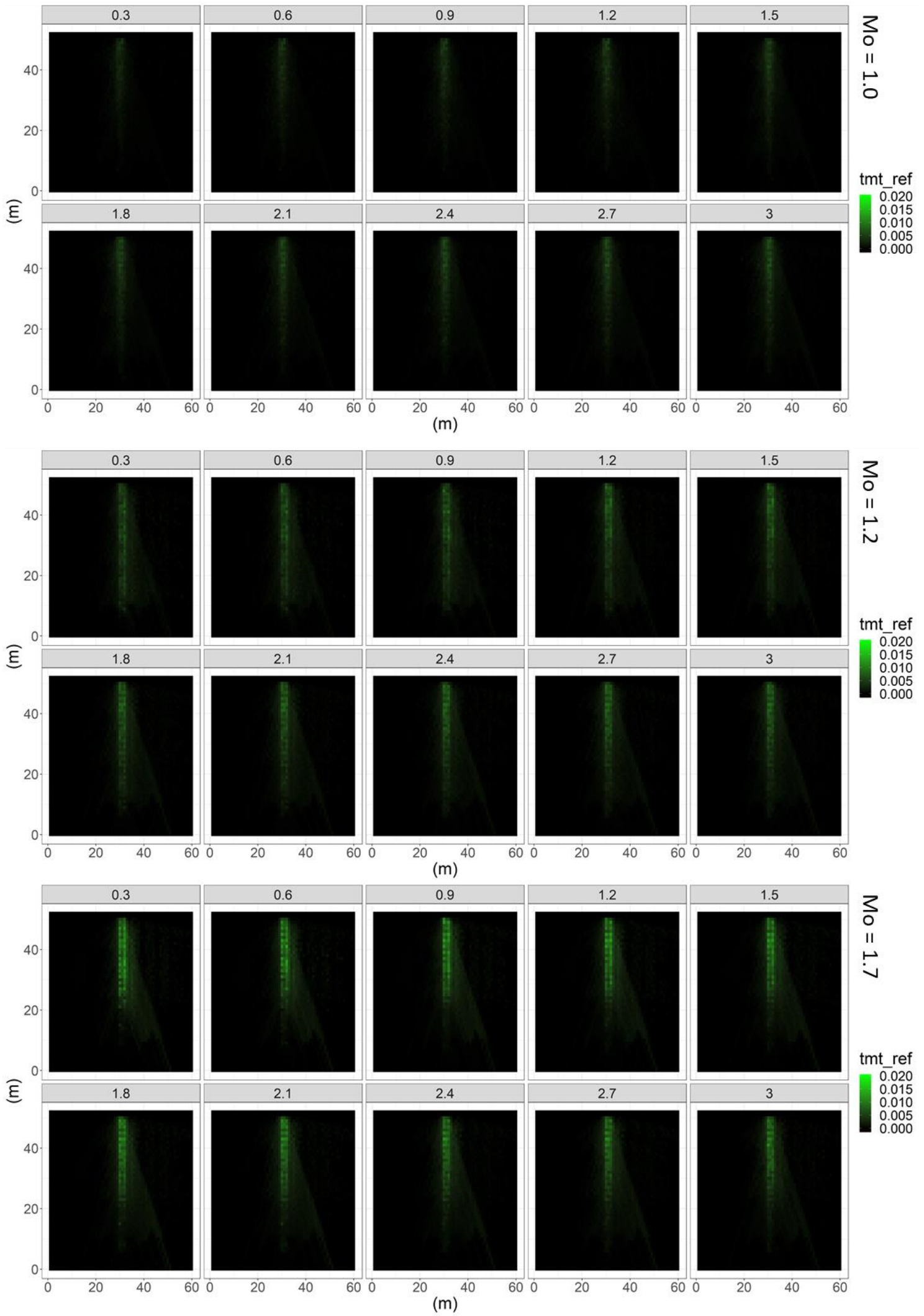

Figura 57-Diferença absoluta entre a transmitância da cena com o albedo da torre reduzido por um fator multiplicativo de 0,7 e albedo da torre reduzido por um fator multiplicativo de 0,2 em diversas condições de $A O D$ em $415 \mathrm{~nm}$ (indicadas no topo dos quadros) e $m_{o}$ (indicada pela legenda à direita dos quadros). 
5. Conclusões 


\subsection{Considerações finais}

A disposição vertical dos radiômetros é um fator fundamental para a análise da transmitância. Se dois ou mais sensores estiverem em uma região não sombreada eles não apresentarão significativas diferenças entre si. $A$ orientação e posição do sensor também deve ser levada em conta para evitar sombreamento artificial, tal como o da torre, e regiões muito iluminadas, devido à presença de uma clareira, por exemplo.

A variação da transmitância ao longo do perfil vertical do dossel em função da AOD foi melhor observada nas camadas centrais do dossel. Porém tal variação também apresentou dependência com a geometria solar e com a estrutura local das árvores. Através da combinação desses tem-se efeito positivo ou negativo da relação entre a transmitância PAR e a AOD.

A principal implicação do efeito tardio das camadas interiores do dossel é que à medida que o sol se eleva (aproxima-se do zênite), a área total projetada da sombra é reduzida de cima para baixo. Dessa maneira as camadas mais internas têm um maior potencial de benefício do efeito fertilizante da luz difusa por passarem mais tempo sombreadas.

Em geral, a transmitância nas camadas mais próximas da superfície não apresentou resposta às variações da AOD. O motivo por trás disso é o efeito de sombreamento das árvores maiores e o aumento da quantidade de árvores menores. O modelo conseguiu representar bem esse comportamento, indicando que as equações alométricas (Tabela 3) utilizadas para a criação do cenário da floresta simulada foram adequadas.

O modelo subestimou em média $3 \%$ a fração de luz difusa incidente no topo do dossel, gerada por diferentes valores de AOD e em diferentes ângulos. Os maiores erros (até 10\%) foram observados com baixo AOD $(<1)$ e $\mathrm{m}_{\mathrm{o}}(<=$ $1,2)$. A subestimativa da fração difusa foi reduzida à medida que aumentou a AOD e m。 para o ATTO e Humaitá. Porém, para REBIO a diferença entre os valores observados e calculados numericamente foi, na maioria dos casos, constante ( 5\%). 
O modelo também reproduziu adequadamente a propagação da luz dentro do dossel sob diferentes geometrias e condições de AOD, incluindo 0 efeito das frestas. Como o aumento da AOD, a cena se tornou mais homogeneamente iluminada e, com isso, a presença das frestas tendeu a desaparecer.

A região preferencial para observar o efeito da luz difusa na transmitância é em camadas que recebem cerca de $25 \%$ da luz incidente no topo do dossel, em condições de baixo AOD. Nesses casos, foi observado aumento na transmitância de $~ 100 \%$. Sensores na face norte e leste foram os que mais responderam positivamente com a variação da AOD.

A torre meteorológica apresentou efeito restrito à sua área e à área de sombra projetada. De acordo com os testes de sensibilidade realizados com o DART, o efeito da sombra da torre foi muito mais sensível ao sombreamento do que à reflexão causada por ela. $O$ efeito da reflexão da torre foi maior quanto mais oblíqua foi a incidência da radiação solar direta.

O que foi observado recursivamente, tanto nos dados observados quanto nos simulados, é que conforme a fração difusa da radiação PAR aumenta, menos a transmitância depende dos fatores internos do dossel, tais como galhos ou a própria torre. $O$ aumento da fração difusa pôde ser observado tanto com o aumento da massa óptica, quanto com o aumento da AOD.

\subsection{Sugestões de trabalho futuros}

Este estudo demonstrou o quão complexo é avaliar o efeito concomitante da fumaça produzida pelas queimadas, da geometria do disco solar e da heterogeneidade do dossel de floresta na transmissão de radiação fotossinteticamente ativa dentro do dossel. Obviamente que não foi possível esgotar o tema, e por este motivo, algumas sugestões de trabalhos futuros são apresentadas a seguir.

Quantificar numericamente a mudança da fração de folhas sombreadas e iluminadas. Isso pode ser feito, através do DART, analisando a distribuição da radiação incidente acima e abaixo da folha. Analogamente, uma outra 
metodologia para classificação de folhas iluminadas e sombreadas voltada aos experimentos de campo pode ser adaptada a partir do perfil vertical de PAR refletida e da densidade de folhas dentro do dossel. A quantificação da fração sombreada também pode ser interpretada como uma outra opção para a avaliação do efeito da transmitância dentro do dossel em função do aumento da fração da radiação difusa.

Analisar a fração PAR absorvida e refletida, visto que esses são parâmetros chave para o entendimento da atividade fotossintética da floresta (fração absorvida) e verificação da competência em descrever o espalhamento dentro do dossel do modelo (fração refletida).

Em experimentos de campo futuros, recomenda-se especial atenção na instalação dos sensores em perfil vertical dentro do dossel, particularmente para evitar o sombreamento sistemático causado por um tronco ou pela própria torre, tentando distanciá-los ao máximo dela.

Finalmente, uma análise de como o efeito tridimensional pode alterar as estimativas do balanço de energia e dos fluxos turbulentos associados (calor latente, sensível e de $\mathrm{CO}_{2}$ ) por modelos que sejam capazes de incorporar esse efeito será fundamental. A taxa de fotossíntese também é alterada por variações de temperatura e disponibilidade de água. $O$ aquecimento diferencial induzido pela incidência de radiação de forma não homogênea pode contribuir para intensificar a turbulência dentro do dossel. 
6. Referências 
ALTON, P. B., ELLIS, R., LOS, S. O., \& NORTH, P. R. Improved global simulations of gross primary product based on a separate and explicit treatment of diffuse and direct sunlight. Journal of Geophysical Research: Atmospheres, v. 112, n. D7, 2007.

ANHUF, D.; ROLLENBECK, R. Canopy structure of the Rio Surumoni rain forest (Venezuela) and its influence on microclimate. Ecotropica, v. 7, p. 2132, 2001.

BARBIER, N. et al. The variation of apparent crown size and canopy heterogeneity across lowland Amazonian forests. Global Ecology and Biogeography, v. 19, n. 1, p. 72-84, 2010.

BONAN, G. B. Forests and climate change: forcings, feedbacks, and the climate benefits of forests. Science, v. 320, n. 5882, p. 1444-1449, 2008.

BOND, T. C., DOHERTY, S. J., FAHEY et al. Bounding the role of black carbon in the climate system: A scientific assessment. Journal of Geophysical Research: Atmospheres, v. 118, n. 11, p. 5380-5552, 2013.

BOUCHER, O., D. RANDALL, P. ARTAXO, C. BRETHERTON, G. FEINGOLD, P. FORSTER, V.-M. KERMINEN, Y. KONDO, H. LIAO, U. LOHMANN, P. RASCH, S.K. SATHEESH, S. SHERWOOD, B. STEVENS E X.Y. ZHANG, 2013: Clouds and Aerosols. Em: Climate Change 2013: The Physical Science Basis. Contribution of Working Group I to the Fifth Assessment Report of the Intergovernmental Panel on Climate Change [STOCKER, T.F., D. QIN, G.-K. PLATTNER, M. TIGNOR, S.K. ALLEN, J. BOSCHUNG, A. NAUELS, Y. XIA, V. BEX AND P.M. MIDGLEY (eds.)]. Cambridge University Press, Cambridge, United Kingdom e New York, NY, USA.

CIRINO, G. G., SOUZA, R. A. F., ADAMS, D. K., \& ARTAXO, P. The effect of atmospheric aerosol particles and clouds on net ecosystem exchange in the Amazon. Atmospheric Chemistry and Physics, v. 14, n. 13, p. 6523, 2014. 
COAKLEY, J. A. Reflectance and albedo, surface. Encyclopedia of the Atmosphere, p. 1914-1923, 2003.

COSTA, Tássio Santos. Estimativa Numérica do Efeito Radiativo Simultâneo de Aerossóis e Nuvens sobre a Amazônia. Dissertação de Mestrado apresentada ao Instituto de Astronomia, Geofísica e Ciências Atmosféricas, 2013.

DA ROCHA, V. R.; YAMASOE, M. A. Estudo Da Variabilidade Espacial E Temporal Da Profundidade Óptica Do Aerossol Obtida Com O Modis Sobre A Região Amazônica. Revista Brasileira de Meteorologia, v. 28, n. 2, 2012.

DOUGHTY, C. E.; FLANNER, M. G.; GOULDEN, M. L. Effect of smoke on subcanopy shaded light, canopy temperature, and carbon dioxide uptake in an Amazon rainforest. Global Biogeochemical Cycles, v. 24, n. 3, 2010.

DUSEK, U., FRANK, G. P., HILDEBRANDT, L., CURTIUS, J., SCHNEIDER, J., WALTER, S., CHAND, D., DREWNICK, F., HINGS, S., JUNG, D., BORRMANN, S., \& ANDREAE, M. O. Size matters more than chemistry for cloud-nucleating ability of aerosol particles. Science, v. 312 , n. 5778, p. 13751378, 2006.

ECK, T. F., HOLBEN, B. N., REID, J. S., O'NEILL, N. T., SCHAFER, J. S., DUBOVIK, O., SMIRNOV, A., YAMASOE, M. A. \& ARTAXO, P. High aerosol optical depth biomass burning events: A comparison of optical properties for different source regions. Geophysical Research Letters, v. 30, n. 20, 2003.

FINCH, D. A.; BAILEY, W. G.; McARTHUR, L. J. B.; NASITWITWI, M. Photosynthetically active radiation regimes in a southern African savanna environment. Agricultural and Forest Meteorology, v. 122, n. 3-4, p. 229238, 2004.

FRAGA, M. E.; BRAZ, D. M.; ROCHA, J. F.; PEREIRA, M. G.; FIGUEIREDO, D. V. Interação microrganismo, solo e flora como condutores da diversidade na Mata Atlântica. Acta Botanica Brasilica, v. 26, n. 4, p. 857-865, 2012. 
GASTELLU-ETCHEGORRY, J. P. et al. Modeling radiative transfer in heterogeneous 3-D vegetation canopies. Remote sensing of environment, v. 58, n. 2, p. 131-156, 1996.

GASTELLU-ETCHEGORRY, Jean-Philippe et al. Discrete anisotropic radiative transfer (DART 5) for modeling airborne and satellite spectroradiometer and LIDAR acquisitions of natural and urban landscapes. Remote Sensing, v. 7, n. 2, p. 1667-1701, 2015.

HANSEN, J., SATO, M., KHARECHA, P., \& SCHUCKMANN, K. V. Earth's energy imbalance and implications. Atmospheric Chemistry and Physics, v. 11, n. 24, p. 13421-13449, 2011.

HANSEN, M. C.; POTAPOV, P. V.; MOORE, R. et al. High-resolution global maps of 21 st-century forest cover change. Science, v. 342 , n. 6160 , p. 850853, 2013.

HOMMA, A. K. O., WALKER, R. T., SCATENA, F. N., DE CONTO, A. J., CARVALHO, R. D. A., DA ROCHA, A. N. et al. A dinâmica dos desmatamentos e das queimadas na Amazônia: uma análise microeconômica. Em: Embrapa Amazônia Oriental-Artigo em anais de congresso (ALICE). Em: CONGRESSO BRASILEIRO E ECONOMIA E SOCIOLOGIA RURAL, 31, 1993, Ilhéus. Desenvolvimento agrícola e desenvolvimento rural: anais. Brasília, DF: SOBER, 1993.

IQBAL, Muhammad. An introduction to solar radiation. Elsevier, 2012.

KANNIAH, Kasturi Devi et al. Control of atmospheric particles on diffuse radiation and terrestrial plant productivity: A review. Progress in Physical Geography, v. 36, n. 2, p. 209-237, 2012.

KNOHL, A.; BALDOCCHI, D. D. Effects of diffuse radiation on canopy gas exchange processes in a forest ecosystem. Journal of Geophysical Research: Biogeosciences, v. 113, n. G2, 2008. 
LIMA, L. S., COE, M. T., SOARES FILHO, B. S., CUADRA, S. V., DIAS, L. C. P., COSTA, M. H., LIMA, L. S. \& RODRIGUES, H. O. Feedbacks between deforestation, climate, and hydrology in the Southwestern Amazon: implications for the provision of ecosystem services. Landscape ecology, $v$. 29, n. 2, p. 261-274, 2014.

LIOU, K. N. - An Introduction to Atmospheric Radiation. Academic Press. New

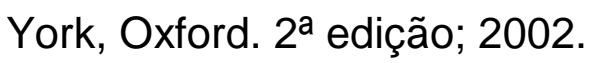

MALHI, Y., ROBERTS, J. T., BETTS, R. A., KILLEEN, T. J., LI, W., \& NOBRE, C. A. Climate change, deforestation, and the fate of the Amazon. Science, $v$. 319, n. 5860, p. 169-172, 2008.

MCARTHUR, L. B., HALLIWELL, D. H., NIEBERGALL, O. J., O'NEILL, N. T., SLUSSER, J. R., \& WEHRLI, C. Field comparison of network Sun photometers. Journal of Geophysical Research: Atmospheres, v. 108, n. D19, 2003.

MERCADO, L. M., BELLOUIN, N., SITCH, S., BOUCHER, O., HUNTINGFORD, C., WILD, M., \& COX, P. M. Impact of changes in diffuse radiation on the global land carbon sink. Nature, v. 458, n. 7241 , p. 1014 , 2009.

MOREIRA, D. S., LONGO, K. M., FREITAS, S. R., YAMASOE, M. A., et al. Modeling the radiative effects of biomass burning aerosols on carbon fluxes in the Amazon region. 2017. Atmospheric Chemistry and Physics. p. 14785-14810, 2017.

OliVeiRA, P. H., ARTAXO, P., PIRES, C., et al. The effects of biomass burning aerosols and clouds on the CO2 flux in Amazonia. Tellus B, v. 59, n. 3, p. 338-349, 2007.

PETTY, Grant William. A first course in atmospheric radiation. Sundog Pub, 2006. 
POORTER, L.; BONGERS, L.; BONGERS, F. Architecture of 54 moist-forest tree species: traits, trade-offs, and functional groups. Ecology, v. 87, n. 5, p. 1289-1301, 2006.

RAP, A., SCOTT, C. E., REDDINGTON, C. L., MERCADO et al. Enhanced global primary production by biogenic aerosol via diffuse radiation fertilization. Nature Geoscience, v. 11, n. 9, p. 640-644, 2018.

RAP, A., SPRACKLEN, D. V., MERCADO, L. et al. Fires increase Amazon forest productivity through increases in diffuse radiation. Geophysical Research Letters, v. 42, n. 11, p. 4654-4662, 2015.

ROSÁRIO, N. E. Estudo da Variabilidade das Propriedades Ópticas dos Aerossóis sobre a América do Sul e dos Impactos do Efeito Radiativo Direto das Partículas de Queimadas. Monografia de doutorado apresentada ao Instituto de Astronomia, Geofísica e ciências Atmosféricas, 2011.

ROSÁRIO, N. E. et al. Modeling the South American regional smoke plume: aerosol optical depth variability and surface shortwave flux perturbation. Atmospheric Chemistry and Physics, v. 13, p. 2923-2938, 2013.

ROSÁRIO, Nilton E. et al. Downwelling solar irradiance in the biomass burning region of the southern Amazon: Dependence on aerosol intensive optical properties and role of water vapor. Journal of Geophysical Research: Atmospheres, v. 116, n. D18, 2011.

SAYÃO, A.C. Estudo da variabilidade sazonal da profundidade óptica do aerossol em São Paulo a partir de radiômetros MFRSR. Dissertação de Mestrado apresentada ao Instituto de Astronomia, Geofísica e Ciências Atmosféricas, Universidade de São Paulo, 130p, 2008

SHUKLA, J.; NOBRE, C.; SELLERS, P. Amazon deforestation and climate change. Science, v. 247, n. 4948, p. 1322-1325, 1990. 
SOUZA, R. P.; VÁLIO, I. F. M. Leaf optical properties as affected by shade in saplings of six tropical tree species differing in successional status. Brazilian Journal of Plant Physiology, v. 15, n. 1, p. 49-54, 2003.

TOOMEY, M., ROBERTS, D., \& NELSON, B. The influence of epiphylls on remote sensing of humid forests. Remote Sensing of Environment, v. 113, n. 8, p. 1787-1798, 2009.

WALLACE, J. M. \& HOBBS, P. V. - Atmospheric science: an introductory survey, International Geophysics Series, Academic Press, Elsevier Inc., 2a edição, 09-177, 2006

WU, J., KOBAYASHI, H., STARK, S. C., MENG, R., GUAN, K., TRAN, N. N. et al. Biological processes dominate seasonality of remotely sensed canopy greenness in an Amazon evergreen forest. New Phytologist, v. 217, n. 4, p. 1507-1520, 2018.

YAMASOE, M. A., \& CORREAA, M. DE P. (2016). Processos Radiativos na Atmosfera. Fundamentos (Edição: 1). Oficina de Textos.

YAMASOE, M. A., ROSÁRIO, N. M. É. D., COSTA, T. S., BRAGHIERE et al. Medições e estimativas numéricas da irradiância solar descendente em superfície na Região Amazônica: estudos de casos em Humaitá, AM. Ciência das mudanças climáticas e sua interdisciplinaridade, 2015.

YAMASOE, M. A., VON RANDOW, C., MANZI, A. et al. Effect of smoke on the transmissivity of photosynthetically active radiation inside the canopy. Atmospheric Chemistry and Physics, v. 5, n. 4, p. 1645-1656, 2006.

YAMASOE, Márcia A. et al. Chemical composition of aerosol particles from direct emissions of vegetation fires in the Amazon Basin: water-soluble species and trace elements. Atmospheric Environment, v. 34, n. 10, p. 1641-1653, 2000. 
ZHANG, F. \& LI, J. A note on double Henyey-Greenstein phase function. Journal of Quantitative Spectroscopy and Radiative Transfer, v. 184, p. 40-43, 2016. 